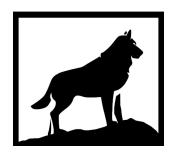

Michigan

Technological

1 8 8 5 University
Michigan Technological University

Digital Commons @ Michigan Tech

2016

"UNBLACKBOXING" TECHNOLOGY THROUGH THE RHETORIC OF TECHNICAL COMMUNICATION: BIOMETRIC TECHNOLOGY AND GHANA'S 2012 ELECTION

Isidore Dorpenyo

Michigan Technological University, ikdorpen@mtu.edu

Copyright 2016 Isidore Dorpenyo

Recommended Citation

Dorpenyo, Isidore, "'UNBLACKBOXING" TECHNOLOGY THROUGH THE RHETORIC OF TECHNICAL COMMUNICATION: BIOMETRIC TECHNOLOGY AND GHANA'S 2012 ELECTION", Open Access

Dissertation, Michigan Technological University, 2016.

https://doi.org/10.37099/mtu.dc.etdr/125

Follow this and additional works at: https://digitalcommons.mtu.edu/etdr

Part of the Technical and Professional Writing Commons 


\title{
“UNBLACKBOXING” TECHNOLOGY THROUGH THE RHETORIC OF TECHNICAL COMMUNICATION: BIOMETRIC TECHNOLOGY AND GHANA'S 2012 ELECTION
}

By

Isidore K. Dorpenyo

\begin{abstract}
A DISSERTATION
Submitted in partial fulfillment of the requirements for the degree of DOCTOR OF PHILOSOPHY

In Rhetoric, Theory and Culture
\end{abstract} MICHIGAN TECHNOLOGICAL UNIVERSITY

2016

(C) 2016 Isidore Kafui Dorpenyo 
This dissertation has been approved in partial fulfillment of the requirements for the Degree of DOCTOR OF PHILOSOPHY in Rhetoric, Theory and Culture

Department of Humanities

Dissertation Advisor: $\quad M A B$ Brady

Committee Member: $\quad$ Robert R Johnson

Committee Member: $\quad$ Marika A Seigel

Committee Member: Godwin Y Agboka

Department Chair: Ronald Strickland 
To the Dorpenyo, Tordzro and Afiadenyo families. 


\section{Contents}

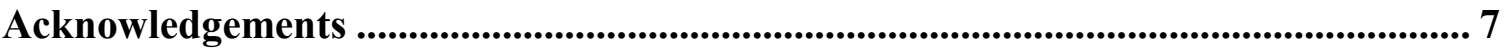

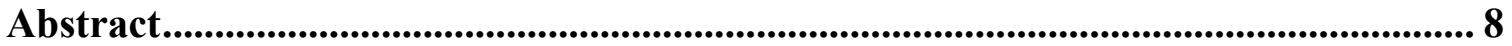

Chapter One: Paying Attention to and Exposing the Gaps in (International)

Technical Communication ....................................................................................

Mapping the political history of Ghana: Contextualizing research ....................... 14

International technical communication and technology studies .............................. 22

Technical documentation design in international contexts and technology studies ..... 33

Rhetorical genre studies and international technical communication......................... 35

Chapter Two: Tracing the conversation about technology............................................ 43

Cultural studies and technology: relevance of articulation and assemblage................ 44

Philosophy of technology: what is technology? ............................................. 51

Rhetoric of technology: where lies the connection between rhetoric and technology? 57

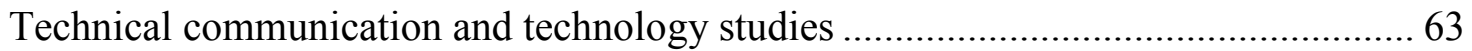

Chapter Three: Studying the "International" through Rhetorical-Cultural

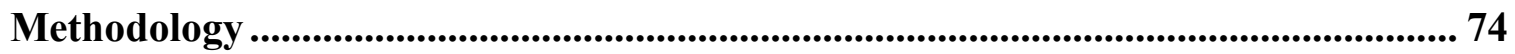

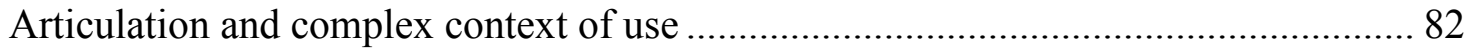

Situating the Research in a Broader Context .................................................... 89

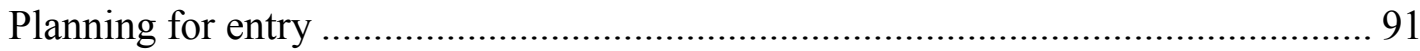

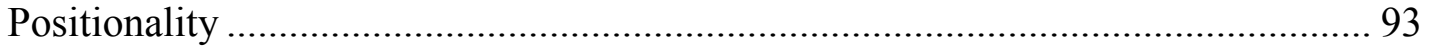

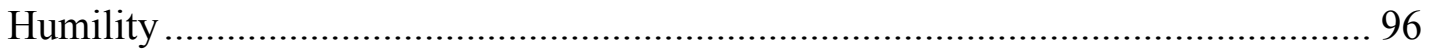

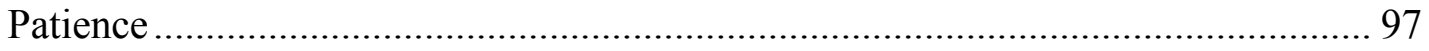

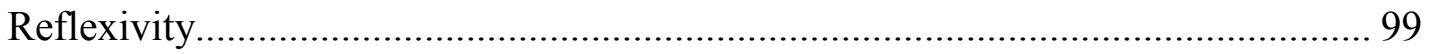

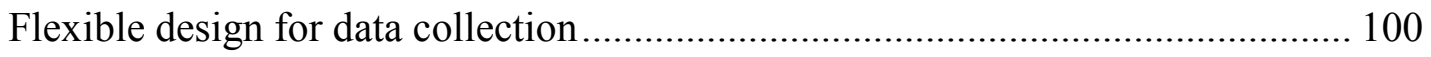

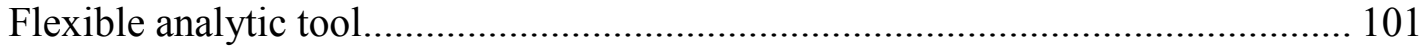


The manual as an articulation of instruction writing 'pieties' 106

Manual as an articulation of rhetorical cultural patterns in a context....................... 122

Common human thresholds and their relevance to document analysis ................ 123

Manual as an articulation of broader entanglements in a complex context of use .... 135

The user manual as it furthers knowledge on localization.................................. 136

Technology Adoption and Regimes of Authenticity and Ideology ...................... 139

Technology disciplining and surveilling bodies ................................................ 143

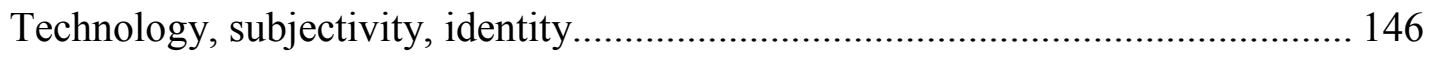

Technology adoption, social justice and the technical communicator .................. 147

\section{Chapter Five: Mapping the Biometric System in the Discursive-Material Practices}

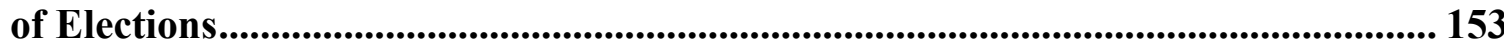

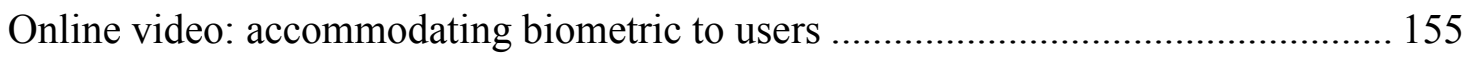

Online video as it articulates rhetorical cultural patterns................................... 157

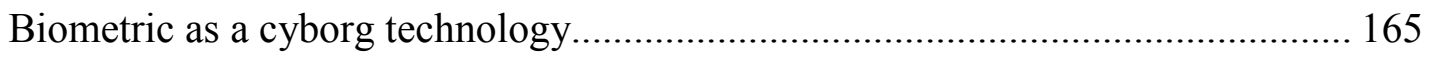

Biometrics and the politics of technology .................................................. 167

Biometric as the articulation of gendered patterns .......................................... 170

Parliamentary Hansard: Deliberating on the Biometric Law ................................. 176

Parliamentary Hansard as it articulates broader rhetorical cultural entanglements 178

Somnambulism as a Consequence of "Technological Mindset” ......................... 178

Critical access to technology: Questioning the technological mindset................. 185

Suite of Posters: Educating the Populace on Biometric Registration ...................... 188

Biometric and the articulation of cultural entanglements: Governmentality, Ideology, Subjectivity and Technologies of the Self ..................................................... 190

Chapter Six: Importance of 'Unblackboxing' to the Technical Communicator .... 195 


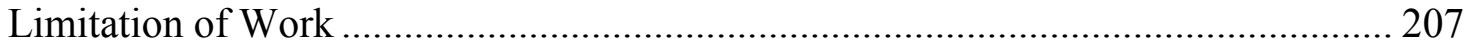

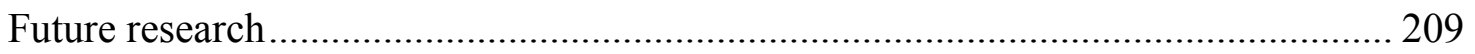

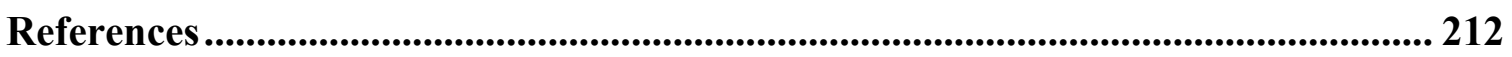

Appendix: Copyright Permission ............................................................................ 228 


\section{Acknowledgements}

My experience working on this project has strengthened my belief that dissertation writing is not an individual task; instead, it is an articulation and assemblage of efforts from me, my supervisor, committee members, friends and family. I owe these people my every gratitude.

Before I move on, I would like to acknowledge the source of my strength: Nyame Kokroko (God Almighty) for how far He has brought me. His abundant blessings has nourished me through the entire writing process. To Him be Glory, Power and Honor. I do not forget the constant intervention of the ever blessed Virgin Mother Mary.

To Ann Brady, my supervisor and number one cheerleader, I say I am eternally grateful. She never stopped making me believe that my work is "top notch." Her excitement about my project kept me going. Also, her feedback, weekly meetings and guidance saw me through this journey. I also appreciate the efforts of my committee members, Robert Johnson, Marika Seigel and Godwin Agboka for sharing their depth of knowledge, insights and advice with me. Their final comments strengthened the structure and content of my work. My committee members are awesome!

I would like to offer a special thanks to officials at the Electoral Commission of Ghana, especially Mr. Samuel Tettey, Mr. Samuel Odonkor, Mr. Christian Owusu-Parry and Mr. Augustine Okrah. I could not have gathered the documents without your help. Thanks for also granting me permission to use the documents I gathered in my dissertation. 


\section{Abstract}

In this project, I seek to "unblackbox" technology; by which I mean, I seek to, in the words of Latour, "open up" or "debug" the biometric technology used by Ghana for its 2012 presidential and parliamentary elections. Through the process of "unblackboxing," I demonstrate the value of technical communicators to technology studies by analyzing technical documents that accompanied the biometric verification device which was adopted and used by Ghana to conduct its 2012 presidential and parliamentary elections. I argue in this dissertation that technical documentation does not merely accommodate users to technologies, but also it provides avenues to articulate broader issues like localization, ideology, subjectivity, and the social justice implications of the various technologies we adopt and use. We are also positioned to understand how a society reacts to issues that are historically, politically, culturally rooted in their context.

I maintain that documentation writing is one of the defining activities of technical communication. Thus, it is important to continue to build upon and expand the analyses of these types of documents to critically assess the role they can play in discussions about technology especially in international contexts. By performing a rhetorical-cultural analysis of various technical documents that accompanied the biometric device used in Ghana, I hope to aid technical communicators to reconsider received knowledge about the purposes and uses of technical documentation, such as instructional manuals. More importantly, by embarking on this project, I am able to:

- destabilize the "international" in international technical communication;

- discuss documentation design in international context;

- expand research on the importance of technical documentation to technology studies in a non-Western context (Ghana);

- demonstrate how rhetorical and cultural theories can be combined to study technology in international contexts;

- interrogate the biometric technology as a rhetorical artifact at the vortex of cultural entanglements. 


\section{Chapter One: Paying Attention to and Exposing the Gaps in (International) Technical Communication}

"Technologies bear the imprint of the people and social context in which they developed" (Wajcman, 1991, p. 22)

This dissertation is about technology adoption in a non-Western society (Ghana) and how the adoption provides an opportune moment for technical communicators to contribute to the conversation on technology. More specifically, the study is about the role disciplinary rhetoric, technical writing and electoral culture played in the adoption of the biometric verification system for the 2012 presidential and parliamentary elections in Ghana, a small country which lies on the coast of the Gulf of Guinea in West Africa.

The use of the biometric technology, a system which "scans a subject's physiological, chemical or behavioral characteristics in order to reify or authenticate their identity" (Pugliese, 2010, p. 2), leads to an investigation of the relationship between humans and technology. I contend that "technology," by which I mean a means to an end and a human activity, plays a vital role in human affairs and thus must be subjected to critical study. The past, present and future of humanity is tightly connected to the tools that we make. Feenberg (1991), for instance, advances the argument that "what human beings are and will become is decided in the shape of our tools no less than in the action of statesmen and political movements" (p. 3). By this statement, Feenberg establishes an intricate relationship between tools and humans, and indeed, between the political implications of our actions and the tools we use. It is not surprising that the intricate relationship has assumed an unprecedented role in technology studies literature. Johnson (1998b) 
identifies that many scholars have pondered over the question "what is the relationship between humans and technology?" (p. xi) from different dimensions. In all of their explorations, they agree that the relationship is inextricable. Different metaphors have been used to refer to this affinity.

Miller (1978) indicates that technology is part of our consciousness; it shapes our forms of thought. She deliberates on the extent to which technology has assumed an unprecedented role in human affairs. to Miller makes us understand that technology affects the ways we think, speak, write and what is ethical (p. 230). As a result, she admonishes us to probe technology by examining the ways in which it both reflects and shapes form and thought.

If technology shapes form, thought and what is ethical, then we have become citizens of an unknown country: Technopolis, Winner (1986) makes us understand. This intricate union between humans and technology is revealed "through how our lives are shaped by interconnected systems of modern technology, how strongly we feel their influence, respect their authority, and participate in their workings..." (p. ix). According to Winner, technologies are inherently political and we must accept it. By politics, he refers to the "arrangements of power and authority in human associations as well as the activities that take place within those arrangements" (p. 22). Therefore, to understand the political nature of technology we must examine the realm of tools and instruments from fresh perspectives because our instruments are institutions in the making.

In another masterpiece, Winner (1977) tells us we are not only citizens of technopolis, we are ruled by technocracy and technocratic thoughts. By which he means, we are ruled by 
scientific and technological elites. In technocracy, "technology in its various manifestations is a significant part of the human world. Its structures, processes, and alterations enter into and become part of the structures, processes, and alterations of human consciousness, society and politics" $(1977$, p. 6). Langdon Winner makes us understand that Western thought is swaddled in its traditional conception of ideas of control and mastery to the extent of believing that technologies have become autonomous, that is, "technology has gotten out of control and follows its own course, independent of human direction" (p. 13). Looked at from the autonomous model, we say that technology is self-governing, not ruled by an external law or force and it is independent. Technocracy traps us in the means-ends spectrum. We become instrumental and as a result, we adapt ourselves to the order, discipline and pace of the organization in which we work.

Like Miller, Winner identifies that "Efficiency, speed, precise measurement, rationality, productivity and technical improvement become ends in themselves applied obsessively to areas of life in which they would previously have been rejected as inappropriate (p. 229). Instrumentality becomes part of our psychological formation in which the technical aspect begins to control the rest of our individual personalities and we become conditioned to socially situate all problems in the realm of instrumentality and instrumental concerns. Thus instrumentality shapes how we produce artifacts and use them. Like the fictional character, Frankenstein, the instrumental reasoning that has engulfed us forces us to "release powerful changes into the world with cavalier disregard for consequences; that they begin to 'use' apparatus, technique, and organization with no 
attention to the ways in which these "tools" unexpectedly rearrange their lives; that they willingly submit to governance of their affairs to the expertise of others" (p. 314).

Finally, Heidegger (2014) reveals that "we remain unfree and chained to technology" (p. 305). If we remain unfree and chained to technology, then it means that humans cannot exist without technology. What is more frightening is the power that modern technology exudes over humans and nature. Heidegger observes that modern forms of technology operate in two directions. First, it unlocks and second it exposes. A typical example is found in how modern technology unlocks energy concealed in nature, transforms what is unlocked, stores up and distributes what has been stored up (Heidegger, 2014). To this end, Heidegger intimates that everything that exists is in a way ordered to stand by, a "standing -reserve." We are not mere "standing reserves," we are also "enframed." The essence of modern technology, according to Heidegger, "shows itself in enframing," that is, "the way in which the actual reveals itself as standing-reserve...enframing as a destiny of revealing, is indeed the essence of technology" (Heidegger, 2014). Thus according to Heidegger, we cannot rule out the relationship we have established with technology. This relationship which is inextricable, because we remain unfree and chained to it, is revealed through the way humans are enframed, and ordered about as standing reserves. To explore the relationship between humans and technology is to search for ways that technology entraps and also reveals humans. Our humanness is tied to the modus operandi of technology.

Just like technology, I believe that history also shapes what we do as humans. In my view, history and technology "have been integral to one another" (Long, 2014). Thus, in 
order to understand why and how Ghanaians decided to adopt the biometric technology, we must take a critical look at the history of elections in Ghana and how electoral issues provided an affordance for the technology. History, to me, means more than a mere narration of past events and occurrences. It means a critical inquiry into the past. History in many ways:

helps us understand people and societies, particularly their values and beliefs. History also helps us to understand change and how the group or body we are members of came to be; it contributes to moral understanding, provides identity, helps us develop a sense of context and coherence while recognizing complexity and ambiguity, and gives us a broad perspective that enables us to possess the range and flexibility required in many work situations (Dubinsky, 2004b, p. 65).

In this regard, I contend that an inquiry into the role of technical writing in adopting the biometric system to solve electoral problems in Ghana cannot be adequately interrogated if we fail to pay attention to the history of Ghana and more importantly, the history of elections in Ghana. This history provides a window for us to understand and question why or how Ghanaians developed a specific need — that is, a need to adopt a biometric verification system to solve specific problems. As a technical rhetor, I say that history provides us with the rhetorical situation, that is "the context in which speakers, writers [decision makers, problem solvers] create rhetorical discourse" (Bitzer, 1992, p. 1); and the rhetorical situation provides a web of relationships between the various historical, cultural, rhetorical, political, legal and economic issues that pushed or pulled the country to adopt the technology. Longo and Fountain (2013) describe the importance of history colorfully by saying that "making use of history involves more than knowing what happened: one must also consider the cultural, social, and individual forces that shaped those events - the forces that have given us the story instead of another" (p. 166). In this 
direction, I look at the forces that pushed or pulled Ghana to adopt the technological system and how writing is used to advance the goals of adoption. As Seigel identifies in Rhetoric of Pregnancy, "Too often, the question of how or why users have come to have particular wants or needs in the first place is not asked" (Seigel, 2013, p. 14). Therefore, in the next section, I work to answer the question: how did we get here? How did Ghanaians or the Electoral Commission of Ghana decide to adopt a biometric verification system? I achieve this goal by tracing the history of elections in Ghana.

\section{Mapping the political history of Ghana: Contextualizing research}

In this section, I offer a gist of what Foucault terms a "geneology" of the political history of Ghana to demonstrate the kind of efforts the country has made in its democratic trajectory. The context is the political history of Ghana, formerly known as the Gold Coast - a name which depicted the country's wealth in gold. Ghana is "a product of a colonial and postcolonial legacy with its historical, socioeconomic, political and cultural problems" (Agboka, 2013a, p. 31). With agriculture as the major source of employment for most of the citizenry (Smith, 2012, p.12), the country's economy is and has always relied on the exportation of cocoa, gold, timber, diamond, manganese and more recently, crude oil. The country's educational system is, as Smith (2012) identifies, "a remnant of colonial domination" with emphasis placed on "alphabetic literacies—reading, writing and computing" (p. 19). A former colony of Britain, Ghana became independent on the $6^{\text {th }}$ of March 1957 and a republic on the $1^{\text {st }}$ of July 1960. In its 58 years after independence, the country has witnessed four major military upheavals. The first coup d'etat was staged in 1966 to oust the first president of Ghana: Osagyefo Dr. Kwame 
Nkrumah. The second coup was staged in 1972 by Col. Ignatius Kutu Acheampong; the third and fourth in 1979 and 1981 by Jerry John Rawlings.

In 1992, Ghana began another road to democracy by adopting a new constitution that established the fourth republic in 1993. Ever since the fourth republic was ushered in, Ghana has organized five successful elections in 1996, 2000, 2004, 2008 and 2012. I am careful with the use of "successful" because the history of elections in Ghana has been fraught with such electoral malpractices as over voting, bloated voters' register, and vote rigging. For instance, Heinz Jockers, Dirk Kohnert and Paul Nugent identified in "The Successful Elections of 2008: A Convenient Myth?" that block voting ${ }^{1}$ in the Ashanti and Volta Regions in Ghana influenced "the level of electoral malpractice designed to stack up additional votes in areas of strength" (Jockers, Kohnert, \& Nugent, 2010, p. 97). In their article, they conjectured that "vote rigging...could acquire a decisive importance, possibly representing an even more important 'third force"” (Jockers et al., 2010) than smaller parties in Ghana. They also identified issues of inflated voters' registration which consequently resulted in high voter turnout, especially in the Ashanti and the Volta regions - the strongholds of the New Patriotic Party (NPP) and the National Democratic Congress (NDC) respectively. These and many other issues make the authors conclude that the electoral success of Ghana is a convenient myth.

In another study, Smith (2002) reported that prior to the 2000 elections, the electoral commissioner, Dr. Afari-Gyan "stated publicly that there was a substantial 'bloating' of

\footnotetext{
${ }^{1}$ The perception that the two major political parties in the country represent the interest of two major regions: National Democratic Congress (NDC) represent the interest of ewes in the Volta Region while the New Patriotic Party represents the interest of the Akans or Ashantis in the Ashanti Region. These two political parties work hard to maintain high votes in the respective regions.
} 
the register..." (p. 624). Interestingly, though the provisional national census figures recognized 18.4 million Ghanaians of which half was of voting age, the Electoral Commission had recorded 10.7 million names on the voters register "roughly $58 \%$ of the country's total population" (ibid p. 624). Per the census data, the author identified that the "EC's register was bloated with more than 1.5 million ghost voters" (ibid p. 624). Smith and Jockers et al are not the only scholars who have identified such malpractices as over voting and bloated register: Oquaye (1995); Saaka (1997); Salia (2000); and GyimahBoadi (2004) have also uncovered these in their scholarship.

In spite of these incongruities, Ghana has been hailed as the beacon of democracy in Africa-at least the nation has witnessed peaceful transitions of governance between the two major political parties in Ghana both in 2000 (when the opposition NPP unseated the ruling NDC) and in 2008 (when the opposition NDC unseated the ruling NPP) - an unprecedented story in the history of democracy in Sub-Saharan Africa. Prior to 2000, the (P)NDC had been in power since 1981. Ghana, spearheaded by the Electoral Commission, has sought ways to organize clean, transparent, free, fair and incontrovertible elections, and this led to the adoption of the biometric verification voting system for the 2012 presidential and parliamentary elections.

The Electoral Commission, the constitutionally mandated institution charged, among other things, to conduct and supervise all public elections and referenda in Ghana (1992 Constitution of the Republic of Ghana, 1992, p. 39), asserted that the device [biometric technology] was introduced to "the electioneering process in Ghana as a means of 
enhancing the integrity of the electoral process of the country" ("The Biometric Verification Device User Manual," 2012, p. 1).

The purpose of the device, as the Chair of the Commission stated, was "to assist in the detection and prevention of practices of impersonation and multiple voting that have characterized our electoral process in the past" ("The Biometric Verification Device User Manual," 2012, p. 1). The biometric verification voting system required that the biological features, that is, photograph, and fingerprints of qualified voters (Ghanaian citizen, 18 years and above, of sound mind) were captured electronically into the electoral register using portable computer, finger print scanner, a webcam and mobile printer ("Revision of the Voters Register 2014: User Manual for Data Entry Clerks," 2014). Voters could only vote if their fingerprints were identified and verified by the biometric verification system. It was a case of "no verification...no vote." The biometric device was, I would say, introduced to serve both as an identity check and a security check. This move to adopt a technology to solve a problem in the electoral systems of Ghana goes to an extent to confirm the perceived assumption that "...technology is seen as a quick and cheap fix for the perceived problems” (qtd. in Banks, 2005, p. 18).

\section{Research questions and foci of project}

Interestingly, at a consultative meeting after the 2012 election, the Deputy Chairman of the Electoral Commission in charge of operations revealed that

the Commission had technical, operational and logistic challenges during the Biometric Voter Registration exercise and the voting process in Election 2012 and said these created delays the in [sic] a number of polling stations across the country. He mentioned challenges such as the 
failure of some Data Entry clerks to follow simple operational instructions regarding the usage of the biometric machines, failure of the machines to recognise the fingerprint of some eligible voters, and some reported cases of attacks by "Macho men " in some polling stations as negative incidents that nearly marred the success of the entire exercise. ${ }^{3}$

More so, after the election, the opposition New Patriotic Party challenged the validity of the election results at the Supreme Court. The opposition party "alleged that the figures for the presidential election were distorted at the constituency level before" (Kelly \& Bening, 2013, p. 480) they were sent to Accra, the capital of Ghana, for final declaration by Dr. Kwadwo Afari-Gyan, the Chairman of the Electoral Commission. There were such other issues as: failure to comply with regulations requiring mandatory biometric verification, failure by Presiding Officers at some polling stations to sign the official results sheet, over-voting at a number of polling Stations, and discrepancies in the size of the voters' register (Gyimah-Boadi, 2013, p. 4). For the first time in the history of Ghana, election results were challenged at the highest court of judicature. As Justice Atuguba indicated in his judgement, merit was given to three core grounds of the petition: overvoting, voting without biometric verification and absence of the signature of a presiding officer (judgement, p.3). These incidents and stories leave us to ponder over why humans adopt and use technology.

The revelation made by the Director of Operations and the 8 months long legal tussle at the Supreme Court of judicature leaves me with some questions:

- Why will a "simple" instructional manual not be effective?

\footnotetext{
${ }^{2}$ Militia and thugs

${ }^{3}$ http://www.ec.gov.gh/news.php?news=116
} 
○ What elements in the supposedly "simple" instructional manual made it rather complex for Data Entry Clerks to follow?

- How can the study of the effectiveness or ineffectiveness of a user manual lead to a fruitful discussion of localization, social justice, ideology, and the way technologies, such as the biometric, shape material lives of users?

- How does the adoption enable scholars to examine the relationship between rhetoric, technology, technical communication/writing in cross-cultural contexts?

- What role does technical writing play in creating, maintaining and unmasking societies' assumptions about technology?

- How is technical writing used to create an exigence for technology adoption?

- Of what benefits will studying technology in international context bring to research, pedagogy and practice in the field?

- How can a cross-cultural study of technical documentation influence prevailing theories in rhetoric of technology, genre studies and international technical communication?

These questions provide an exigence to study the role and relationship among disciplinary rhetoric, defined by Scott (2003) as "discursive bodies of persuasion that work with extrarhetotical actors to shape subjects and to work on and through bodies" (p. 7); technical writing, that is, writing that gives "users control over technological systems, to empower" (Seigel, 2013, p. 34); and electoral culture, by which I refer to the various systems, practices and rituals that accompany presidential and parliamentary elections in Ghana. I do not limit electoral culture to the ballots, machines, and systems used for casting on voting day. Rather I extend it to mean

the system of people and processes in which [election] operates - the legislators, executives, and the judges elected by those ballots, the laws 
they pass, enforce and interpret, the budgets they have discretionary power over, the individuals they are able to hire and fire, the police [and military] (along with their guns...) used to uphold [and resist] them (brackets mine Banks, 2005, p. 60).

The concept of disciplinary rhetoric is derived from Foucault's concept of disciplinary power, a concept which identifies the powerful nature of institutions such as the human sciences in the nineteenth century. Foucault realized that institutions had become so powerful that they created "norms and standards" (Bertens, 2013, p. 148) that conditioned and controlled human existence. Although disciplinary power is less visible, "its ultimate effect can be to heighten the visibility of subjects' bodies in relation to institutions" (Koerber, 2006, p. 88).

I do not equate the Electoral Commission to a scientific institution in any sense; however, I make a case that the Commission is an institution that has been mandated and empowered by the constitution of Ghana to conduct all manner of public elections. In essence, the commission makes rules that control electoral processes in the country. The Electoral Commission provides grounds for me to interrogate the role that state institutions play in driving technology needs. Thus, through technical writing, by which I mean, such documentation as instruction manual, parliamentary hansard, suite of posters, and an online video, the Electoral Commission created rhetorical frames and appeals that helped persuade or condition Ghanaians to accept the biometric technology as the surest way of producing authentic electoral results.

The Commission dwelt on extrarhetorical tools such as malpractices that have characterized electoral culture in Ghana to make a powerful case for the adoption to be possible. Technical writing in this regard becomes the medium or instrument through 
which institutions, societies, organizations and individuals create exigence for a technology to be adopted. It also becomes a knowledge producing practice. Thus disciplinary rhetoric, technical writing and electoral culture are inextricably related and they combine to create a rhetorical situation - that is, a moment necessary to adopt and use a technology in a non-Western world. By "adoption," I make reference to the acceptance or borrowing of a new product, such as a technology, to solve a problem. Thus, it is most likely that a non-Western society willing to adopt a technology to solve specific problems, in my case, electoral problems, will draw on an aspect of its culture to develop rhetorical patterns that will persuade. Technical writing will be the powerful medium used to pursue this agenda. This establishes an intricate relationship between rhetoric and culture.

The adoption of the biometric technology in Ghana and the reasons for the adoption point to the fact that technology use is not specific to the Western world; it is, I would say, a universal case. Perhaps, we could say that Westerners and non-Westerners have similar ideologies or assumptions about technology: it is a quick fix to our problems and it provides efficient results. Therefore, we must study how cultures other than Western cultures relate to technology. This will broaden the purview of technology studies research and arguments made about technology. Just like Bernadette Longo, I argue that we should study how technology works in non-Western or international contexts. This call should not be left to a particular group of scholars. This is an avenue for technical communicators to broaden their research horizon because the world has become a globalized society; technology is used by international and cross-cultural audiences. 
Furthermore, I hold that before we can adequately conduct research in international contexts, we must interrogate the term "international." In the next section, I work to unpack what the term "international" means to my work and how its interrogation can enhance the study of technology in "international" contexts.

\section{International technical communication and technology studies}

Technical communication, as a field and as a practice, is tied to Western traditions and ideals (predominantly American) and is still "relatively restricted to Western nations" (Thatcher \& Amant, 2011, p. 1). This is not surprising since the field was developed to meet the needs of societies in the West (Kynell, 1999; Longo, 2000; Fountain \& Longo 2013; Staples, 1999). While this may be true, it has become necessary for the field to extend its purview beyond Western frontiers to non-Western cultures because of the phenomenon of globalization. As a result of globalization, the world has increasingly become interconnected in a variety of ways. As global economies, humans, different forms of knowledge merge, and as the world become intertwined through the use of technologies, technical communicators have found themselves designing documents for different audiences from a larger global audience. Hence, it is appropriate to say that technical communication has gone "international," which supposes technical communication has extended to include different countries, nations or continents. A critical study of international technical communication research and practices, however, reveals that scholars and practitioners have paid little attention to defining the premodifier "international" in international technical communication. 
Mostly, though scholars have captivating titles that place importance on the "international," they proceed to use intercultural frames to study what is international. It is as though "international" and "intercultural" are synonymous. See for example: Agboka (2013b, 2014); Walton (2014); Thatcher (2006); Boiarsky (1995); Thrush (1993); Hunsinger (2006); Amant (2006); deWinter (2014) and Brady and José (2009). This proclivity to drop "international" for "intercultural" abounds because the field tends to depend on such fields as intercultural communication (Lovitt \& Goswami, 1999, p. 2). It has become difficult to discuss international technical communication without resorting to intercultural frames. This is a decent move since intercultural approaches enable scholars to acknowledge the importance of culture to communication research and practices. This move also speaks to the interdisciplinary nature of (international) technical communication. The benefits that come with interdisciplinarity are numerous. For instance, Johnson (1998b) states that borrowing allows the field of technical communication to build a very strong theoretical, methodological and historical base. But, there are downsides to interdisciplinarity such as "the problem of becoming so dependent on the borrower that we fail to reciprocate back into the interdisciplinary milieu with any contributions of our own" (p. 15). Lovitt (1999) has also warned, and I agree, that it is egregious for the field of international technical communication to rely on other disciplines. He mentions that depending on allied fields for research tools could lead to research results and findings that do not answer questions pertaining to the field of international professional/technical communication (p. 2). Again, borrowing from other disciplines also means "imposing the other disciplines conceptions of international professional [or technical] communication" (ibid, p. 2) which may not necessary favor 
our discipline. Lovitt's stance helps us to appreciate the relevance of interrogating the relationship between "intercultural" and "international." I ask: is doing intercultural technical communication research similar to doing international technical communication research? I find this call worthy, since, in my mind, although we conduct research in international contexts, we have not properly interrogated what the term "international" means to international technical communication researchers and practitioners. I must indicate that I am aware scholars such as Sun (2012) and Hoft (1995) have discussed concepts as "internationalizing" technical communication, but their approaches, I would say, discuss the concept to favor business corporations and not necessarily technical communication. We really have to interrogate the international in a way that will incorporate concepts relevant to technical communication research. My take is that when we define "international" in our field, using our concepts and approaches, we will better address issues in international technical/professional communication. If we have to (re)examine our approaches and objectives, as Agboka (2013b) calls for, then we have to start by really interrogating the "international" in international technical communication.

I must say that our notion of what constitutes the international has been limited to national cultures. We also have a static notion of what constitutes the international. This notion is well exemplified in Hoft's (1995) definition of international technical communication as "the development of information that can be exported to any country in the world" (p. 1). In her enunciation of international technical communication, she mentions that the field is sensitive to "user requirement;" it "bridges cultural differences and national boundaries;" it requires "multicultural and multilingual awareness;" and it 
"seeks diversity." More importantly, she identifies that the extension of technological products means the "need to balance business needs and cultural understanding of people who need to learn how to use high-technology products" (p. 3). Her definition is apt, but lacking in the sense that it presents an instrumental approach to information design. Embedded in the definition is the assumption that information can be developed from one source point (probably the designer source) and can be used globally without any regard for local cultures and attitudes. It assumes that nations are monolithic and culture is static.

Sun (2012) profoundly identifies that culture has been narrowly conceptualized and that scholars and designers must move beyond the narrow representation. Often, approaches employed to study culture capture local cultures in terms of 1) do's and don'ts, anecdotes and business cases. This focus, she identifies, only reports the dominant culture in a country; and 2) value-neutral cultural dimensions. This approach also promotes the spirit of positivism because culture from this perspective places concrete cultural realities into static dimensions; 3) structured fieldwork methods which focus on richness and texture of everyday life and is concerned with "the production of and exchange meanings between the members of a society, or a group in an enthnomethodological sense" (p. 14). Context is presented in a limited sense, mostly, to the workplace or site of study. Sun believes that local culture can be represented and manifested in technology design when we focus on the nexus among technology, design and culture. This is necessary because technology and culture are inextricable, design matters profoundly in a technological culture, and technology design plays a role in technological culture. She argues for "a dialogic view 
of culture that is both robust and flexible to study local culture and offer a more complete vision of culture for technology design."

Similarly, Agboka (2012) identifies that the discussion of culture in intercultural technical communication is heavily influenced by "large culture" sentiments. The focus on "large culture" leads to a concentration on dominant groups in a country to the neglect of cultural practices of less dominant groups (p. 161). This concentration on "large" cultures leads to descriptive notions about countries. We pay little attention to the various local and sub-cultures that make up nations and how such sub-cultures tend to influence decisions and national policies.

The descriptive or static notions of national cultures trickle down to our research reports as one reads articles with such titles as: "Cross-cultural considerations in instructional documentation: contrasting Chinese and US home heater manuals;" "Illustrations in user manuals: Preference and effectiveness with Japanese and American readers;" "Russian Teaching Contracts An Examination of Cultural Influence and Genre;" "Convergence in the Rhetorical Pattern of Directness and Indirectness in Chinese and US Business Letters;" and "Analyzing the Genre Structure of Chinese Call-center Communication." We tend to look at nations as constituents of a single or monolithic cultural attributes with little regard for the rhetorical practices. Or we tend to conflate culture with nation or ethnicity (Piller, 2007, p. 210). We need to acquire information about cultures, but not with a monolithic lens. We also need to equip ourselves "with more rhetorically sensitive strategies and processes for evaluating cultural interactions and for adapting...communications to the needs of particular situations" (Lovitt \& Goswami, 
1999, p. 7). This way, we approach international technical communication from a more dynamic stance than what presently exists.

In the geist of rhetoric, I argue that what is "international," is fluid, dynamic, and unstable. Therefore, in this project, I define "international" research to mean a study of the dynamic, contingent, fluid, unstable rhetorical cultural bodies that influence decision making processes in a locale. I offer this definition as an "opening to future conversations in our field...so that our uniquely situated field might further contribute to disciplinary, interdisciplinary, and everyday understandings" (Haas, 2012, p. 282) of what it means to conduct international technical communication research. International technical communication should be a study of the amalgamation of local, national and global cultures. We should also be cognizant of the fact that cultures are rhetorical. I do not use "rhetorical" to refer to the mundane meaning of the word that links it to deception. Neither is it a sham art or cookery as Socrates and other classical scholars would want us to believe (Kennedy, 1999; Matsen, Rollinson, \& Sousa, 1990). By rhetorical, I mean, "the situated, persuasive use of language that can include both verbal and visual discourse, both public and interpersonal communication and both explicit and implicit arguments" (Scott, p. 3). I emphasize that rhetoric is "situated" to acknowledge the fact that practices are "always exercised at particular moments, at a particular time and place in a culture, society, or group" (Sullivan, 1997, p. 28). I contend that "situatedness" is not a static or monolithic concept. Rather, "situatedness" connotes movement, time, place, dynamism, fluidity, dialogue, instability, construction and contestation. Looked at from this perspective, we can say that rhetoric is a techne, an art of making. In the same way, 
culture "is an open set of practices and a dynamic process in which cultural meanings, objects, and identities flow across institutions, nations and generations in diffuse timespace" (Sun, 2004, p. 8). "Culture" is situated "in the dynamic interactions of the instrumental and social affordances of the technological artifact" (Sun, 2006, p. 464); it is "situated in concrete use activities within concrete contexts, which should be approached in a dynamic fashion and in a broad way" (Sun, 2006, p. 474); and it is contingent. In this sense, what is "cultural" and what is "rhetorical" is situated, dynamic, open ended, fluid, unstable, dialogic and a site of contestation. Both rhetoric and culture intermingle in a particular locale. Thus, culture is always already rhetorical.

I admit that my work falls within the purview of international technical communication because it examines technical communication and rhetoric in a non-Western country, but my notion of the term "international" goes beyond a narrow conception that limits what is international to nations or countries. Or the conception of international as practices that cut across "different continents, countries, and cultures" (Gurak \& Lannon, 2012). I study Ghana with a lens that is more accurately described by cross-cultural notions. By this, I mean to say that my notion of international is not about nations converging; it is about different local-global rhetorical cultures influencing national policies. It is about the local, the dynamic and the fluid cultures first before national cultures. Of importance to cross-cultural notions is the dialogic, rhetorical, fluid, unstable and dynamic nature of local-global cultures. To study cross-cultural patterns means focusing on the "locale," that is "that part of the user's environment that is dependent on language, country/region, and cultural conventions in cross-cultural design practices" (Sun, 2009b, p. 248). This 
focus leads scholars to be "cognizant of local contexts and their histories" (Agboka, 2013b, p. 34). As Sun (2012) advocates, local culture becomes a dynamic and openended dialogue among developers and users, insiders and outsiders, local and the global, and diverse factions (p. 25). In essence, to study the various ways that different cultures and rhetorical situations influenced the adoption of the biometric is in a way a study of how Ghana has been influenced by the forces of globalization. It is as a result of the dialogic and dynamic nature of rhetorical and cultural bodies in countries that I choose to approach my work with a rhetorical-cultural methodological lens. As will be discussed later, rhetorical-cultural lens holds that cultures are rhetorical. Rhetoric is hidden in culture and culture is unveiled through rhetoric and vice versa.

To talk of international is first and foremost to talk of nations, but some nations have varied cultures and attitudes and these local cultures which are also rhetorical play major roles in decision making processes. Looked at from this perspective, we can argue that what is national cannot be studied from a monolithic or static lens. What is national is dynamic, unstable and fluid. My work looks at the role that different local cultures and rhetorical situations in Ghana played in the adoption of the biometric verification system. Thus, it is almost impossible to look at how the national culture of Ghana influenced the adoption because Ghana has varied cultures and different rhetorical situations. These varied cultures and rhetorical situations were invoked during the adoption process. More so, looking at the national culture of Ghana may limit my examination of the role of subcultures, such as the electoral culture, in the adoption process. 
When we look at international not in terms of dialogue among nations but in regard to an open-ended dialogue among local and global, developers and users, insiders and outsiders, we extend our research practices beyond a concentration on language and culture to an effective localization need that works to "understand ideology, power, economic, knowledge, politics, law, and ethics all as dimensions of a locale, not separate from it” (Agboka, 2013a, p. 29). Embedded are a critical consideration of rhetorical, "cultural and contextual factors" (Brady \& José, 2009, p. 58). In this direction, we can study not only the formulaic nature of the genres or technologies we design but the actions they enable.

My project responds to Longo's (2000) claim that technical communicators should turn attention to how the non-Western world relates to the world and to technology (p. 167). I consider Longo's suggestion a call on technical communicators to intensify research in international contexts. It is a call that pushes forward the agenda that other rhetorical bodies should be given space in technical communication research and practices. We are challenged by Longo's call to define technology to reflect the various ways that people of color, for example, use technologies. When we heed to this call, we might "rupture widely held theoretical and political assumptions and racial stereotypes about technological expertise" (Haas, 2012, p. 288). We might also include "diverse and underrepresented history of technological use, production, and expertise in our disciplinary conversations" (Haas, 2012). This way, our research will not be focused on Western societies but non-Western societies as well. Thus, this study contributes to and is 
situated in the field of technical communication in general and international technical communication scholarship in particular.

While technical communicators are user advocates, the important question is: how can we advocate that designed technologies should "meet the cultural [and I add, rhetorical] expectations of local users, support their complex activities in concrete contexts, and empower agency and mediate their identities in" (Sun, 2012, p. 4) non-Western societies? We need to investigate this issue by conducting and reporting case studies that consider the various ways users outside Western societies relate to and use technology. Huatong Sun has taken a bold step in this direction with her study of mobile technology use in both American and Chinese cultures. In this study, she identifies that technology design processes create "a disconnect between action and meaning" of local users (Sun, 2012, p. 8). That is, little is done to incorporate the meanings, behaviors, practices and state of consciousness of users into technology design. As a result of this neglect, she proposes that design philosophy and principle should attend to "both action and meaning through a cyclical design process." This, she believes, will help "the cross-cultural design community to create a technology both usable and meaningful to local users." There is the need to push for a user-localization, that is, a study of the various ways that users localize technology to fit everyday lifestyles (Sun, 2006, p. 459), as this provides an insight into local forms of life and how we can adapt or design technologies to meet user needs.

Similarly, Agboka (2013a) advocates a "participatory localization" in the design of documents and technologies in international or cross-cultural contexts. By "participatory 
localization," the author refers to the extent to which users will be involved in design phases. The user who participates in localization processes is not an isolated person, but he/she is involved as a member of a community (Agboka, 2013a, p. 42). He identifies that though technical communication scholarship is replete with ideas and notions of localization, little is done to account for user needs in unenfranchised and disefranchised cultural sites. Localization “often starts from the developer's site and trickles down to the users' site." As a result, "users are not cast as agents who initiate and implement change themselves" (p. 30). Thus we can conjecture that designs and technologies that are sent to unenfranchised sites reinforce the system-centered design model discussed by Johnson in User Centered Design ${ }^{4}$. Again we can contend that designs carry the stigmata of the developers. User advocacy in international context is a ripe domain for technical communicators to study technology use.

It is interesting, however, to note that research has neglected political contexts of technology in non-Western societies. For instance, Rosario Durao (2013) who makes an attempt to map out the various thematic strands that run through international technical communication/professional research, identifies five interesting dimensionsenvironment, human, communication, technology, and artifacts. Under technology dimension, Durao reveals that discussions on technology are connected to "equipment, professional contexts, educational contexts, entertainment contexts... viewpoints" (Durao, pp. 18-19). Nothing is said about the political contexts of technology. This silence on the political is probably due to the fact that technical communication as a field

\footnotetext{
${ }^{4}$ For more on system-centered design, read Robert Johnson (1998).
} 
has shied away from discussing issues relating to politics. The field has still not heeded to Blyler's (1998) call that the field ought to take a political turn in its research practices. Godwin Agboka has also reverberated Blyler's call. My research to a larger extent, examines the concatenation between politics and technology in an international context. I have embraced Blyler's and Agboka's calls. My work moves away from the narrow focus of research on workplace contexts "toward serious engagement with under-examined issues such as" (Ding \& Savage, 2013, p. 1) social justice, localization, ideology, power, gender, policy, democracy and human-technology relationship in a non-Western society.

\section{Technical documentation design in international contexts and technology studies}

By conducting this project, I also respond to calls made on scholars in technical communication to study instructional manuals developed for international audiences or calls that we should study instructional manuals in international context. Thatcher (2010), for instance, bemoans the lack of interest on the part of scholars to assess instructional design in international contexts (p. 24). If technical documentation, by which I refer to "the collection of materials that describe how to operate and maintain a given operating system or piece of software or hardware...[or] all of the written materials...that support a particular technology of technological system..." (Seigel, 2006, p. 12) is "one of the things that determine how we use technology and in turn how technology uses us" (ibid p. 13), then, I argue that we can study technology by studying those documents that accommodate technology to users. I do not limit my work to instructional manuals. I 
extend to look at other technical documents such as an online video, parliamentary hansard and a suite of posters to assess the role they play in technology adoption and use.

By analyzing documentation in an international context from a rhetorical-cultural perspective, I hope to unmask "assumptions ...about the roles of writing in creating or maintaining certain types of rhetorical, social, organizational, and cultural interactions in new technology contexts" (Thatcher, 2006, p. 385). In this sense, technical writing or technical documentation as I contend has a social role to play in the adoption of a technology. It also has a role in the way a group of people make decisions about issues and policies that advance their interests.

My hope is that this study will bring a new direction to the study of rhetoric of technical communication, by which I mean, the various meaning-making discourses about technology that are captured in technical documents. I pay attention to how the meaningmaking discourses captured in technical documents can shape technical communication practices as we design, evaluate, and write technical documents for international audiences and users of technology.

Also, I hope to propose the use of a hybrid rhetorical-cultural analysis as a methodological approach for conducting research in international contexts and as an analytical lens. A hybrid approach is relevant to studying international and cross-cultural contexts because research in the field has focused so much on doing cultural analysis without considering the rhetorical nature of such societies. Moreover, as Barry Thatcher indicates, the focus only on local culture leads to "ethnocentrism, methodological aporia, poorly theorized global-local relations, and ignoring large-scale variables" (Thatcher, 
2010, p. 2). He advised that scholars should use comparative frames. Hence, it is necessary to use a hybrid methodology that considers rhetorical and cultural situations, and global and local issues in international contexts. In tune with my assertion, I adopt Blake Scott's rhetorical-cultural approach as a methodological framework.

This methodological framework (I provide a detailed discussion in chapter 3) establishes a dialogic relationship between rhetoric and culture. This approach comes with several benefits to my work. First it will enable me to focus work on rhetorical actors and conditions, as traditional rhetorical analysis. In this regard, I take a critical look at policies "shaped from complex relations among rhetorical, ideological, political, economic, institutional, and social forces" (Scott, 2003); second, I map out the shifting relationships among rhetorical cultural practices around the biometric; third, I dwell on rhetorical-cultural mapping to see how the biometric system is taken up and what it enables and disables; lastly, I work to discover opportunities for local intervention. In order to make my approach meaningful and to see the relationship between culture and rhetoric and how they can shed light on both global and local contexts, I employ two theories: articulation theory from cultural studies and context of use by which I extend to mean access from a rhetorical theory.

\section{Rhetorical genre studies and international technical communication}

My work dwells on rhetorical genre studies to push forward the agenda that technical communicators can contribute to technology studies when they examine genres that accompany technologies we adopt and use. Genre is used in two senses. First, it refers to 
texts that contain knowledge of what we want to do (Johnson, 2008b). It also refers to "a way of talking about how people regularly interpret and use texts" (Spinuzzi, 2004, p. 110). It is a call for more research to be conducted into the various ways that different local rhetorical cultures, continents and societies relate to technology. I must say that some work has gone into studying technology in Western societies but little on nonWestern societies. Hence, our knowledge of how societies outside the West use technology is limited. Therefore, we must study technology use in international contexts and we can start by analyzing genres that accompany technologies. Such research takes into cognizance the broader cultural, historical, and rhetorical patterns that push or pull societies, nations and organizations to adopt a particular technology for a specific purpose. It is a journey into the micro and macrocosmic rhetorical and cultural contexts which provides and captures attitudes about technology. Subsequently, the project advances that more research is to be conducted into how international or cross-cultural users relate to technology. This can inform designers on how to include international user needs in technology design. It is also a means of informing technical communicators on the various ways they can adapt documentation to international user needs.

My inquiry will not look at the various forms that the genres take, rather, I look at the actions that the genres enable and how those actions can be tied to a social context. Or in pursuant of my goal, I look at how "genres are tied to the spaces in which they perform rhetorical work" (Swarts \& Kim, 2009, p. 211). I am not the first to have placed emphasis on the actions that genres enable. Several scholars before me have charted this path. Steven Katz, for instance, makes us aware that "technical writing, perhaps even more 
than other kinds of rhetorical discourse, always leads to action, and this always impacts on human life...”(Katz, 1992) and it almost always furthers organizational goals (Ornatowski, 1992). Miller's (1984) groundbreaking article "Genres as Social Action" also stresses that the study of genre should not be about the taxonomy it will create, rather, it should center on the action it is used to accomplish. "if genre represents action, it must involve situation and motive, because human action, whether situation symbolic or otherwise, is interpretable only against a context of situation and through attributing of motives" (1984, p. 152). Genre becomes a pragmatic entity and not syntactic or semantic.

I make a case that genre study in international context focuses so much on genre forms to the neglect of the actions genres enable. Most scholars have channeled their energies into studying how materials accompanying technologies are designed to meet the needs of users or how cultures outside the United States or North America design such technical documents as memos, reports, proposals and letters. Mostly, research focus in this direction is to learn ways that other cultures design technical documents with the purpose of informing students. See for example (Barnum \& Li, 2006; Beamer, 2003; Connor, 1998; Dong, 2007; Fukuoka, Kojima, \& Spyridakis, 1999; Honold, 1999; Khadka, 2014; Roach \& Byrne, 2001; Stevens, 2000; Thatcher, 2006, 2010; Thatcher \& Amant, 2011). This tendency to study the ways that other cultures design documents tends to tokenize and label culture as a monolithic entity. This perspective is common because of the belief that each culture is unique and hence has "its own specialized knowledge related to what constitutes an acceptable and a credible presentation of information" (Amant, 2006, p. 49). As Agboka (2012) indicates, "the worry is that this conceptualization can be a 
catalyst for stereotyping,...[and] they may limit our appreciation of diversity among groups." Worst still, "stereotyping can lead to tokenism, and tokenism can lead to essentialism. Essentialism can lead to racism, while racism may lead to culturism. Culturism can, in turn, lead to cultural/economic imperialism, because it becomes an instrument of oppression against many marginalized groups by powerful groups" (Agboka, 2012, p. 172).

Therefore, international technical communication must research into the dynamic ways genres enable action in international contexts. Scholars must pay attention not only to the genres but also the various situations and motives that enable the use of the genre.

Genres, therefore, become "a rhetorical means for mediating private intentions and social exigence" (Miller, 1984). Not only will the emphasis on actions genres enable communicate our values and our worth within workplace, it will add value to international technical communication research by resolving "the tension related to balancing local appropriateness of methodologies with comparability across global contexts" (Walton, 2014), or the tension between culture and rhetoric (Amant, 2006; Boiarsky, 1995; Ding \& Savage, 2013; Hunsinger, 2006; Lovitt \& Goswami, 1999; Thatcher, 2010; Thrush, 1993). We also become exposed to the ways that diversity "affects the ways in which technologies and documents are designed and used, how national and political values can inspire users to transform the work of technologies beyond their designed intent, and how non-Western cultures use and produce with Western and non-Western technologies differently than Westerners do" (Haas, 2012). My fourth chapter, for example, analyzes an instructional manual that came with the 
biometric device. My end goal is to find out whether or not the instructional manual helps users to gain power over the biometric technology and how the use of the instructional manual articulates users into a technological system. How do we use or how are we used by technologies through the genres we create? The fourth chapter leads to a more informed discussion on technology studies and how it enables or informs our knowledge of localization, social justice, and technical document designs.

I look at genre studies also as a study of technology. It is indisputable to consider genres as technologies and technologies as genres: genres are human constructs, so are technologies. Genres come to being through the activities of humans. Genres, are "specific human activities" and "enactments of recognized social motives" (Sun, 2012, p. 66). They are "produced, reproduced, and modified by individuals through a process of structuring" (ibid p. 68). Just as technologies, genres are structural. This notion of structuring is captured vividly in Langdon Winners claim that "technologies are not merely aids to human activity, but also powerful forces acting to reshape that activity and its meaning" (Winner, 1986, p. 6). Genre, Bazerman states, "shape regularized communicative practices that bind together organizations, institutions, and activity systems" (Bawarshi \& Reiff, 2010, p. xi). As a technology, genres shape human activity.

We must also bear in mind Winner's claim that technologies or artifacts do have politics. Thus genre and artifacts are political. Adam Banks also draws the connection between genres and technologies when he argues that "genres and the discursive conventions that comprise them can, through their privileging of certain kinds of knowledge and experience while dismissing others, can become instruments, tools, technologies even, in 
maintaining established patterns of social, political, and economic relations" (Banks, 2005, p. 87); or he makes us understand that language and discourse are "our trump technologies, especially when specific language and discursive conventions are codified in generic conventions as they are in legal scholarship and jurisprudence" (Banks, 2005, p. 89). Language in this sense has technological functions. If we accept that genres are technologies, then a study of the rhetorical nature of genres, or a study of the various ways that genres enable action, or a study of the various ways that we solve problems using genres, is a study of technology. A study of genres is a study of technology and, in my case, a journey into the political, economic and legal situations in a country. If we study the rhetorical nature of genres, we embark on a rhetorical study of not just technology but also technical communication. In sum, genre studies “provides a foundation for interpreting actions from a social angle" (Sun, 2004, p. 46); it enables us to "understand the artifact we are studying in a social and historical context" (ibid pp. 47, emphasis mine); and finally, it illustrates "how uses of technologies are structured in social contexts" (ibid p. 47).

\section{Overview of project}

I have stated that my work examines the role that technical writing (used interchangeably to refer to technical documentation or genres), disciplinary rhetoric and electoral culture played in the adoption of the biometric verification system for the 2012 presidential and parliamentary elections in Ghana. I argue that through the study of the documentation/genres, we are positioned to understand what it means to design documents for international audiences. We also get to understand the role that technical 
writing plays in creating, maintaining and unmasking societies' assumptions about technology. For this project, I draw on rhetorical-cultural approach to examine the rhetorical strategies that the Electoral Commission of Ghana used in persuading Ghanaians to adopt the technology. I analyze textual documents produced in the process of adopting the technology and corresponding manuals that accompanied the technology. I, more importantly, suggest ways that documentation can be localized to meet local needs. I also suggest ways that technology can be studied through the genres that make technologies we adopt fit local needs.

Chapter two, which is the literature review section, identifies the conversation in the field of technical communication as regards technology studies and I look at ways that my research will fit into this conversation. I perform a review of three fields that are very prominent in technology studies scholarship: cultural studies, philosophy of technology and rhetoric of technology. These three areas helped me to identify the various ways that technology is inextricably related to humans and how necessary it is for technical communicators to engage in and contribute to technology studies scholarship.

Chapter three presents my methodology and method. I discuss how Blake Scott's rhetorical-cultural methodology provides a viable environment to study technology in international contexts. More importantly, I stress the relevance of concepts such as articulation and context of use can help us study international contexts. I also explain the method I used in collecting and analyzing data. Mention is also made of my research site and the documents I collected. In this chapter, I also stress the importance of reflexivity, 
humility, patience, flexibility and positionality to conducting international technical communication research.

In chapters four and five, I present my analysis and findings. Chapter four is devoted solely to instructional manuals that came with the verification device. I seek to find out how the instructional manuals make "arguments for constituting a technological system, maintaining it, disrupting it, or replacing it" (Seigel, 2013, p. 32); while chapter five maps out at an assemblage of technical documents to find out how those genres were used to persuade Ghanaians and other stakeholders to accept the biometric system. I perform two tasks in this regard; first, I study the rhetoric surrounding the biometric technology, then, I dwell on Foucault's biopolitics and Haraway's cyborg to argue that the biometric functions as a cyborg technology because its success depends on the presence of a body. As a cyborg technology, the biometric becomes a site to discuss the political nature of technologies. The biometric is also a "disciplinary" technology which is used to control electoral fraud.

Chapter six concludes my work. Here, I revisit the concept of "unblackboxing" as I use it in my title. I unpack the term in order to identify how the metaphor enables me to produce a dissertation project that contributes to the field. I look at how I answer the questions I pose in my first chapter. I also reiterate the major contributions of my work to research, practice and teaching. I touch on the limitations of my work and how my future work will resolve the limitations. Finally, I set out plans for future work. 


\section{Chapter Two: Tracing the conversation about technology}

Dzogbese Lisa has treated me thus

It has led me among the sharps of the forest

Returning is not possible

And going forward is a great difficulty

The affairs of this world are like the chameleon faeces

Into which I have stepped

When I clean it cannot go...

(Songs of sorrows by Kofi Awoonor)

One would wonder why I begin the exploration of the conversation on how various fields have approached the study of technology with a dirge that narrates the persona's disenchantment with life. The poem paints a sense of entrapment: "Returning is not possible//And going forward is a great difficulty." Second, the poem reveals an inextricable relationship between the persona and the world: "The affairs of this world are like the chameleon faeces//Into which I have stepped//When I clean it cannot go.” These two senses of the extract above speak to 1) the sense of entrapment humans find themselves in their relationship with technology; 2) the inextricable relationship between humans and technology. It is almost impossible to discuss one and not mention the other. Thus the relationship among these words- "technology" and "humans" can be likened to the chameleon faeces: they form an assemblage and we can only articulate them together. Can humans exist without technology?

It is without a shred of doubt that technology has assumed an unprecedented role in human affairs. Every day humans make decisions about which technologies to adopt, use, and develop. These decisions more often than not have positive or negative implications. 
Humans deliberate on the consequences of technology on environment, health, politics and the ecosystem. We ponder whether technology is a blessing or a curse that humans have to contend with. These and many other concerns make the study of the relationship important. Technology shapes humans and humans shape technology (or are we yet to shape it?). To borrow from Winner (2010), I say "technology has become woven into the texture of everyday existence, and the devices, techniques, and systems we adopt tend to shed their tool-like qualities to become part of our very humanity" (p. 12). We need to study and understand the ways technologies shape our lives because "without systematic study of our relationships with technologies and technological issues, we remain subject to those technologies..." (Banks, 2005, p. 10).

This chapter offers a review of literature on the status of technology studies in fields as diverse as cultural studies, philosophy of technology and rhetoric of technology. These areas are reviewed in order to identify the various ways that conversations in other disciplines intersect with, can and should inform technology studies in (international) technical communication scholarship. Arguments made by scholars in these areas move my work further to discuss the rhetoric of technical communication.

\section{Cultural studies and technology: relevance of articulation and assemblage}

Technical communication is always already cultural. By this I mean technical communication practices have always been grounded in larger political, ideological, legal, technological, discursive and economic practices. More so, technical communication functions in organizational settings and these institutions are considered 
cultural agents. We are user advocates and we participate in the knowledge formation of users who are also cultural agents. Our advocacy work leads us to contact users from different backgrounds and cultures. It is appropriate to say that technical writing has worked to control people in institutions and societies. Nonetheless, little attention was given to the role politics, ideology and social relations play in our activities. Not until this consciousness to the "cultural turn" of technical communication was whipped by Longo (1998), much research in the field had tended to identify the social nature of technical communication practices. These social constructionist approaches, according to Longo, present a limited view of culture because work is situated "within the walls of one organization" (ibid, p. 55). More so, social constructionist approaches took an "explanatory and pragmatic stance" (Scott and Longo, 2006, p.3) which hardly paid attention to "the politics of knowledge legitimation" (ibid ). Longo (1998) makes us understand that our present notion of what falls within the domain of technical writing has developed alongside of cultural elements; therefore, she is of the opinion that like any other cultural product, technical communication can be subjected to scrutiny from a cultural studies perspective. If we have to pursue this project, then we must reconstruct institutions as cultural agents because institutions influence discourse productions. "Institutions constitute and disseminate systems of rules, conventions, and practices that condition the creation, circulation, and use of resources, information, knowledge, and belief" (p. 55). Technical writing, Longo admits "participates in a system of knowledge and power within our culture...Technical writing also enables technology users to participate in our culture's knowledge/power system — a system that can be illuminated and analyzed using critical approaches to discourse practices" (p. 60). Hence, a cultural 
studies understanding of what we do as technical communicators can illuminate "a broader cluster of historical and cultural forces (both material and ideological) that shape and are shaped by technical communication" (Scott \& Longo, 2006, p. 3).

I must say that little attention is paid to the cultural in our field because there seems to be a silent tension between cultural studies and technical/professional writing. This tension is voiced out by Sullivan and Porter (2004) when they observed that graduate students they taught at Purdue felt professional writing/rhetoric and cultural studies "seemed...incompatible if not mutually hostile" (p. 300). However, Longo, Herndl, Scott and many other cultural theorists in technical communication make us aware that it is worth using cultural perspectives to study technical communication because we participate in a cultural economy or, more aptly, technical communication plays a major role "in hegemonic power relations..." (Scott, Longo \& Wills, 2006, p. 1). More so, technical communicators "facilitate, sustain, generate, and disrupt relations of power" (Slack, Miller \& Doak, 1993, p. 15). As Thralls and Blyler (2002) indicate, cultural studies scholarship revolves around four areas: 1) the "political effects of social practices and modes of representation" (p. 185). In this direction, the focus has been to study "the relationship between the knowledge a society produces and the material conditions and ideological structures through which that knowledge is produced" (ibid p. 185); 2) culture is complex and can only be captured through interdisciplinary scholarship; 3) special attention to social practices and social discourses of the everyday mundane practices; and 4) attention to "how people can intervene to change social and discursive practices." The scholars identify that cultural theorists draw on connections or linkages across practices, 
that is, among texts and institutional discourses and social structures. These relationships, which are very necessary to cultural theorists, have been referred to as "articulations" (more on this in the next chapter), that is, "the form of the connection that can make a unity of two different elements, under certain conditions" (Grossberg, 1986, p. 141).

Considering the enormity of the grounds that have been covered by cultural theorists in technical communication, it will not be unwarranted to review scholarship on technology by cultural critics. The question thus is: how can reviewing conversations about technology in cultural studies influence my work and scholarship in the field of (international) technical communication? I respond to this question in subsequent paragraphs. Slack and Wise (2005) identify that in stories we tell about human evolution, technology occupies three central roles. First, technology defines our humanness. In this sense, we are humans because we develop and use technology. Each stage of human development has been defined based on its technologies. For instance, "we move through ages: Stone Age, Bronze Age, Iron Age, Industrial Age, Electronic Age, Information/Computer/Digital Age" (p. 3). Second, the causal agent of the various stages of development is technology. Thus, "the ability to craft stone produces the Stone Age....The computer produces the Information." Third, "the driving force, or goal of each of the ages is to perfect these technologies" (ibid p. 3). According to Slack and Wise, the stories we tell about technologies present technology and culture as though they were separate entities which in effect they are not. The scholars countered these notions that separate technology and culture by offering alternative stories that reveal that technology and culture are inseparable. Hence, it is no longer appropriate to talk about 
technology and culture but instead "technological culture," which implies that technology should be fully brought "into the concept of culture" (p. 5). The two scholars offer new stories from cultural studies: "stories of how the definition of technology shapes technology, how change happens, how agency works, how connections are made and unmade, and stories of space, identity, politics and globalization” (p. 2).

We are made aware that technology studies from a cultural studies perspective pushes the agenda that technologies are a site of struggle "over meanings and power." This statement introduces the core of doing a cultural studies research: the quest to reveal ways "inequalities of power are produced, maintained, and transformed through culture" (Slack \& Wise, 2005, p. 2). A cultural studies approach to technology, Slack and Wise tell us, "considers the power of language in shaping our assumptions about technology, provides a more nuanced theory of how change happens and how agency works, offers a model of change based on the concepts of articulation and assemblage, considers the following dimensions that shape technological culture: agency, space, identity, politics, and globalization" (p. 5). Articulation and assemblage bring new perspectives on technology studies. "Articulation draws attention to the contingent relations among practices, representations, and experiences that make up the world. Assemblage draws attention to the structure and effective nature and work of those articulations" (p. 120). Looked at from the perspective of articulation and assemblage, technology is not autonomous but integral to the context within which it is produced and used; culture is not separated from the connections that are made between technology use and production; and technologies emerge as part of the connections and within the various 
connections. In the next paragraphs I look at the ways that technologies as articulations and assemblages lead to the discussion of identity, politics and globalization.

According to Slack and Wise (2005), identity, "who or what someone is" matters to technology use and production because : 1) we develop technologies to meet user needs; 2) there is an uneven distribution of technology; and 3) embedded in technologies are assumptions about who uses and how technologies are used (p. 149). A special case of how technologies are tied to identity issues such as race, gender, class are explored in More Work for Mother by Ruth Schwartz Cowan and Feminism Confronts Technology by Judy Wajcman. Cowan (1983) for instance, narrates instances where industrialization and technology adoption increased the dichotomy between housework and work outside the home, or how technology changed the roles of individuals in the home. She narrates a story of the effect of a standard wall cabinets they installed in their kitchen. Prior to the installation, setting a table meant that 1) an adult will make a decision on the kairotic moment to set the table; 2) the decision was communicated to the children; and 3) children went for dishes and placed them on the table. "The adults in the family functioned as managers and decision makers; the children as workers" (Cowan, 1983, p. 10). With the introduction of the cabinet emerged a new set of roles. Since the children were not old enough to reach the cabinets, the adults had to be part of the work process. As she narrates "not only must my husband and I make the decision that it is time to set the table, but we must also do part of the physical labor; we have ceased to be the managers of the work and have been forced to become unwilling participants in it" (ibid p. 10). 
Wajcman (1991) also narrates the impact that technology has had on the sexual division of labor. A typical case is office automation and how it has affected women's employment. The introduction of computers into offices is a means of deskilling women, "mainly because the majority of clerical and secretarial workers almost everywhere are women" (p. 29). For instance, some authors argue that the introduction of word processers are aimed at making the traditional role of secretaries obsolete. Tasks such as routine typing for instance will be minimized leaving the office worker with no option but to take on more tasks (ibid). It was found out by Juliet Webster that instead of transforming occupations, automation increased inequalities between typists and secretaries (cited from Wajcman, 1991, p. 31). The vignettes presented by Cowan and Wajcman point to one truth: "tools are not passive instruments, confined to doing your bidding, but have a life of their own. Tools set limits on our work;....People use tools to do work, but tools also define and constrain the ways in which it is possible and likely that people will behave" (Cowan, 1983, p. 11). "Technologies are not merely aids to human activity, but also powerful forces acting to reshape that activity and its meaning" (Winner, 1986, p. 6).

I contend that technologies do not merely shape identities or activities, they are political as well because "political choices are embedded"(Wajcman, 1991, p. 22) into their designs and selections . By politics, I refer to the "arrangements of power and authority in human associations as well as the activities that take place within those arrangements" (Winner, 1980, 1986). The first time I encountered Langdon Winner's article "Do Artifacts have Politics" in my HU 5003 graduate seminar, I resisted the notion that 
technologies can be political. I asked: how on earth can technologies be political? At that point, my notion of politics was limited to the politics of governance. In my mind, only humans could be political because they have the ability to negotiate policies, and make decisions that influence lives. But after I patiently finished reading the article, I realized that indeed artifacts do have politics. Winner made me believe that politics is about human arrangements and the activities that take place in those activities. A tacit example of how artifacts are political or how artifacts carry the imprint of their creators is captured in Robert Moses' story narrated by Winner. Winner (1980) points to the extraordinarily low nature of "the bridges over the parkways on Long Island, New York" (p. 123). These overpasses, it turns out, were constructed in such manner to "discourage the presence of buses on his parkways" (ibid). These design decisions, it was revealed later by Robert A. Caro, “reflect Moses' social-class bias and racial prejudice”(p. ibid). The designs gave access to upper class whites who owned automobiles and middle class individuals but discriminated against poor people and blacks who normally used public buses because the parkways were so low that public transits could not go through to the parks.

\section{Philosophy of technology: what is technology?}

In this section, I narrate one aspect of the conversation concerning technology by philosophers: the "issues at stake in trying to define technology" (Scharff \& Dusek, 2014, p. xiv). So I ask: what is technology? Heidegger helps us to understand that to pose this question is to embark on a search for the essence or "whatness" of technology. In his view, we can only get to answer this question if we establish a free relationship with technology. In Heidegger's estimation, “we remain unfree and chained to technology" 
(Heidegger, 2014, p. 305). Early responses to the "whatness" of technology have identified technology as either a means to an end or as a human activity. Heidegger, however, believes that there is no clear-cut distinction between technology as a means to an end and technology as human action. These belong together. Technology as a means and human activity gets us to think about the instrumental nature of the essence of technology. This definition only holds true for modern technology. To further think about the essence or whatness of technology, he questions the source of the instrumental nature of technology: what is the instrumental itself? Within what do such things as means and ends belong? He answers by stating that "means is that whereby something is effected and thus attained" and anything that has an effect, he states, has a cause. Thus where instrumentality lies, there causality reigns supreme. He identifies that classicists identify four main causes: the causa material, the causa formalis, causa finalis and causa efficiens. Until we find the source of causality and its instrumentalist notions, we should forget about the quest to define technology or identify what it is. He paves a way by making us understand that classical use of "causality" strikes a notion of "bringing forth" or "appearance." He states that "through bringing forth the growing things of nature as well as whatever is completed through the crafts and the arts come at any given time to their appearance" (p. 308).

We can identify from the above paragraph that bringing forth plays a good role of bringing out things that are concealed into unconcealment. This gives a sense of revealing and "within revealing belongs end and means as well as instrumentality" (p. 308). The fundamental character of technology is instrumentality, Heidegger makes us understand. 
Therefore, technology becomes a way of revealing, by definition. In essence, anything that reveals is a technology, "technology is a mode of revealing. Technology comes to presence in the realm where revealing and uncolcealment take place, where truth happens" (p. 308). He quickly adds that these modes of revealing are different in both classical and modern senses. It is not wrong to say that whatever brings something to being is a technology.

Hannah Arendt also gets us to look at technology from the perspectives of three human activities: labor, work and action. Whereas labor involves a daily activity which is repeated for the maintenance of life, household (bathing, cooking and cleaning) and this becomes a biological responsibility in which humans and animals must engage; work is the production of objects and it constructs the world. The end result of labor is temporal and that of work is permanent. The product of work unlike that of labor endures and it has a beginning and an end. The work of human hands fabricates things. The third activity; action, finds power in speech. In the hierarchy of human activities, action is rated the highest (Arendt, 2013, p. 8). Among the three human activities, work is the most related to the acts of creating/making and use (similar concepts and ideas expressed by Heidegger and Mitcham). According to Arendt, the work of our hands gives the world stability and solidity. Similar to Heidegger's “challenging forth,” Arendt's enables us to understand that the work of our hands challenges nature by using materials of the earth to construct a world for humans. The work of our hands is driven by the philosophy that nature is valueless and imperfect until human hands add value and perfection to it. For instance, the production of a chair will call for using or cutting down the tree; before a 
paper is produced, a tree is used as a basic material; and before a mineral is mined, the earth must be dug and trees cut down. These processes of cutting down, producing, and mining wear out the durability of the world: they cause violence to nature.

From Heidegger and Arendt, we gather that "technology" is captured in human activity of making or bringing forth. Mitcham (1994) adds to this definition when he refers to "technology" as "the making and using of artifacts..." (1994, p. 1). In Thinking through Technology, the author exposes the various ways that ideas about technology are reduced to the application of scientific ideas (p. 95). He helps us to see technology from four different perspectives. First, technology is seen as an object (the most obvious use of the term). According to Mitcham, anytime technology is mentioned, what registers in our mind are "artifacts-material objects such as tools, machines and consumer products" ( $\mathrm{p}$. 161). He identifies how this narrow association of technology works to exclude other forms of systems from being technological. Second, technology can also be seen as a form of knowledge. Here he draws on etymology. Etymologically, he announces, "the very word "techno-logy-is often thought to connote knowledge" (p. 192). Like Heidegger and Arendt, Mitcham reveals that technology is an activity. In this sense, technology is "the pivotal event in which knowledge and volition unite to bring artifacts into existence or to use them; it is likewise the occasion for artifacts themselves to influence the mind and will” (p. 209). It is associated with different forms of human behavior. Thus, from this perspective, such human activities as crafting, inventing, designing, manufacturing, working are considered a form of technology. Finally, Mitcham makes us understand that 
technology is volition: the association of technology with "diverse types of will, drive, motive, aspiration, intention and choice" (p. 247).

Though the scholars above have diverging views on how to define technology, they accept that it traces back to the concept of techné. According to Mitcham (1994), "virtually all historians use the word 'technology' to refer to both ancient and modern, primitive and advanced making activities, or knowledge of how to make and use artifacts, or the artifacts themselves" (p. 116). Techné is commonly used in Greek to refer to "art," "craft," or "skill" and it is used literally to refer to "cleverness and cunning in getting, making, or doing as well as to specific trades, crafts and skills of every kind" (p. 117). $\mathrm{He}$ identified the use of techné in both Platonian and Aristotelian senses. In Plato's conception, techné is linked up with episteme. There is, thus, a relationship between art and systemic or scientific knowledge. Every techné "is involved with logoi (word, speech, reason)". Plato identifies two senses of techné. First, it is used to refer to work that involves physical activities and it requires the use of language. Also, it is used in reference to activities that involve less physical action, such as, arithmetic. This is extended in the classification of knowledge by Plato: knowledge which stems from education and upbringing and knowledge involved with making or producing. This second form of knowledge can proceed by conjecture, practice and experience or by the conscious use of numbering, measuring and weighing. According to Mitcham, techné, as used by Plato, "points toward a conception easily associated, at least intuitively, with modern technology-that of rationalized production, or production made maximally efficient through mathematical analysis" (p. 119). 
Aristotle also makes a contribution to the use of the term. Techné, according to Aristotle, refers "to a special knowledge of the world that informs human activity accordingly" ( $\mathrm{p}$. 120). Mitcham identifies that techné as used by Aristotle forms a continuum that moves from sense impressions and memories through experience to systematic knowledge, episteme. That is a distinction between art (techné) as a form of bringing forth, or coming to be and epistemé (science), the realm of being. Thus techné, is in one sense epistemic because it involves the use of consciousness about the world, it can be taught or communicated. In another sense, it is not episteme because it deals with what is contingent, it depends on things that change rather than the unchanging.

Based on these incongruities, Mitcham (1994) strikes a difference between modern technology and techné. He makes us aware that techné "involves logos, but only in grasping form, not in directing the actual process of production, the activity qua activity. There is no logos of this activity" (p. 128), but Mitcham believes that what modern technology proposes is a furnishing of ancient techné: "a logos of the activity, a rationalization of the process of production, independent of, if not actually divorced from, any particular conception of eidos or form" (p. 128). He works assiduously to identify the tensions that exist between ancient techné and modern technology. According to Mitcham, the difference between the two lies in "a conception of matter, an ontology or metaphysics of matter....it is the theory about the nature of what one is working with that is a primary determinate of how one works, the structure of the working itself' (p. 132).

If someone does a better job establishing the distinction between ancient techné and modern technology, that person is Martin Heidegger, I will argue. In his zeal to identify 
the essence or whatness of technology, he pits modern technology against ancient techné. Though he agrees that both forms of technology reveal, they have different forms of revealing or bringing forth. He makes us understand that the root for "technology," is the Greek term Technikon, which means "that which belongs to techné." It could be interpreted to mean that technology is not techné, per se. Rather it belongs to techné. Techné, according to Heidegger, refers to two things. 1) It is not only limited to the activities and skills of craftsmen but also for the arts of the mind and the fine arts (308). In this sense, techné belongs to "bringing-forth, to poiesis, it is something poetic". 2) From early people before Plato, techné was linked with episteme (knowing). The knowing provided an opening up, as an opening up, it revealed. Heidegger makes us understand that "what is decisive in techné does not at all lie in the making and manipulating, not on the using of means, but rather in the revealing" (p. 308). As a mode of revealing, "technology comes to presence in the realm where revealing and unconcealment take place, where truth happens" (p. 308). He cautions that technology in the sense discussed above holds true for ancient thought but not for modern technology.

\section{Rhetoric of technology: where lies the connection between rhetoric and technology?}

Though young and late in this scholarship, rhetors of technology have contributed to our knowledge on technology. I ask: what is rhetoric of technology? How will rhetoric of technology help us to understand technology? What is the relationship between rhetoric

and technology? In the forward to the book Rhetorics and Technologies: New Directions in Writing and Communication, Carolyn Miller (2010) establishes a strong connection 
between rhetoric and technology: "both can push and pull at us" (p. ix). This 'pushmipullyu' dynamic which is central to both rhetoric and technology accentuates the notion that rhetoric and technology are "both arts of design" (Selber, 2010, p. x). Hence, if we define rhetoric as the "art that adjusts ideas to people and people to ideas, we might characterize technology as the art that accommodates the material world to people and people to the material world" (ibid ). Haas (2012) also identifies that rhetoric and technology are connected in two ways: rhetoric has been used to set limits, prescribe and define what technology is; and it has been used to upend our notions of technology ( $\mathrm{p}$. 287). Similarly, Banks (2005) through the concept of digital divide, unravels the various means by which technology has structured and maintained racism and the politics of exclusion in the American society. He challenged mainstream English Studies scholars to make issues such as technological access, racism, and race the "central ethical questions" (p. xii) of the field. According to Haas and Banks, there cannot be a discussion of rhetoric of technology without careful attention to social justice, race, racism and meaningful access to technology because technologies are used to structure and maintain these issues.

Dwelling on classical rhetorical concepts, Johnson (1998b) reveals an age long relationship between rhetoric and technology which has been in existence since preSocratic Greeks. One of these connections, Johnson states, is found in their ends or what Greeks term the telos (p. 19). For instance, he reveals that in as much as modern humans have hailed the powerfulness of technology, that is, its ability to resolve many of our social ills, others have been skeptical of the good that technology brings. Thus, 
technology is perceived to have two ends: it can be used for good or evil. In the same way, rhetoric has been cast in the good/bad paradox. Some classic Greek scholars such as Plato and Socrates have reduced the art of rhetoric to sham art, cookery or "the use of language to deceive" (Johnson, 1998b, p. 21). But, rhetoric has also been seen positively to mean "the art of creating (inventing), arranging, and delivering language for the purpose of evoking action upon the part of an audience" (pp. 21-22).

More so, Johnson (1998b) states, rhetoric and technology are connected to art which is referred to by Aristotle as techne, that which is concerned with production and action. Techne involves the ability to make or bring forth into being. Techne, which forms the root of our modern conception of technology, is linked to two issues which are relevant to a rhetorical theory of technology: first, it is "aligned with a "true course of reasoning;", (p. 24). In this regard, techne or rhetoric has the ability to reveal knowledge and make knowledge making possible. Techne creates a knowledge base for scholars to explore the realms of users and technology; second, "techne is not concerned with issues of certainty" (ibid). This second usage of the word enables scholars to study technology from a mutable and contingent perspective. Technologies are used by humans who operate in a world which is "constantly changing, constantly 'coming into being"” (p. 24). What we gather is that technology cannot be studied from a static or monolithic lens. It takes a fluid, dynamic, unstable rhetorical theory to study the technological.

Like Johnson, Miller (1994) demonstrates that the classical concept Kairos, that is the concept of timing or opportunity, can serve as both a theme within technological discourse and an analytical lens that can unearth the various persuasive means that we 
use to maintain things technical. Cast in what she referred to as "technological discourse," that is, "a discourse in which the characterization and construction of moments in the present are crucial to the projection of the future" (p. 82), she captures images in technological discourses that justify the importance of Kairos to technological discourse. Miller makes us understand that Kairos as an analytical concept provides three useful dimensions to the study of technology. First, it combines two schools of thoughts — realist and constructivist — way of understanding a situation and emphasizes the dynamism that exists between the two schools; second, Kairos enables us to figure change as continuous and discontinuous, evolutionary or revolutionary; third, Kairos is subjected to the temporal-spatial dichotomy (p. 83). In order to point out the importance of Kairos to the study of technological discourse, she critically assesses technical discourses surrounding the Japanese inaugurated project dubbed "the Fifth Generation" which sought to "develop new computer systems that would combine artificial intelligence, new programming languages, and parallel processing to produce 'intelligent' machines" (p. 81). Such descriptive terms as "at the cutting edge of computer research;" “The Fifth Generation artificial intelligence machine is the machine we've all been waiting for;" or "never before in history was there a better time for technological change," are used to define the moment in computer history, Miller states. These descriptive phrase allows one to "threaten and cajole, to mobilize a community, to win grants and contracts" (p. 84). More profoundly, the title of the project "Fifth Generation," defines and makes an attempt to seize a moment in the advancement of computer technology. Fifth Generation was developed at a time when most computers were still in their third generations. "Generation," in itself, is kairotic and it "combines both 
continuous and discontinuous versions of change..." (ibid). Several phrases that point to temporal-spatial images abound in the technical discourse surrounding the project. Thus, through these analyses, Miller helps us to understand the role that rhetoric can play in examining discourse patterns of "enterprises concerned with the development, production, and marketing of artifacts and practices" (p. 92).

In another study, Bazerman (1998) makes reference to a bigger project in which he studied the "symbolic, representational, and rhetorical work that accompanied the emergence of the incandescent light as an everyday technology" (p. 381). His work, he identifies, falls within the domain of rhetoric of technology "because it examines the rhetorical productions that surround a material technology" (ibid). According to Bazerman, technologies are always already rhetorical because we develop technologies to meet the needs of humans and they are always "part of human needs, desires, values, and evaluation, articulated in language and at the very heart of rhetoric" (p. 383). More so, technologies must go through several publics for approval before they become a material reality. Technology must argue for value in regard to business, law, government, the public and consumers. These varied publics must be persuaded to accept the technology. Also, technologies produce objects and material processes. Hence, rhetoric of technology is "the rhetoric that accompanies technology and makes it possible - the rhetoric that makes technology fit into the world and makes the world fit with technology” (p. 385). This domain of studies, first, shows how objects we build become part of "our systems of goals, values, and meaning, part of our articulated interests, struggles, and activities" (p. 386); second, technologies create new realms of discussions as they constantly invite 
"social, legal, personal, and economic discussions that shape how that technology becomes incorporated into new ways of life" (ibid); finally, technologies are in constant conversations with other powerful systems. In this modern era, our lives are being caught up by the technologies we use so it is important to study "the rhetoric of all the discourse that surround and embed technology." It is only through such studies that we can gain control over technology and regain our voices on decisions concerning our technological future.

Koerber (2000) helps us to understand rhetoric of technology as "a tool that facilitates meaning making about technological aspects of the world" (p. 59). I find her work very inspiring because it presents an interesting twist to rhetoric of technology scholarship: she extends our understanding of rhetoric of technology through feminist lenses. In order to chart the path for a feminist rhetoric of technology, Koerber, dwells on feminist critiques of technology. She suggests three ways that feminist rhetoric of technology will differ from current discussions: first, feminist scholars are to adopt a wide-ranging definition. This definition should ensure that women's contributions to technological development are included; second, feminist scholars, she suggests, should ask questions different from questions that currently exist. Specifically, feminists "should ask research questions that attempt to account for technologies' participation in the construction of gendered meanings" (p. 60); and third, feminist scholars are advised to move beyond the design and development stages of technology.

I sum up the discussion on rhetoric of technology with Miller' (1998) claim that rhetoric of technology "should help us understand the wide dissemination, diverse applications 
and minds; they should reorient our understanding of technoscience and at the same time stretch and test our conceptions of rhetoric" (p. 310). According to Miller, rhetoric of technology can be put into three categories:

- Rhetoric about technology: often captures public representations or debates in public policy forums

- Rhetoric within technology: private proprietary discourse by which technological work 'gets done'

- Rhetoric from technologies: the ways in which values and thought patterns developed by technological work extend to and prevail other cultural arenas ( $p$. 307).

Rhetoric of technology, and especially, Miller's characterizations are necessary to my work as they stress the importance of discourses surrounding technologies. I seek to look at how the language surrounding the biometric device adopted can help technical communicators to study the various forms that genres lead to the study of technology. Hence, rhetors help me to pay particular attention to language use and how they articulate technology adoption goals. In chapter five, for example, I demonstrate the powerful use

of language to represent the biometric technology. Rhetors, like the other fields reviewed make us understand that technologies are not neutral, they are political and that we must subject them to critical scrutiny.

\section{Technical communication and technology studies}

Technical communication scholars have done little to participate in conversations about technology even though we trace our roots to technology and things technical (Connors, 1999; Kynell, 1999; Longo, 2000; Longo \& Fountain, 2013; Staples, 1999). More concerned about the minimal contribution of technical communication scholars to 
conversations about technology, Johnson (1998b) queries: "where are the technical communicators in this important field of scholarship [technology Studies]?” (p. xiii). He suggests ways that technical communicators can contribute to this discussion. First, Johnson contends that one of the ways that technical communicators can contribute to technology studies scholarship is to tell tales about how people use, learn about and resist technology. Johnson is right in proposing that we tell stories. Stories, I believe, are not mere narrations or reflections of events, rather, "they are organizing devices through which we interpret and constitute the world" (Lawler, 2008, p. 32). David Trotter categorically states the relevance of stories to technology studies when he assets that "stories tell us what technology means. They remind us that it has a meaning before it has a use. If we want to alter the use to which a technology has been put, we must first alter the meanings which authorize that use" (quoted in Seigel, 2013, p. 139).

We are enmeshed in stories and we need to critically assess them. Stories are both social and cultural resources through which we encounter the world and things around us. Therefore, it is not inappropriate to call on scholars to study stories about how people encounter, use and resist technology. Part of my work is storytelling. I tell the story of events that led to the adoption of the biometric device for the parliamentary and presidential elections in 2012 through the various documentation accompanying the adoption. I seek to understand how such a study can enable the study of technology in international contexts and also how we can study technology through such documentation. I tell a story because I believe that stories are integral to meaning-making and they provide "a necessary mode of understanding of the world" (Lawler, p. 36). 
Stories provide avenues for interpretation and understanding. They also provide tools to critically assess the social, cultural and historical situations surrounding the way a people relate to the world or situations that lead people to adopt and use a technological system. In essence, the story I tell will lead us to answer the question: how did Ghanaians come to "have certain needs and goals that necessitate engaging with a particular practice, a technological system, and its accompanying documentation" (Seigel, 2013, p. 20). The story gives us a critical access to the electoral system of Ghana.

Second, Johnson (1998a) believes that instructional aspects of technology are within the domain of technical communicators and it is by looking at this domain that we can add to scholarship. In Rhetoric of Pregnancy, Marika Seigel demonstrates how we can study technology through the documents or manuals technical communicators create by telling a "story of prenatal care through its documentation and ... how it developed alongside of, out of, and sometimes in opposition to the technological system of prenatal care" (Seigel, 2013, p. 6). Through a critical study of various pregnancy manuals, she identifies that prenatal care in America exhibits tendencies of a technological system; a system that did little to help users to become critical of the technologies they use during pregnancy. She identifies anomalies in prenatal system and argues that "the technological system of prenatal care is in need of change both to facilitate access and to ensure that it is centered on the needs of all of its users" (Seigel, 2013, p. 5). As a user, Seigel only had material and functional access to the prenatal system but could not ask questions. She was literally a passive consumer who does not question anything that is dumped on her during this time. Seigel's work, though not explicitly stated, suggests that technical communicators 
can study and contribute to technology studies by critically studying the manual and instructions that accommodate users into a technological system. Also, Seigel's work brings a critical urge to the study of technology. When users become critical of technologies, they become better users of those technologies. Technical communicators, Seigel suggests, do not only have to look at the effectiveness or ineffectiveness of technical documentations. Rather, technical communicators can study instructions or procedures to come into an understanding of "how the technological systems and work processes being documented came to be configured as they are and how they might be configured differently" (Seigel, 2013, p. 10). We are also challenged to broaden the purview of our research beyond the workplace. Most of the claims made by Seigel are advanced in the project I undertake.

Manuals do not only usher us into a technological system. They are exegetical and they serve to mediate meanings, applications for lay people who use technologies to perform certain tasks. Operator's manuals, for instance, provide avenues for "written discourse to construct a world of 'reasonable' actions that would resolve the polarities inherent in almost any technology between mechanical function and social purpose"(Paradis, 2004, p. 367). In this role of mediation, operators manuals employ four textual elements that binds human action, and external objects with human behavior. They: 1) construct a written analogue of the tool or process itself; 2) introduce a fictional operator who represents an average or suitably qualified individual; 3) capture "the material context of conditions and situations requisite for effective and safe use of the instrument" (387); 4) capture the action itself. In this sense, the operator's manual fuses human purpose into 
mechanical device. Instructions mediate the gap between experts of technology and lay users. In transporting technologies to the lay public, instructions play "a necessary role in the exportations of expertise, whether simple consumer technologies or complex instruments of institutional proportions" (p. 371). This role of written discourse gives texts permanence in the world. Users can learn how to operate an artifact by operating on text. One can also not dispute the legal ramifications that operator's manuals carry along. Legal ramifications point to the fact that writers are held accountable to what they scribble. The operator's manual presents two affordances: a) we are persuaded into believing that the technology can be explained; b) it is the evidence that the expert has reasoned out about how the user can use the technology. It is a warranty.

I take a cue from Seigel's analysis and Paradis' exposê and argue that one of the ways that we can study the various ways that we relate to technology is to study the genres that accompany the technologies we adopt or the genres that make technology fit into the world. Genres capture the various discursive processes: "many aspects of communication, social arrangements, and human meaning-making are packaged in genre recognition" (Bawarshi \& Reiff, 2010, p. xi). Genres also capture and dictate the meaning-making processes or debates about technologies. I contend that genres do not only enable action or help solve problems. They also become the tools for us to study technology. Genres enable us to investigate "the interactions and relationships between action and meaning" (Sun, 2012, p. 4). Mostly, genres are used to represent these technologies to audiences. Genres enable us to study how "many things about the institutional and social setting, the activities being proposed the roles available to writer 
and reader, the motives, ideas, ideology and expected contact of the document, and where this all might fit in our life" (Sun, 2012, p. 66). We become more encouraged to study technology through genres when we take to heart Huatong Sun's claim that the study of genres enables us to understand technological artifacts in their social and historical context. In this regard, by studying the various documents that went into the adoption and use of the biometric verification system and by studying instructional manuals that accompanied the biometric device in Ghana, I hope to uncover the various rhetorical moves, ideas, ideologies, political, ethical, power structures, economic structures and social and historical exigencies that influenced the adoption. Through the study of the various genres, I also hope to uncover the ways that genres do not only mediate or solve problems but also how they enable action. By action, I make reference to "how particular practices - ways of thinking, ways of problem solving, ways of being into the world - are valued (or not) within specific cultural systems and/or communities" (Powell, 2014).

When mention is made of genres that accompany technology, what comes to mind are instructional manuals and procedures. I demonstrate that manuals and procedures are not the only documents that are used to "accommodate technology to users of technology" (Dobrin, 2004). Modes of accommodation become more complex when the technology in question has to go through an adoption process. As Doheny-Farina (1992) demonstrates, technology adoption or technology transfer provides a complex rhetorical process. It is a process of negotiation: "At their core their processes involved individuals and groups negotiating their versions of technologies and applications, markets and users in what they all hope is a common enterprise" (p. 4). Therefore, if we limit the study of 
technology to only the manuals and procedures that accompany a specific technology, we might lose sight of the potential importance of other technical documents to the study of technology. I can argue fervently that other documents are used in accommodating technology to users and we must study those other documents. We are also at most times quick to study single documents that accompany technology while we lose track of the fact that in most cases documents are used in assemblage. At least Clay Spinnuzi helps us to understand that genres work in ecologies or assemblages to solve problems. By this, the author meant that genres work together to achieve/ answer complex problems. Genre ecologies, according to Spinnuzi, account for the contingent, decentralized and stabilized nature of genres in use. According to this perspective, genres mediate activities in conjunction with other genres. Genre ecology accounts for compound mediation, that is, "the ways that people habitually coordinate sets of artifacts to mediate or carry out their activities" (p. 98). Genre ecologies emphasize the dynamic, organic and messy nature of genres. Ecology emphasizes official and unofficial documentation as they are connected through contingency, decentralization and stability (Spinuzzi \& Zachry, 2000, p. 173). Genre ecology emphasizes "interpretive and cultural-historical aspects of compound mediation" (Spinuzzi, 2003). Spinuzzi, through his concept of genre ecology, gives enough evidence to not only focus on a single genre and how it relates to its social context. Rather, we must consider a range of genres. Thus in chapter five, I analyze a range of documents in order to identify how these documents assemble to persuade Ghanaians to adopt the biometric technology. I also examine how they accommodate Ghanaians into a technological system. I argue that when we study these range of genres in conjunction with instruction manuals and procedures we get to understand the role that 
technical writing plays in creating, maintaining and unmasking societies' assumptions about technology.

Johnson (1998a) suggests, again, that as technical communicators, our responsibility should far exceed the technologies we write about: he wants us to examine the human elements of technologies. This quest to examine the human elements of technologies, I believe, has led to a study of the users and designers of technologies. Technical communicators have become advocates of technology users. They have called on designers to include users in the design processes (Brady, 2004; Johnson, 1998b, 2010; Salvo, 2001; Seigel, 2013; Sun, 2006, 2009a, 2012).

The central question here is, how have such issues as user advocacy in technology design been taken up in (international) technical communication? I must say that though technical communicators pride themselves as user advocates, little has been done to look at the various ways that designers work to include international users in technology design. Worse still, little has been done to look at the ways technical documents or technical genres participate in public policies that relate to technology adoption, use and design. In an era of globalization, it becomes very important to study the various ways that non-Western societies relate to technology in order to develop technologies to meet their needs. The zest to study non-Westerners' use of technology is lacking in the field of technical communication. Only a handful of scholars have charted this path. Two scholars are worth mentioning in this direction. First, is Godwin Agboka; arguing from a social justice perspective, he pushes for a "participatory localization" in the design of documents and technologies. By participatory localization, the author refers to "user 
involvement, not as isolated user participation but as user-in-community involvement and participation in the design phase of products" (Agboka, 2013a, p. 42). He identifies that though technical communication scholarship is replete with ideas and notion of localization, little is done to account for user needs in unenfranchised and disefranchised cultural sites. Localization "often starts from the developer's site and trickles down to the users' site." As a result, "users are not cast as agents who initiate and implement change themselves" (Agboka, 2013a, p. 30). Thus we can conjecture that designs and technologies that are sent to unenfranchised sites reinforce the system-centered design model discussed by Johnson in User Centered Design. Again we can contend that designs carry the stigmata of the developers. In a study of documentation of sexuopharmaceutical marketing documentation and design, Agboka challenges technical communicators to emphasize less on factors as language and culture because such emphases work to de-emphasize "broader ideological, economic, legal and social justice issues that shape localization processes in specific contexts..." (Agboka, 2013a, p. 29). He advises that 1) localization should happen at the user's site, where prevailing local conditions influence design; 2) localization needs to be a collaborative effort between user and developer; 3 ) localization should not be looked at in terms of translation; 4) localization should be based on long engagement in the target community; 5) localization should pride itself on relevance of local needs and that localization should be based on mutual understanding (2013a, p. 45). We can conclude that Agboka wants technologies to be developed in local sites; or that developers and users should collaborate on technology development. 
Similarly, in an attempt to identify how technologies are designed to meet the needs of local users, Huatong Sun identifies that technology design processes create "a disconnect between action and meaning" of local users (Sun, 2012, p. 8). That is, little is done to incorporate the meanings, behaviors, practices and state of consciousness of users into technology design. As a result of this neglect, she proposes that design philosophy and principle should attend to "both action and meaning through a cyclical design process." This she believes will help "the cross-cultural design community to create a technology both usable and meaningful to local users." This design philosophy and principle she calls Culturally Localized User Experience (CLUE) (Sun, 2012, p. 4). Before this design philosophy can be applicable, designers have to consider the culture of the locale. According to Sun, though the word "culture" poses a lot of problems because it comes with different connotations, it still is the omphalos of cross-cultural design. She identifies that culture has been narrowly conceptualized and that scholars and designers must move beyond the narrow representation. Context is presented in a limited sense, mostly, to the workplace or site of study. Sun believes that local culture can be represented and manifested in technology design when we focus on the nexus among technology, design and culture. This is necessary because technology and culture are inextricable, design matters profoundly in a technological culture, and technology design plays a role in technological culture. She argues for "a dialogic view of culture that is both robust and flexible to study local culture and offer a more complete vision of culture for technology design." Like Agboka, Sun pushes for a thorough understanding of localization, that is, “...a process of adapting anything to a target locale or an interdisciplinary process of 
adapting an information technology (IT) product to the needs or expectations of a specific target audience" (Sun, 2012, p. 7) in cross-cultural technology design.

Little, though is done to study instructional manuals and users in international contexts. Most scholars, for instance, have studied memos, resumes, letters and the various ways that different cultures produce technical documents. Some scholars, however, are worth mentioning in the role they have played in studying instructions that accompany technology. I refer to works by Barry Thatcher (2006), Honold (1999), Dong (2007), and Fukuoka et al (1999). My take is that even though these scholars find it worthy to study instructional manuals, they only perform comparative study of how instructional manuals are used in different cultures. They do not provide an avenue to study the technologies that these documents accompany. Neither do they give a clue about the assumptions that are embedded in the technology. In essence, the scholars fail to advance a study of technology through technical documents. I must say, however, that they provide an avenue for us to understand that rhetorical and cultural patterns of societies influence the way documentation is designed, a revelation that will shape my use of the rhetoricalcultural methodology, the topic for the next chapter. 


\section{Chapter Three: Studying the "International” through Rhetorical-Cultural Methodology}

In this chapter I outline the methodology, method and epistemological assumptions underpinning my research. I hope that the methodological approach I adopt will serve as a guideline to future researchers in international technical communication. Like Sullivan and Porter (1997), I see research methodology not "as a rigid set of structures" (p. 9). Instead, methodology is a heuristic, that is, it is rhetorically constructed by researchers to meet the object of study. My position is that "all methodology is rhetorical, an explicit or implicit theory of human relations which guides the operation of methods" (Sullivan, 1997, p. 11).

Essentially, approaches to international/intercultural technical communication research have emphasized the importance of culture as the most important factor to consider (Agboka, 2012; Ding \& Savage, 2013; Lovitt \& Goswami, 1999; Sun, 2004, 2006, 2012; Thrush, 1993; Walton, 2014). The problem is that scholars have narrowly discussed culture, over-generalized or presented stereotypical and static representation of international audiences (Agboka, 2014; Sun, 2012). For example, Sun (2012) identifies that approaches employed to study culture capture local cultures in terms of 1) do's and don'ts, anecdotes and business cases. This focus, she identifies, only reports the dominant culture in a country; and 2) value-neutral cultural dimensions. This approach also promotes the spirit of positivism because culture from this perspective places concrete cultural realities into static dimensions; 3) structured fieldwork methods which focus on richness and texture of everyday life and is concerned with "the production of and 
exchange meanings between the members of a society, or a group in an enthnomethodological sense" (p. 14). In essence, approaches have favored "“large culture' ideologies" (Agboka, 2012, p. 159). Most often, tensions among international audiences or among individuals in a context are not properly captured by these large culture ideologies. Thatcher (2010) also observes that even though globalization has influenced the work of professional communicators, scholars have still not developed any viable approach to the study of global rhetoric in professional contexts. He identifies that the field still, unabashedly, relies on démondé critical and cultural approaches. This overreliance on antiquated approaches presents such problems as "ethnocentrism, methodological aporia, poorly theorized global-local relations, ignoring large scale variables... and unworkable ethics" (Thatcher, 2010, p. 2). Ultimately, he called for new approaches to the study of global and intercultural contexts, a call which was re-echoed by Agboka (2012; 2013b) and Walton (2014).

I must also say that scholars disagree on what model of culture to adopt as much as what definition of culture to adopt and operationalize. While majority of scholars favor a methodology that emphasizes culture as the omphalos, some scholars such as Lovitt question the over concentration on culture to the neglect of rhetoric. Even though Lovitt (1999) agrees that culture is indispensable in international communication, he holds that students should be equipped with rhetorical strategies that will enable them to be sensitive to "cultural interactions"(p. 7). When students become rhetorically savvy, they will be able to adapt their communications to specific cultural needs, he maintains. 
Moreover, a group of scholars have stressed the necessity for scholars to identify the relationship between culture and language/rhetoric in international/intercultural contexts. Two scholars worthy of note in this direction are Carolyn Boiarsky and Barry Thatcher. Boiarsky (1995) maintains that language is informed by culture hence failure to understand rhetorical conventions of a culture could lead to misinterpretation in communication. According to Boiarsky, while cultural conventions are not easily seen in written communications, they often inform and shape a document's content, organizational pattern, argument structure, style and format (p. 247). Like Lovitt, she stresses the need for students to be immersed in a culture and its language. Similarly, Thatcher (2011) has stressed the need to understand how rhetoric and culture interact with or "act upon" each other in intercultural contexts. Drawing from the work of James Berlin (1987), and expanding on Trompenaars's (1994) onion model, he develops an intercultural rhetorical model which emphasizes the need for research in international contexts to capture and connect how cultures conceive of or define the self, their epistemologies or thinking patterns, ideologies or social behaviors and how these three categories link up with rhetorical patterns (pp. 3-5). 


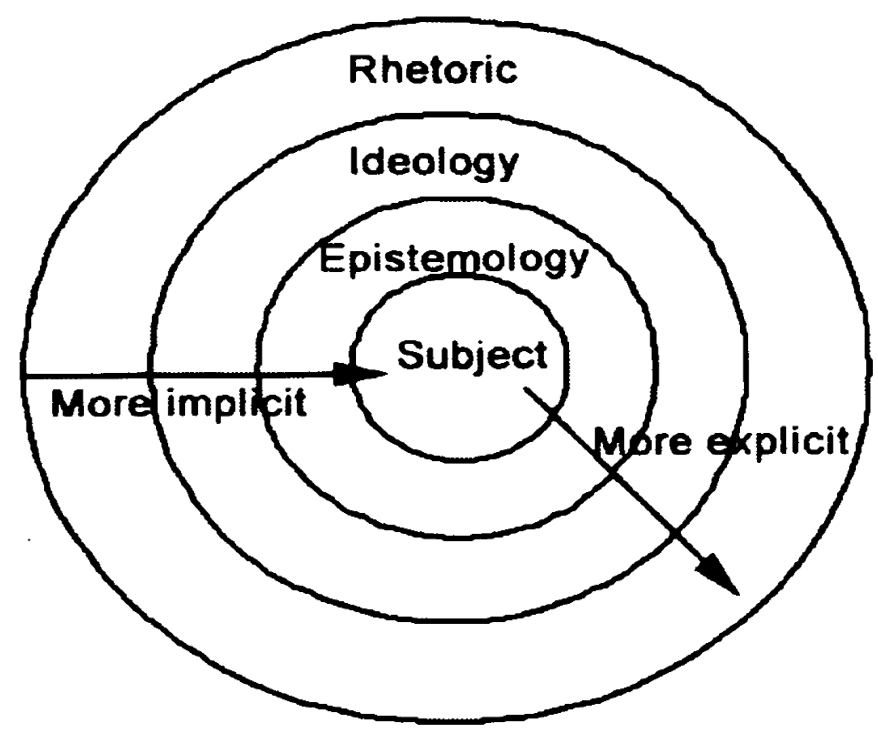

Figure 3.1: Thatcher's onion model of Rhetoric and Culture

He identifies that the model enables researchers to observe the two outer layers; rhetoric and ideology, while the two inner layers; subject and epistemology, are mostly implicit. Second, these layers are not mutually exclusive; they structure each other (p. 4). He states, unequivocally, that "we can observe the social behaviors and rhetorical patterns, and from most patterns, we can infer the epistemologies and the definitions of the self' (p. 4). More so, "writing patterns are a surface manifestation of deep but implicit cultural values" (p.4). The model is relevant to researchers for four reasons. First, it presents a universal or etic frame that can be used to compare cultures; second, it offers an avenue to connect intercultural research to rhetorical patterns; third, it enables researchers to identify how "tacit or unconscious values are related, and how and why they surface in communication patterns" (p.5). Thus, through the rhetoric, we can identify ideology, epistemology and subject. I agree, thus, with Thatcher (2011) and Boiarsky (1995) that international approaches should work towards capturing the relationship between rhetoric 
and culture. In essence, an approach that works to identify the relationship between culture and rhetoric pays attention not only to culture or language but also "local logics, rhetorics, histories, philosophies, and politics" (Agboka, 2014, p. 298) in a context. Therefore, for my project, I employ an approach that will enable me to capture the various ways that rhetoric acts on culture and vice versa.

In order to achieve this goal and work beyond over generalization, polarization, static and stereotypical representations, I adopt Blake Scott's rhetorical-cultural methodology. This approach enables a dialogic relationship between rhetoric, defined by Scott (2003), as "the situated, persuasive use of language that can include both verbal and visual discourse, both public and interpersonal communication and both explicit and implicit arguments" (p. 3) and culture, defined as "an open set of practices and a dynamic process in which cultural meanings, objects, and identities flow across institutions, nations and generations in diffuse time-space" (Sun, 2004, p. 8). Rhetorical-cultural methodology enables me to look at and identify how the biometric technology was represented and argued about in a range of technical documents. Consequently, I began thinking about how the use of a biometric technology in a context can lead to an articulation of broader issues such as ideology, subjectivity, interpellation and local-global tensions. This approach becomes relevant because as we will identify later, issues related to technology have both rhetorical and cultural significations. Moreover, I was convinced by Scott's (2003) claim that the methodology offers a lens for a study of technology "that fruitfully combines rhetoric and cultural studies" (p. 5). It works perfectly to confirm my definition of rhetoric and culture as dynamic, fluid, unstable and contested zones hence the need to 
tap and explore their intersections. In this direction, I align with scholars like Agboka (2012) and Hunsinger (2006) and other scholars who call for a conception of culture from a discursive approach; that is, we should acknowledge the dynamic, fluid, flexible, socially constructed and unstable nature of culture. A hybrid approach, as I advance in this project, stresses that rhetoric is hidden in culture and culture unveiled through rhetoric; that rhetoric and culture are dynamic, fluid, flexible and unstable realms that cannot be studied separately.

According to Scott (2003), a rhetorical-cultural study accounts for four various conditions. First, the critic must focus on rhetorical actors and conditions, as traditional rhetorical analysis. In this regard, the researcher looks critically at policies "shaped from complex relations among rhetorical, ideological, political, economic, institutional, and social forces" (p. 5). Accounting for conditions means 'unblackboxing' science and [technology]. This means reopening science and technology by "treating [them] as a messy and dynamic enterprise and by tracking [their] networks of influence wherever they extend" (ibid p. 22). Second, the analyst must map out the shifting relationships among science [and technology] in action. Even though the progenitor of the approach used it to study HIV testing practices, I appropriate it to look at the material-discursive practices surrounding the biometric technology adopted in Ghana. More importantly, mapping shifting relationship leads to the examination of texts as part of broader "cultural entanglements" (p. 25). That is, the critic maps various public arguments made for and about the biometric technology. This way, the critic "would read all texts as changing ensembles of relations that produce a range of effects, including subjects" (p. 
27). Alternately, the goal of this condition "is to better understand the context in which the text is consumed and used rather than better understand the text itself, independent of context" (p. 23).Third, the analyst must work to evaluate and critique practices around, in my case, biometric technologies according to the effects it creates. What practices does the biometric technology produce? What does it enable and disable? These are the concerns of the rhetorical cultural critic. This third condition helps the critic to pay attention to how users of technologies such as the biometric become subjects to those technologies. Finally, the analyst intervenes to discover opportunities for local interventions.

The conditions above helped my research in several dimensions. Most importantly, I am conditioned to examine the biometric technology and discursive practices around it as a rhetorical artifact at the vortex of broader cultural and ideological entanglements. For instance, in chapter four I analyze a user manual that accompanied the biometric technology. Dwelling on concepts as diverse as Foucault's disciplinary rhetoric, feminist critique of science and technology and localization, I am able to discuss how the technology provided new insights into issues as diverse as social justice, localization, surveillance, truth, subjectivity and control. I also get to question some of the practices that are extolled by instruction writing guidelines. And in chapter five, I map out discursive-material practices surrounding the biometric technology to identify how technologies that are taken up are represented in magical terms. I work to find out whether or not technologies are represented differently or similarly in both non-Western and Western societies. I perform a traditional rhetorical analysis to find out 
argumentative frames and later complicate the findings from my analysis by adopting concepts from Foucault's biopower, disciplinary rhetoric and surveillance and Haraway's postmodern cyborg to critique the rhetorical frames. I identify that discourses around technologies play a role in providing a rhetorical exigence for technologies to be taken up and used. Through Foulcautian and 'Harawayian' biopower and cyborg respectively, I discuss further how rhetorical representations about technologies do not only provide exigence but also, they open a space to understand how technologies such as the biometric technology shape the voters as subjects and affect their "material lives" (Scott 2003, p 6). These scholars help to identify how user identities are articulated into a technological system.

Central to a rhetorical-cultural methodology, and more importantly to my project, is the theory of articulation propounded by Stuart Hall. According to Scott (2003), a rhetoricalcultural approach influenced by articulation "would read all texts [and discursive practices] as changing ensembles of relations that produce a range of effects, including subjects" (p. 27) and, in my case, contexts of use. As Seigel (2013) queries in her rhetorical-cultural analysis of pregnant manuals, "what exactly does it mean to read a text as "changing ensembles of relations"? And "how can a technical communicator analyze a piece of documentation, say, [an instruction manual or parliamentary report] in an international context in order to "describe how its users were articulated at a particular time" (p. 23) to adopt a specific technology? To respond to these questions, I elaborate on how articulation theory operates and how it functions vis-à-vis context of use. 


\section{Articulation and complex context of use}

In an interview with Lawrence Grossberg, Hall defines "articulation" to mean "the form of the connection that can make a unity of two different elements, under certain conditions. It is a linkage which is not necessary, determined, absolute and essential for all time" (Grossberg, 1986, p. 53). It is also the "non-necessary link between a social force which is making itself, and the ideology or conceptions of the world which makes intelligible the process they are going through, which begins to bring onto the historical stage a new social position and political position, a new set of social and political subjects" (Grossberg, 1986, p. 55). From the definitions above, we get to identify that articulation is about connections, linkages, joints and the unity of certain elements or conditions. These connections and linkages must not necessarily belong or connect. Articulation, Slack (2006) indicates, must draw our attention to the "contingent relations among practices, representations, and experiences that make up the world" (p. 126). As Hall continues the conversation, he stresses that a theory of articulation must enable cultural theorists to inquire into the circumstances under which "connections can be forged or made." The quest to understand the circumstances that enable certain conditions to emerge empowers a search into "how an ideology discovers its subjects...empowers people... enabling them to begin to make some sense or intelligibility of their historical situation" (Grossberg, 1986, p. 53).

Articulation is a complex theory that offers cultural analysts and communication scholars the tools to participate in the world. How then is articulation relevant to technology studies in international context? As stated in chapter 2, a cultural studies critic who falls 
on articulation theory to study technology must consider the powerful way language shapes our assumptions about the technology being studied. In my work, for instance, articulation enabled me to inquire into how technical documents can help identify circumstances that led to the adoption of the technology; what relationships exist between circumstances and electoral cultural practices; between ideology and social forces that pushed for the adoption of the biometric; between rhetorical representation of the biometric and broader cultural entanglements? In looking at the role that technical writing plays in technology adoption and use, the technical writer will read various technical documents that went into the adoption process to begin to map out the contexts, assumptions and arguments that were made to persuade users to adopt a specific technology. The technical writer will also critically analyze instructions and other technical documents that accompanied the specific technology under study in order to identify the ways that the technology works to articulate users to a technological system. Seigel (2013) states that "it is possible to investigate articulations by first paying attention to what user practices the manual facilitates" (p. 24) and in any case how such practices shape user identities. Or a technical communicator interested in operationalizing articulation theory "would read manuals in order to begin to map how the user's identity... has been articulated over time" (ibid p. 24). Here, I am talking about how a user is articulated to use a specific technology to accomplish a specific task or how a technology is used to order humans as 'standing reserves' of a technological system in a complex context of use. 
Thus, we can also examine the position of the user who is articulated into a complex context of technology use through rhetorical means. Hence, the second concept relevant to my project is the context of use. This concept leads to an interrogation of the user and the situation of use. The articulated user is not passive, he/she becomes, as Johnson (1998b) identifies, "an active participant who can negotiate technology use" (p. 33). Johnson mentions that context of use has fascinated rhetoricians since classical antiquity. Classical Greeks, for instance, have sought to use taxonomies as aids to their tasks: forums have been categorized; audiences have been placed into different groups in order to "plan what would be appropriate" (p. 34) for them and then work on how to persuade them through the rhetorical appeals (ethos, logos, pathos). Present generation of rhetoricians have carried on this tradition by developing several taxonomic devices. Dwelling on the relevance of context, Johnson works to develop a user-centered theory that situates user in a complex rhetorical context in a form of three concentric circles.

The first ring captures the activity of the user as he/she engages in learning, doing, and producing the technology. These three models, he states "define global activities that users are apt to be involved with during either the design, dissemination, or end use of technological systems or artifacts" (p. 38); the next outer ring depicted as disciplines, institutions, and communities "emphasize constraints that larger human networks place upon technological use" (ibid). In addition, the rhetorical model considers the importance that culture and history play in technology use. As Johnson avers,

Cultural forces define nearly every human action, and in a world more dependent than ever on international communication and technology transfer the element of culture is without question essential when defining the use of a technology. History... refers to the reflective aspect of 
understanding human action,... Thus history informs our understanding of technology in unique and indispensable ways (p. 39).

Lumped together, Johnson helps us to understand that the complex context of use serves a plethora of purposes: "it serves as a heuristic for analyzing technological artifacts or processes. It also can be a mode for exploring the people who use, make, and/or even destroy technology. It can help tell tales of people as they struggle with, become enamored of...technology." Finally, technical communicators can use the complex of technology use "to study the audience we refer to as users" (p. 40). This rhetorical model becomes relevant to my project in the sense that it stresses the roles that disciplines, institutions and communities play in technology use. More so, it emphasizes the importance of culture and history and how these two forces shape technology adoption and use. The users of the technology are not left out.

Thus, articulation and complex context of use emphasize the main goal of my project: to find out the role that electoral culture, disciplinary rhetoric and technical writing played in the adoption of the biometric technology in Ghana. More importantly these concepts help me to answer these questions: how are the identities of users of a technology articulated in a complex technological system; and how can we account for the broader cultural, rhetorical and historical forces that shaped the adoption and use of a technology in an international context. I also stated in my literature review section that my research will in part tell a story of events that led to the adoption of the biometric device for the parliamentary and presidential elections in Ghana. Stories provide avenues for interpretation and understanding. I tell a story which will lead us to answer the question: 
how did Ghanaians come to "have certain needs and goals that necessitate engaging with a particular practice, a technological system," (Seigel, 2013, p. 20). The story I tell, through the documents I analyze will bring a diverse perspective to literature on technology studies in technical communication.

\section{Biometric technology as identifier and verifier of user identities}

If biometric technology and the discursive practices around it are the objects of study, then identity becomes a quintessential aspect of the study because biometric use is tied to identity. The primary function of a biometric machine is to authenticate and verify individuals. Biometric “scans a subject's physiological, chemical or behavioral characteristics in order to reify or authenticate their identity" (Pugliese, 2010, p. 2). These technologies make use of devices as scanners, cameras to "capture images, recordings, or measurements of an individual's characteristics and use computer hardware and software to extract, encode, store and compare these characteristics" (Vacca, 2007, p. 23).

Biometric technology is used to "verify a person's identity, secure the nation's borders, and to restrict access to secure sites..." (Vacca, 2007, p. 3). Mostly, biometric is used to identify "you as you" (Pugliese, 2010) and also "holds the promise of fast, easy-to-use, accurate, reliable, and less expensive authentication for a variety" (Vacca, 2007, p. 15). The biometric system answers two main questions that relate to identification and verification:

- Verification: that is, it is used "to verify a person's identity. This is done in order "to authenticate that individuals are who they say they are"(Vacca, 2007, p. 23). Am I who I say I am? (Magnet, 2011) 
- Identification: that is, it is used to establish a person's identity-here, the system determines who a person really is. It responds to the question: who am I? (Magnet, 2011; Pugliese, 2010).

Three stages characterize the use of biometric technologies. First is the enrollment stage. The subject presents himself/herself in order to enroll in the system. This process of presenting "allows biometric technology to capture an image of the particular imprint of the subject" (Pugliese, 2010, p. 2). One must provide a form of identification in the form an ID. Then, you present the biometric finger. When finger is presented, "distinctive features located on one or more samples are extracted, encoded and stored as a reference template" (Vacca, 2007, p. 22). Thus, the first stage acquires information about your physical behavioral traits (Magnet, 2011, p. 21).

The second stage is the verification stage. The captured image is digitally converted through the use of particular algorithms into a template (Gregory \& Simon, 2008; Liu \& Silverman, 2001; Magnet, 2011; Pugliese, 2010; Vacca, 2007). Your enrolled body must be verified by the system. This way, the "system compares the trial biometric template with this person's reference template which is stored in the system" (Vacca, 2007, p. 23). This is referred to as 1:1 matching, meaning, there can be only you and no one.

The final stage sees to it that "the trail template is compared against the stored reference templates of all individuals enrolled in the system" (Vacca, 2007, p. 25). A person's physiological and behavioral characteristics are turned into a "digital representation in the form of a template" (Magnet, 2011, p. 21). Thus by adopting the biometric, the nation 
declared the elections a security concern which needed to be addressed. Voters became bodies that must be controlled and disciplined.

For instance in one of the documents I analyzed, the main character in the document explains to his listeners that biometric registration involves "the collection of information that is only connected to you and no one else...so that when we say it is you, we know it is you." The speaker also explains the various processes one would have to go through in order to be registered through the biometric. First, complete a form with your personal information; second, registration officer enters your information into the system by capturing your finger print with a scanner; third, your voter ID is issued out. These stages correspond with the stages I enumerated above and as I will explain later in the discussion, they articulate users into a technological system that has its ideologies. More so, the individual who goes through the system becomes a subject of control. In a way, these practices of going through different stages to be able to get registered constitute a form of what Scott terms "disciplinary rhetorics." These disciplinary rhetorics work to shape "people as particular kinds of subjects and subjects them to various exercises of power....disciplinary power elicits knowledge about people to observe, classify, and manage them as individuals and populations" (Scott, 2003, p. 7). Thus the dictum is: once you go through the biometric your data is saved, observed, and managed to the extent that no one can impersonate. The individual voter becomes part of a broader population, yet maintains their individuality and their unique identities.

Having laid down my methodological approach, my next step is to discuss my research design. In subsequent paragraphs, I work to situate my research in a broader context. I 
also discuss how I gained entry to my research site; and how I positioned myself. Walton (2014) and Thatcher (2010) identify that researchers conducting research in intercultural [and international] contexts must be flexible, reflexive and humble. Thus, I also discuss how I exhibited humility, patience, flexibility and reflexivity in conducting international technical communication research and how these traits are quintessential to rhetoricalcultural methodology.

\section{Situating the Research in a Broader Context}

To begin, I share some background and reflection on my study and why I took an interest in studying issues related to technology in an international context. As I have indicated earlier, mostly in my first chapter, I took on this research in response to several calls made that technical communicators should contribute to technology studies. What I have not touched on is my personal interest in the politics of Ghana. I limit my definition of politics to the governance and the electoral process of Ghana. I must say that my consciousness to the political landscape of Ghana is derived from the active participation of my father in the politics of Ghana. As a young child, I followed my dad to political campaigns. I remember vividly how I enjoyed carrying his food and water along anytime he went on political campaigns when on two occasions he contested for the parliamentary seat in the New Edubiase constituency, in the Adansi South District of the Ashanti Region. I have been exposed to what it means to lose and win elections. I also recall the many times I have enjoyed chants of political songs. At an early age, I said to myself I was going to pursue politics and things political. 
More so, my senior high and undergraduate history lessons exposed me to the leakages in the political system of Ghana. I was exposed to the various ways that political parties rigged their ways through to victory; how ballot boxes were snatched from returning officers; how macho men where used to brutalize voters and how in some instances, electoral officers were compromised. At this level, I felt that exigency for electoral reforms. My interest was piqued the more when at an advanced level in my academic career, I have been exposed to the notion that a rhetor owes a civic responsibility to himself, his society, his nation and the world at large.

Hence, when the conversation on adopting a biometric system began in 2010 ("Communique: At the National Conference on Biometric Voter Registration and EVoting in Ghana," 2010), I became very interested and wondered how clean the electoral process was going to be when the country finally adopted it. At that point, I shared in the assumption of many others that technologies were the panacea to social woes. I became more motivated to embark on this study when after the 2012 elections, the opposition New Patriotic Party (NPP) filed a petition to the Supreme Court of Ghana contesting the validity of the election of John Dramani Mahama as the president of the Republic of Ghana. According to the NPP there were the recurrence of such issues as over voting, impersonation, vote rigging and many other malpractices that characterized the 2012 elections (Gyimah-Boadi, 2013; Kelly \& Bening, 2013; MyJoyOnline, 2013; Oquaye, 2012b; "Supreme Court Judgement on the Presidential Election Petition, Akufo-Addo V. Mahama and Others," A.D 2013). As a student interested in technology issues I took it upon myself to examine why even though we adopted the technology, our electoral 
system still suffered such malpractices. I began to wonder if technology could really resolve issues that are culturally, historically and socially rooted. Having conceived of this idea, I drafted my proposal, showed it to my committee members for approval. My major goal was to study how technology adoption provided an exigent moment for technical communicators to contribute to discussions on technology. More specifically, I wanted to know the role that technical writing played in the adoption process.

Once I had thought about my topic and theoretical frames to use, I had to choose my site for my study. In deciding my scene of study I asked the following questions: "is the scene researchable? Can I be confident that a major investment of time, resources, and effort in this scene will be rewarded with a successful study?" (Lindlof \& Taylor, 2011, p. 87).

\section{Planning for entry}

As customs and practices in qualitative research demand, before one can effectively research at a particular field, the researcher must seek approval from a "gatekeeper," "a person or group that has the authority to approve research access" (Lindlof \& Taylor, 2011, p. 98). For a researcher to know who the gatekeepers are in an institution requires that the researcher did initial inquiries. The researcher can read about the institution on the internet before visiting the physical space. It also requires negotiations with gate keepers and people of authority. In my case, I leaned on acquaintances for help. I spoke with my dad about my research and asked for possible ways that I could get access to the headquarters of the electoral commission. He, in turn, spoke with a friend at the electoral commission at a local level in the community I reside. After my dad had spoken with his friend, he asked me to personally call him, introduce myself and the project and ask how 
he could be of help. I called and we spoke at length about my project. After our conversation, he asked me to send an email detailing my project and what my objectives were. I did those and after three days, I received a reply that he managed to contact someone who was willing to help. I contacted this person through phone calls and he promised to help me. Thus, after these initial contacts were made, and after I had received assurance that I could conduct my study, I travelled to Ghana at the end of November, 2014. On December 3, 2014, I reported at the contact's office to introduce myself to him. He asked me to submit an introductory letter and my proposal for consideration. I contacted my supervisor through email, and she responded immediately with an introductory letter. On the $8^{\text {th }}$ of December, I submitted my introductory letter, an abstract and my proposal for consideration. Then, data gathering began immediately after I was given approval.

Data was collected within 38 days at the headquarters of the Electoral Commission in Accra. The Electoral Commission, per the 1992 constitution of Ghana, is required to, among other things; "conduct and supervise all public elections and referenda," and to "educate the people on the electoral process and its purpose" (1992 Constitution of the Republic of Ghana, 1992). Thus, it has become the responsibility of the Commission to find ways to conduct "free, fair and transparent elections to the acceptance of all stakeholders" ("Mision, Vision and Functions,"). The Commission is constituted by seven members: a chairman, two deputy chairmen, and four other members all of whom are appointed by the president of Ghana. In the next paragraph, I discuss the various departments and how department heads helped in the data collection process. 
Structurally, the commission is subdivided into seven different departments: the Elections Department, the Training Department, the Research, Monitoring and Evaluation Department, the Finance and Administration division, the Human Resources and General Services Department, the Information Technology Department, the Public Affairs Department and the Internal Audit. I place emphasis on these departments because I went to each unit to collect data. The heads of the various departments report directly to the Chairman of the Commission. Sections of the biometric adoption process were handled by the various departments. For instance, the Training Department was in charge of the training of Officials. The department was also involved in the writing of the instructional manual that accompanied the biometric technology; the Research Department analyzed and assessed the strength of the biometric system and presented information on findings to stakeholders; and the Public Affairs Department designed educational materials that educated the public on the relevance of the biometric systems and ways to go about the registration process. They also designed flyers that accommodated the technology to the general public.

\section{Positionality}

When I discussed the second condition of a rhetorical-cultural methodology, that is mapping shifting relationships among rhetorical practices, I mentioned how this move emphasized the position of the researcher. Scott stresses how necessary it is for the researcher to map his or her position and ideological perspectives on the map. Thus, positionality played a major role in my research design and data collection. As indicated by Agboka (2014) and Jones (2014) and as it is an important trait in ethnographic 
research (Smith, 2012) and feminist research methodologies (Haraway, 1988; Harding, 1991; Keller, 1996), the position and role that a researcher assumes is very critical to research practice and it is very paramount in conducting international technical communication research. I assumed two positions: an insider (Ghanaian by birth) and an outsider not only because I live outside Ghana and am pursuing my graduate studies, but because I was exposed to Western forms of thought through my education in Ghana. Thus, even though I have lived most of my life in Ghana, my identity as a Ghanaian has shifted between being a native Ghanaian at one point, and an outsider at another point. I am a subject of colonialism. In essence, I was and have always been bi-culturally situated. This is the more reason why it is not a given that my identity as a Ghanaian will lead to an accurate representation of local reality. Considering my Western frames of thought, I would say that it is non sequitur.

I make reference to my bi-situatedness because it forms an important aspect of defining what the parameters are when conducting international technical communication research. I made mention that international must be defined to capture the fluid, unstable and dynamic nature of contexts. Here I extend to include the researcher. The researcher conducting research in international context, assumes a fluid position or identity. My situation is a tacit example. When I go to Ghana (the land of my birth), I am a national, a native who enjoys all the privileges that a Ghanaian must enjoy first before international. However, my identity as an international student is reinforced the more immediately I land on American soil. Thus, my unstable, fluid identity shapes my research report. My take is that when my research is tagged an international research, then, my identity as a 
Ghanaian is missing. But do I have to separate my identity as a Ghanaian from my work? When this happens, I reinforce the ideology that separates the researcher from the researched. I reinforce the dichotomy between subject and object. It is at the backdrop of this fluidity that I ask for a definition of international to include the fluid, and unstable position of researcher. On the other hand, my work is international because I use Western frames to study a non-Western society. My identity is both articulated and disarticulated in both instances. Thus, bi-situatedness and positionality play major roles in international technical communication research. Hence, in defining "international," we must think about the various ways that our identities as researchers are articulated and disarticulated at every stage of the research process.

My interest in questioning the "international" was animated when I took a qualitative research course in the spring of 2012. The final paper I produced in this class worked to interrogate what it means to be an "international student." With this goal in mind, I decided to observe activities at the international center in an institution. I observed the various ways that international students frequented the international center just because they wanted to make sure they were not out of status. I came to realize that to be an "international" meant constantly going through the burden of checking your status or making sure that you were abreast with immigration laws and policies. I kept asking myself if these people, considered international, would go through the hustle of constantly checking their status if they were in their respective countries. The moral behind this story is that international is fluid and unstable. International always comes with bi-situatedness, with fluidity and instability. 


\section{Humility}

In this section, I narrate how the spirit of humility helped me to gather important information from a worker in the elections department at the Electoral Commission. By "humility," I mean the ability to "relinquish" the researcher as expert role in order to listen to participants' knowledge on issues related to one's research. Humility also means paying attention to your research data. On one of my visits to the Electoral Commission, my contact was at a meeting so I was asked to wait for him in one of the offices occupied by a lady and a gentleman. Seeing how idle I was, the gentleman engaged me in a conversation. During the conversation, my research emerged and he asked more about what I was examining. He got very interested in it because he was one of those involved in the adoption process. Although interview was not part of my research method, I let myself go and engaged in a question and answer conversation. During our conversation, he reiterated the very reasons why the machine was adopted. According to this gentleman, the adoption was necessitated by such malpractices as over voting, vote rigging, and impersonation. Even though, these were not new to me, I humbly listened to him. He later told me that the adoption process could not solve most of the issues. Asked why, he said he could fault the process of registration. It was through him that I got to know that the registration for the 2012 elections was conducted in phases. The various ways that polling stations were earmarked for the registration were problematic, he stated. Citizens who were ignorant about the various phases lined up to register when they saw their friends and relatives at different polling stations lined up for the process. These citizens who registered, though it was not their turn to register, lined up again to register when the registration centers were moved closer to their polling stations. A 
situation he said could have been avoided if they really educated the citizenry on registration procedures.

He also revealed to me one of the reasons why the machines broke down. They identified after the elections that most Data Clerks did not follow the instructions that came with the biometric technology. Clerks would rather learn more about the system by doing than referred to the manual. In the process, most of the machines broke down.

Also, it was he who hinted that the research department, the public relations department and the training department played a major role in the adoption process. After our conversation, he led and introduced me to the heads of these departments. Further, in a casual conversation with one official of the Electoral Commission, he revealed that the biometric device was imported from one of the European countries even though he could not recall the name of the country. This official also revealed that most of the Data Clerks and Polling Station Officers were temporary workers hired by the Electoral Commission during elections. Most of the Officers were teachers who have IT knowledge. So, by humbly listening and unlearning what I have learned; and by decolonizing my mind, I got a wind of what some of the causes of the breakdowns were and how some issues as impersonation and over voting reoccurred. I demonstrate in the next paragraphs that it is not enough to be humble, a researcher must be patient and flexible.

\section{Patience}

Related to humility is patience but mostly little is said about the relevance of it to conducting international technical communication research. A researcher conducting 
research in international context is bound to face frustrations and the only way to overcome such vexations is when one exhibits patience. The researcher becomes more offended when they encounter such frustrations in their own countries. In instances where the researcher encounters frustrating moments, the researcher must learn to be calm and not become annoyed easily. I recall the many instances when I had to ask whether I would have been subjected to certain treatments if I were conducting research in a different country. I narrate some of these forms of frustrations and how with humility and patience a researcher could sail through a research process successfully. I stated earlier that my contact at the Electoral Commission asked me to submit my abstract, proposal and introductory letter. My hope was that these documents were going to be attended to with alacrity. I was somehow disappointed when after three weeks of my stay in Ghana, the gatekeeper had not looked at those documents. Meaning that though I arrived early for data collection, I could not begin research immediately because the documents had not been approved. It took several calls and several visits to the commission.

It became more painful when after the documents were approved by the gatekeeper, various heads denied me access to their departments because they had not received any notice "from above" that I was conducting research at the headquarters. Immediately, I went back to the gatekeeper to discuss issues with him. Frustrated himself, and somewhat disappointed that he has delayed my research, he took it upon himself to distribute my documents to the various heads. I only had two weeks more left. Worst still, it took extra one week for heads to identify and locate most of the documents that I requested. I felt the pain and the frustration. I wondered why I even decided to embark on the journey or 
why I decided to undertake such a project. But, I kept my cool, and constantly visited the Commission with the hope that some of the documents will be retrieved. I received most of my documents three days prior to my departure. It was a relief!

After I had finished collecting my data, I went back to my contact to thank him for his support. He apologized to me for the delay. According to him, he was new and did not know about some of the protocols at the Commission. He thanked me for not venting my spleen because he had witnessed the way some students abandoned their projects because they went through similar frustrations and burdensome bureaucratic procedures. To the best of his knowledge, I was patient with them. And I must say that this show of patience showed off as I got $80 \%$ of the documents I requested. I also became friends with most of the heads because I was calm with them and waited till they made the documents available. Some shared in my frustrations and encouraged me to contact them anytime I needed help.

Data analysis also requires the art of patience. For instance, it took me enough time to connect data to literature; I also had to struggle to make meaning of my data; and which analytical lens to use.

\section{Reflexivity}

One of the most cherished practices in conducting qualitative research is self-reflexivity (Tracy, 2010, p. 842) and it becomes an indispensable tool in international and intercultural technical communication research (Agboka, 2014; Jones, 2014; Thatcher, 2010; Walton, 2014). Self-reflexivity guides or pushes researchers to be honest with 
themselves, their research and their audiences. Self-reflexivity encourages "writers to be frank about their strengths and shortcomings" (Tracy, 2010, p. 842) because in reflexivity "you ask yourself the same questions that guide your analysis and other interpretations" (Goodall, 2000, p. 141). Reflexivity therefore becomes "a process of personally and academically reflecting on lived experiences in ways that reveal the deep connections between the writer and her/his subject" (Goodall, 2000, p. 137). It also becomes a tool that gives researchers the opportunity to reflect and understand the cultural constructions of their theories and methods..." (Walton, 2014, p. 3). So how did my identity as a national (Ghanaian by birth) and an international student researcher shape the way I conducted the research? What are those things that are worth recording? What is the culture of the place and how does this culture help me to proceed with my research work? How did I even become interested in my project? How did I choose data collection method and analysis? I demonstrate how reflexivity worked vis-à-vis other research practices.

\section{Flexible design for data collection}

Data was limited to technical documents such as instructional manuals, parliamentary reports, online videos, educational guides, and PowerPoint slides. In all, I collected 18 different textual materials. Since these documents were too much for my project, I decided on which documents were relevant and could help contribute to knowledge in the field. Eight criteria informed my decision. First, the document must meet my working definition of technical writing. Second, the document should work to control/initiate an action. The document must be produced by or for the electoral commission and it should 
give an instruction about the biometric device or the biometric verification system. Fourth, document should be targeted towards EC officials, Ghanaian who is of voting age, and Data Entry Clerks. Also, the document should discuss issues pertaining to the 2012 elections. Last and most importantly, the document should make a case/argument for why it is necessary to adopt the technology. In this regard, the document "might be argument for constituting a technological system, maintaining it, disrupting it, or replacing it" (Seigel, 2013, p. 32). I settled on the user manual that accompanied the biometric device, parliamentary hansard (recordings of parliamentary debates), an online video of biometric voter registration education and a suite of posters used to communicate issues about the biometric technology to the public.

\section{Flexible analytic tool}

The rhetorical-cultural approach provided a flexible lens for document analysis. As Seigel (2013) identifies, a technical communicator using rhetorical-cultural approach as an analytic lens "would read manuals [and genres] in order to begin to map how the user's identity has been articulated over time. Because they tend to focus on user tasks and actions, it is possible to investigate articulations by first paying attention to what user practices the manual facilitates" (p. 24 bracket mine ). This way, the critic can isolate, describe, classify, interpret and evaluate a phenomenon (Hart \& Daughton, 2005, p. 25) under study. In this project, I perform a rhetorical-cultural analysis of technical documents to identify the role such documents played in maintaining assumptions about the biometric technology. In line with this goal, I critically work to identify implicit and 
explicit arguments about the necessity to adopt the biometric device and the consequence of adopting the biometric.

In chapters that fellow, I perform rhetorical-cultural analysis of such documents as instruction manual, online video, parliamentary hansard and a suite of posters to demonstrate how the rhetoric surrounding a technology can enable an articulation of broader issues. Findings will be discussed over two chapters. 


\section{Chapter Four: Studying Technology through Accompanying User Manual}

In this chapter, I make an attempt to articulate why the "simple instruction" that accompanied the biometric technology adopted could not be followed. As I stated in chapter 1, after the 2012 election, the Deputy Chairman of the Electoral Commission in charge of Operations reported that Data Clerks, for instance, could not follow simple instructions to operate the biometric device. Thus, in this chapter, my major point of inquiry is the user manual that accompanied the biometric technology. I focus on the manual because the manual not only provides instructions for how to use the biometric device, but also a lens through which I can analyze and articulate issues such as localization, social justice, ideology, subjectivity, culture, power, truth and assumptions about technology. In essence, the manual provides an articulation of broader issues relevant to a context of use.

I also focus on the manual because of the following reasons: first, Ghana's increasing economic development and business exchange with the West, especially the U.S make it possible that the Ghanaian will purchase more items from America or the West. Hence, it is possible that technical communicators in the West will write documents for Ghanaian users. It is also possible that Ghanaians may collaborate to write documents for Ghanaians or Western audiences; second, documentation has long been the province of technical communication (Johnson, 1998a; Seigel, 2006); third, "written instructions govern, guide, and control user actions on a daily basis in tasks that range from operating industrial equipment, installing a wireless router, to using computer software" (Hogan, p. 
155); fourth, documentation can "sustain" a system or disrupt a system. "It is the rhetoric that accompanies technology and makes it possible - the rhetoric that makes technology fit into the world and makes the world fit with technology" (Bazerman, 1998, p. 388); fifth, in spite of its usefulness, Thatcher $(2010,2011)$ makes us understand that scholars in the field have done little to assess "elements of instructional design for cross-cultural contexts"; sixth, and more importantly, documentation is "one of the things that determines how we use technology and in turn how technology uses us" (Seigel, 2006, p. 13). This final point needs special consideration as it exposes a dualism: using and being used. I ask: what does it mean to use a technology and be used by technology? It is mostly obvious to talk about using a technology but we are less aware of the fact that technologies use us. The first part of the sentence: using technology, leads us to interrogate the various ways that manual becomes ineffective or effective. In this regard, I work to assess the design of the document to understand how it hinders or enables its proper use.

The second part of Seigel's statement, being used by technology, presents a more philosophical perspective to our relationship with technology. For me the process of being used by technology leads to an investigation into the various ways that humans become subjects to technology. It leads to an articulation of such concepts as ideology, subjectivity, control, and varied assumptions societies hold about technology. I understand Seigel's statement to mean a confirmation of Thatcher's (2011) claim that a study of instructional manuals across cultures is a study of such cultural values as assumptions people hold about technologies, layouts, assessment, flow, and feedback ( $\mathrm{p}$. 
285). A simple instruction manual, Thatcher avers, can connect to "very large legal, economic, social,...values" (xiv), which are ultimately connected to the cultural and rhetorical patterns of the local context. To this end, I have developed paragraphs that will guide us to identify what it means to be used by technology. I will also attempt to identify how design of documentation and technology reveal implicit cultural values and assumptions in the context of study. I hope that my analysis will help us to identify the various ways that technologies use us, by which I mean, how technologies act upon us or in Heideggerian terms, how we are 'enframed' and become 'standing-reserves' to technology. We will realize that technical communicators will find their self-worth in not only helping people to use technology but also in helping understand how they are used by technology. When we help users to identify ways that they are being used, then we respond to calls that challenge us to help users encounter technology critically (Banks, 2005; Johnson, 1998a; Seigel 2013. In making an attempt to answer how we use and are used by technology, I confirm the claim I make in chapter three that rhetorical-cultural analysis can lead to an articulation of broader issues in contexts where technologies are adopted and used, or Seigel's (2013) argument that "the goal of rhetorical-cultural analysis...is to better understand the context in which the text is consumed and used rather than to better understand the text itself, independent of context" (p. 22). I begin my analysis with a description of the user manual. 


\section{The manual as an articulation of instruction writing 'pieties'}

The manual is a 31-page booklet produced by the Training Department of the Electoral Commission and SuperLock Technologies Limited (STL), the providers of the biometric device. The manual serves as a training guide and a reference tool for operational staff, notably key trainers and polling staff who will handle the biometric device at the various polling stations. It mostly contains the procedures and legal precedents that articulate the operation of the biometric device. Words and phrases used are meant to identify the different aspects of the process in using the biometric device and what polling agents should do when they encounter such issues as the inability of biometrics to identify voters.

I describe the features of the instruction manual in light of the guidelines to writing manuals that are taught in traditional technical communication classrooms in the U.S. My decision is based on the fact that these guidelines are what technical communicators or designers "typically consider when planning, drafting, and revising" (qtd. in Dong, 2007, p. 224) instruction manuals. In a way, the guidelines outlined in the books I have selected can be considered the best practices. Seigel (2013) refers to these practices as "pieties" that users or in this case, writers must follow. I review four technical communication textbooks I have used at one point or the other in the HU 3120: Professional and Technical Communication classes I have been teaching at Michigan Technological University since the fall of 2012 to identify what best practices manuals must follow. A critical study of these four technical communication textbooks used in my introductory technical communication classes in the United States: Writing that Works, by Walter Oliu 
et al; Strategies for Technical Communication in the Workplace by Laura Gurak and John Lannon; Practical Strategies for Technical Communication by Mike Markel; and Technical Communication: A Practical Approach by William S. Pfeiffer and Kaye A. Adkins outline some best practices that instruction manuals must follow.

All four textbooks indicate, for instance, that it is necessary for an instruction manual to have an introduction or an overview. They hold that the introduction or the overview works to explain the purpose of the instruction or all of the required information the user needs in order to perform the instructions (Gurak \& Lannon, 2012; Markel, 2013; Pfeiffer, 2003). The best practices also reveal that an instructional manual must: describe a sequence of steps; group items under task headings and subheadings; be written from a command point of view using an imperative voice. That is, each step must proceed with an action verb; speak to the rhetorical situation; use accessible language; emphasize caution, warning and dangers; use visual symbols and signal words; contain a title, brief overview/general introduction, step-by-step instructions and conclusion. Instructions must follow these guidelines in order to enable users to perform their activities or actions (Gurak \& Lannon, 2012; Oliu, 1994; Pfeiffer, 2003); or "they must get out of the way of the user" (Seigel, 2013) so they can operate a technology. One of the four books I reviewed suggests that clearly written instructions should "enable your audience to carry out the procedure/task successfully" (Oliu, 1994, p. 415).

The manual fulfills most of the elements that an introduction to a user manual must exhibit. The manual begins with a "Forward" which was written and signed by the Chairman of the Electoral Commission, Dr. Kwadwo Afari-Gyan. The "Forward" serves 
as an introduction to the manual and it gives an insight into why the manual was produced, to whom it was produced and why the biometric system was adopted. It basically identifies the rhetorical situation. For instance, it is written in the forward that the manual "contains procedures for operating the biometric verification device" and it will "serve as a training document and a reference tool for the operational staff" ("The Biometric Verification Device User Manual," 2012, p. 1). Also, the forward introduces the importance or purpose of the device: it was "introduced to the electioneering process in Ghana as a means of enhancing the integrity of the electoral process of the country" and it was going to "assist in the detection and prevention of practices of impersonation and multiple voting that have characterized our electoral process in the past" (ibid). Subsequently, the forward introduces the audience of the device as "key trainers and polling staff who will handle the device at the polling station, as well as key stakeholders." These "trained personnel will use it to "authenticate the identity of voters by means of finger prints" (ibid). In addition, the rule that guides the use of the biometric system is revealed: "a voter whose fingerprints are not recognized by the device will not be allowed to vote: while voters whose finger prints are recognized by the device will be issued with ballot papers and allowed to cast the votes at the polling station" (ibid).

What the forward to the manual accomplishes is a barrage of promises about the successes that will be chalked when the technology is used. Little room is put into commenting on the quality of the biometric device. In this sense, the manual becomes an example of an epideictic documentation. By "epideictic" documentation, I mean to say that the manual is only "concerned with present action" (Seigel, 2013, p. 71). It provides 
"functional but not conceptual aspects" (qtd. in Seigel, 2013) of the biometric device. The sole purpose is to get users engaged with the biometric so that results are perceivably captured accurately and efficiently.

Also these textbooks used in technical communication classes reveal that it is sine qua non to use headings and sub-headings when writing instructions. The purpose of grouping tasks under headings and subheadings, is two-fold: first, "they divide fragmented information into manageable chunks" (Pfeiffer, 2003, p. 225) for readers. Second, "they give readers a sense of accomplishment as they complete each task..." (ibid ). The manual meets this criterion as sections are organized under main headings which are captured in caps, and subheadings captured in lower cases. Such headings as "the biometric verification device," "how to unpack the BVD," "tips for using the BVD," and subheadings as "functional elements of the BVD," "sleep mode of the BVD," "how to replace batteries" help readers to move to necessary sections of the manual in order to use the technology efficiently.

Some other peculiar features of the manual need to be mentioned. The manual relies almost entirely on visual cues such as headings, labeling, pictures of the various stages of registering, images of messages to expect at each stage of the process and warnings. For example, in figure 4.1, users are introduced to the functional parts of the biometric device: 


\section{The Biometric Verification Device}

\section{(BVD)}

The main purpose of the biometric verification device illustrated below is to assist in verifying the identity of eligible voters who turn up at the polling stations to vote.

\section{Functional Elements of the BVD (oblique view)}

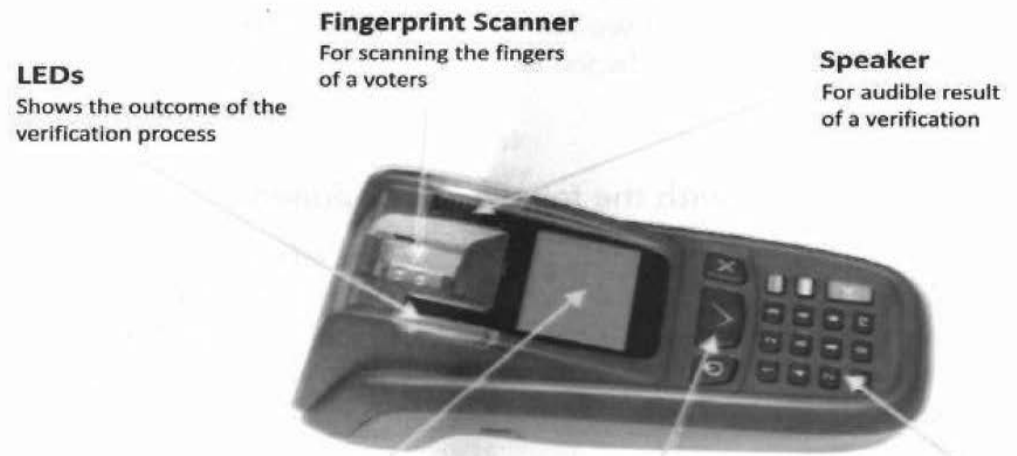

\section{Display}

Shows the status of the verification process
Soft Key buttons

Used to make choices indicated on the display
Keyboard

Used to type in a

barcode (if required) or to start a self-test

Figure 4.1: Functional elements of the biometric device. ${ }^{5}$

I would like to point out, however, that while some command prompts do not reflect their headings, some other visuals are placed haphazardly. For example, figure 4.2 has the heading: "how to unpack the BVD" but steps under this section say nothing about how to unpack the device.

${ }^{5}$ Figure is from The Biometric Verification Device User Manual (p. 2), designed by the Electoral Commission of Ghana for the 2012 presidential and parliamentary elections. Republished with permission (See Appendix for documentation of permission to republish this material). 


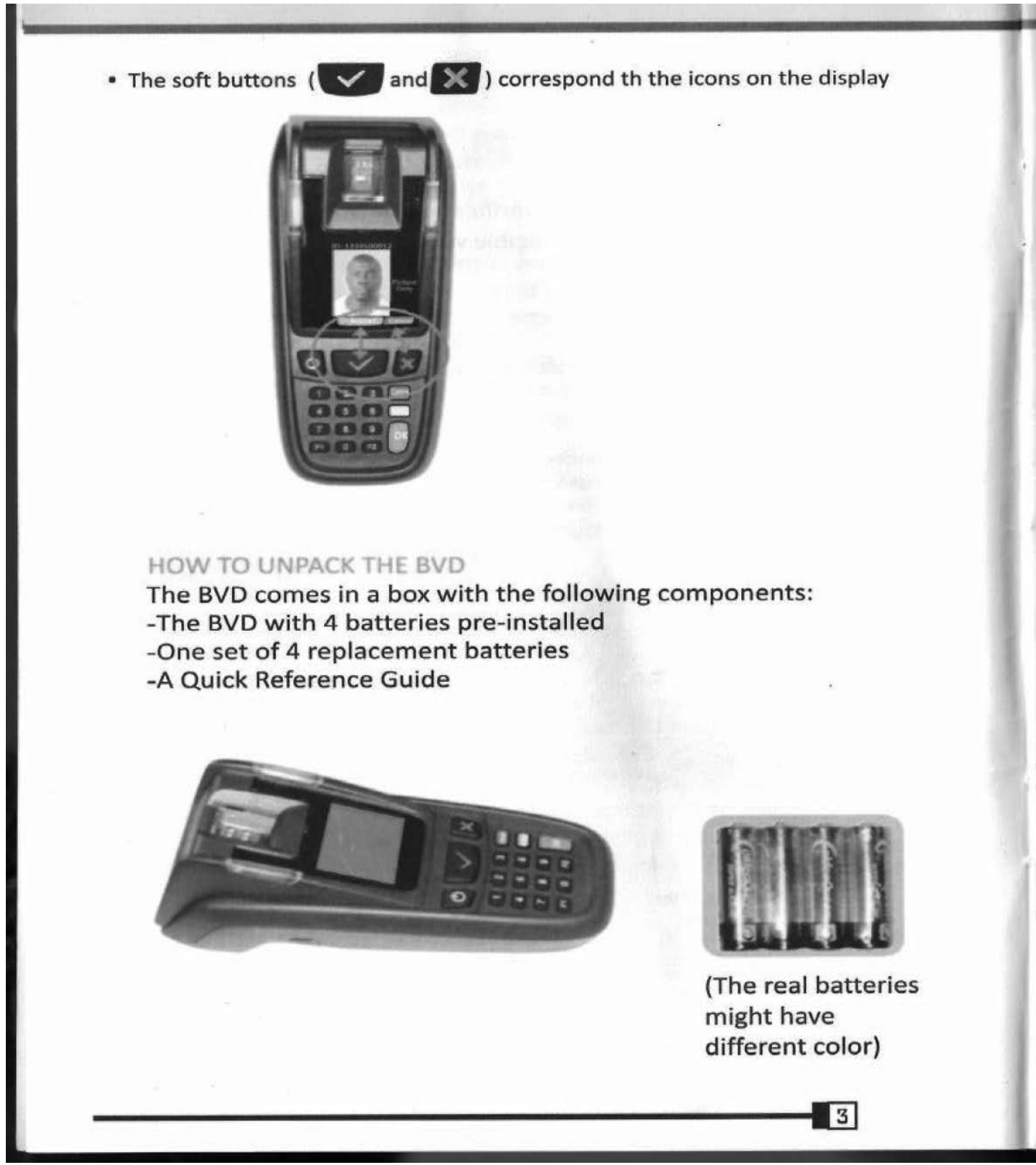

Figure 4.2: The process of unpacking the biometric device. ${ }^{6}$

${ }^{6}$ Figure is from The Biometric Verification Device User Manual (p. 3), designed by the Electoral Commission of Ghana for the 2012 presidential and parliamentary elections. Republished with permission (See Appendix for documentation of permission to republish this material). 
A similar case is found in the section headed "Message requiring cleaning the fingerprint scanner" in figure 4.3:

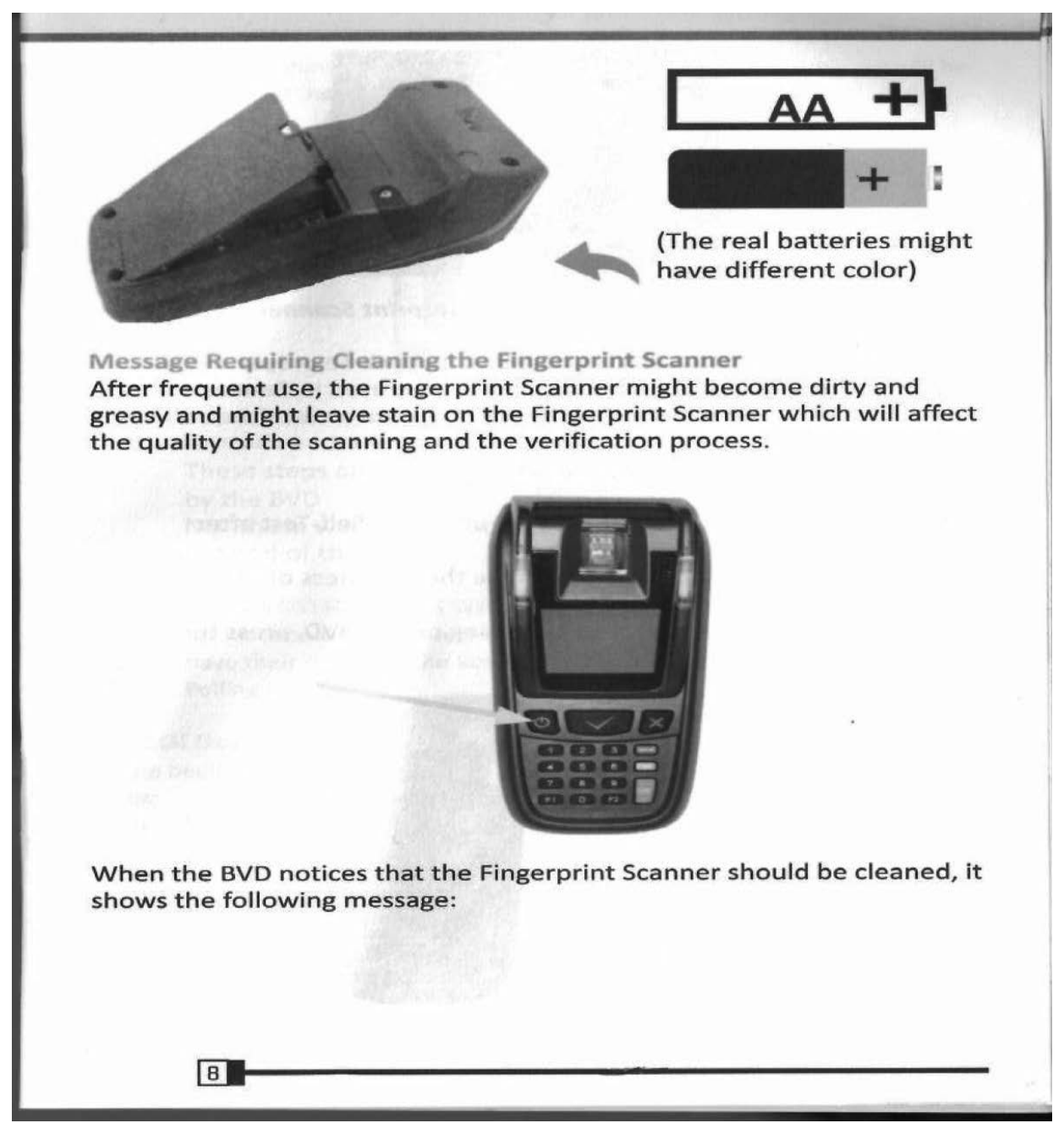

Figure 4.3: Message indicating when to clean scanner. ${ }^{7}$

${ }^{7}$ Figure is from The Biometric Verification Device User Manual (p. 8), designed by the Electoral Commission of Ghana for the 2012 presidential and parliamentary elections. Republished with permission (See Appendix for documentation of permission to republish this material). 
Some images are also placed in document without any accompanying texts to indicate what they mean. Figures 4.4 and 4.5 below are tacit examples:

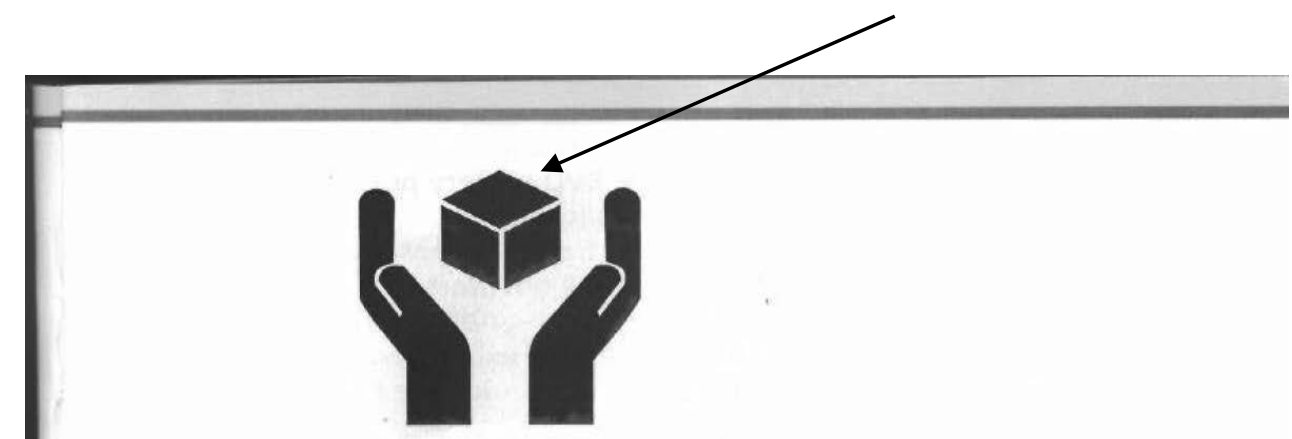

Maintenance Messages of the BVD

The BVD internally checks its own status and issues messages when there is the need to perform maintenance.

Other messages that will be displayed by the BVD and the required actions to be taken are indicated below.

LOW BATTERY POWER

- When the battery power is getting too low, the BVD will indicate by showing the following message:

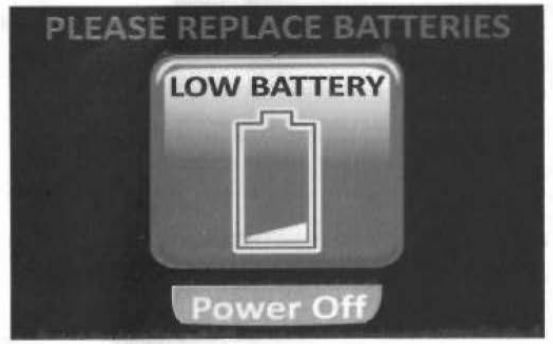

- The required action is to Replace the Batteries

圆

Figure 4.4: Message indicating when to replace batteries. ${ }^{8}$

${ }^{8}$ Figure is from The Biometric Verification Device User Manual (p. 6), designed by the Electoral Commission of Ghana for the 2012 presidential and parliamentary elections. Republished with permission (See Appendix for documentation of permission to republish this material). 

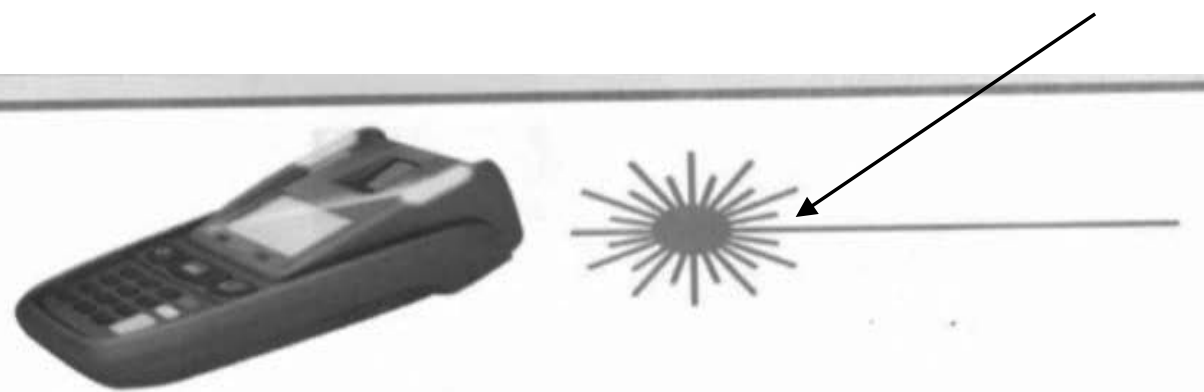

b. Scanning Finger-print

After Scanning the Barcode, the next process of identifying the voter is to scan the fingerprint.

When scanning a fingerprint using the Fingerprint Scanner, do the following:

- Place the BVD on a steady surface (e.B. a table)

- Make sure that the surface of the table is smooth and that the BVD is stable (not wobbly)
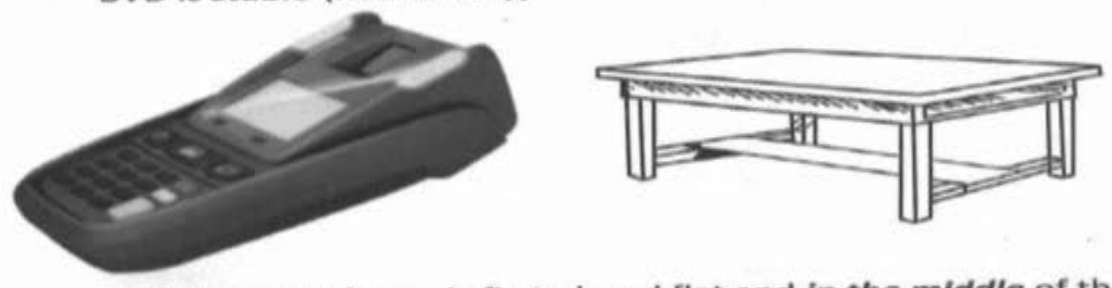

- The left index finger is first placed flat and in the middle of the Fingerprint screen

- The finger is placed firmly (but not too strong)

- The finger is kept on the scanner until it is captured. The device will request the voter to place a particular finger if it does not recognise the first one. There is the possibility that a number of recognise the first one. There is the possibilty that an aye the be placed on picks a valid fingerprint.

Figure 4.5: Instructions on how device should be positioned before use. ${ }^{9}$

Also, best practices of instruction writing state that the body of an instruction manual

must be written in steps. Steps should begin with active verbs and they should be phrased

as commands (Gurak \& Lannon, 2012; Markel, 2013; Oliu, 1994; Pfeiffer, 2003).

${ }^{9}$ Figure is from The Biometric Verification Device User Manual (p. 13), designed by the Electoral Commission of Ghana for the 2012 presidential and parliamentary elections. Republished with permission (See Appendix for documentation of permission to republish this material). 
According to Markel (2013), steps form "the heart of a set of instructions" (p. 381). The importance and rationale in phrasing steps as commands or tasks is grounded in the idea that "users want to spend a minimum amount of time reading instructions" (Seigel, 2013, p. 78). Users want to use their products to achieve a goal. Seigel states that this advice is because we assume that instructions are to maintain systems and not disrupt them. As I stated earlier, the user is made to engage with the system through the tasks they perform. In this regard, one only focuses on the promises the system provides: you can only achieve your goal if you use it (the system). In the case of the user manual that I analyzed, we can say that users are instructed to focus on tasks because they have to live to the promises that the biometric system provides: to assist in the detection of malpractices. Thus, an electoral process that has been historically, socially, politically, culturally, and legally marred by deep-seated malpractices can be corrected if users piously followed laid down procedures about the system to the letter.

Not only are instructions supposed to be task oriented, they must also be written in imperative voice (Gurak \& Lannon, 2012; Markel, 2013; Oliu, 1994; Pfeiffer, 2003). We are encouraged to use imperative voice because imperatives clarify "when the user her-or himself should be carrying out a particular action" or "instructions carry the weight of expertise, of authority" (Seigel, 2013, p. 82). In essence, instructions represent the system experts. These suggestions, Seigel indicates, carry implicit political and ideological undertones. For instance, although The Biometric Device User Manual does not explicitly say that if one fails to follow instructions to the letter the promise of delivering credible results will be compromised, this argument is implicitly implied in discourses 
surrounding the biometric technology. It is argued, for example, that the biometric device internally checks its own status and issues messages when necessary; or that the BVD gives an indication to the user when battery power is getting low. Relatedly, when BVD notices that the fingerprint scanner should be cleaned, it indicates. When such messages pop up, the user only has to either "replace the batteries;" "clean the fingerprint scanner" or take an action when necessary. These discourses implicitly push forward the promise that the device will enhance the integrity of the electoral process of the country by assisting to detect or prevent malpractices. The implication is that the system is fool proof; hence, any user of the technology can operate the BVD because the machine has in-built security mechanisms.

The idea that anybody or any user can operate the BVD successfully received little resistance from the populace as discourses persuaded Ghanaians to trust and have confidence in the system. This promise of credible electoral results was however challenged when after the elections the NPP petitioned the Supreme Court over malpractices that occurred during the election. More so, after the election, we encountered such newspaper headlines as "EC 'Steals 1.3m Votes for John Mahama;" "More Issues Over Election Results;" "Let's Recount Votes;" "Making Nonsense of Election Technology" et cetera. These headlines critically looked at not only the BVD but the users of the BVD as well. Thus the promise made by the Chairman of the Electoral Commission is subjected to scrutiny; ideologies about BVD contested.

In The Biometric Device User Manual, instructions include prescriptions about how to scan fingers of voters; how to unpack the biometric system; how to place fingers of 
voters on biometric device; how to switch device on/off; how to respond to maintenance prompts; how to scan barcodes et cetera. Though some of the tasks are phrased in commands, most of the tasks are not phrased as such. Instead, instructions are presented as descriptions. For instance, in figure 4.6, under "how to switch on/off the BVD," the command is written as follows:

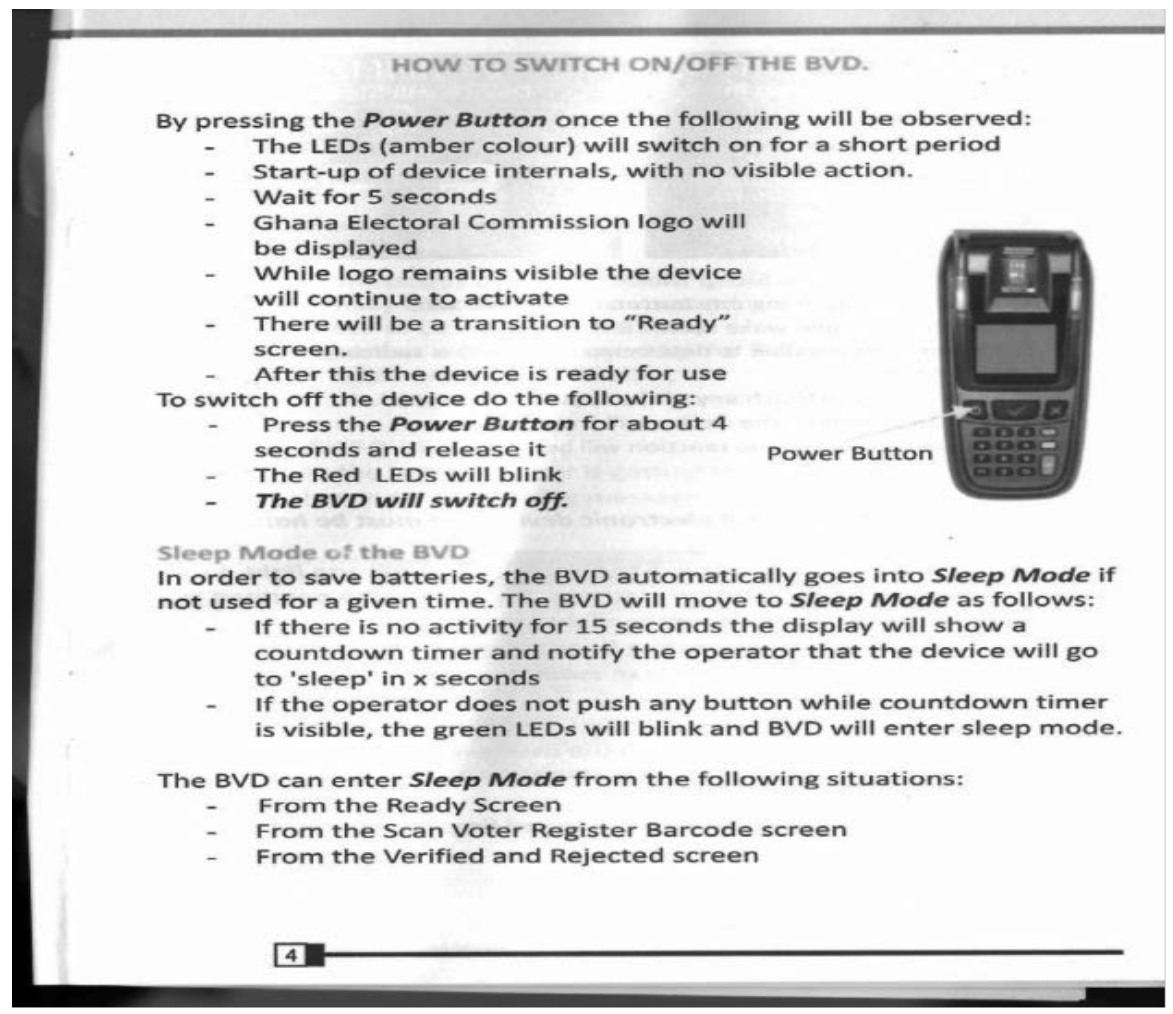

Figure 4.6: Instructions on how to switch device on/off. ${ }^{10}$

And in figure 4.7 below, under "scanning the barcode:"

${ }^{10}$ Figure is from The Biometric Verification Device User Manual (p. 4), designed by the Electoral Commission of Ghana for the 2012 presidential and parliamentary elections. Republished with permission (See Appendix for documentation of permission to republish this material). 


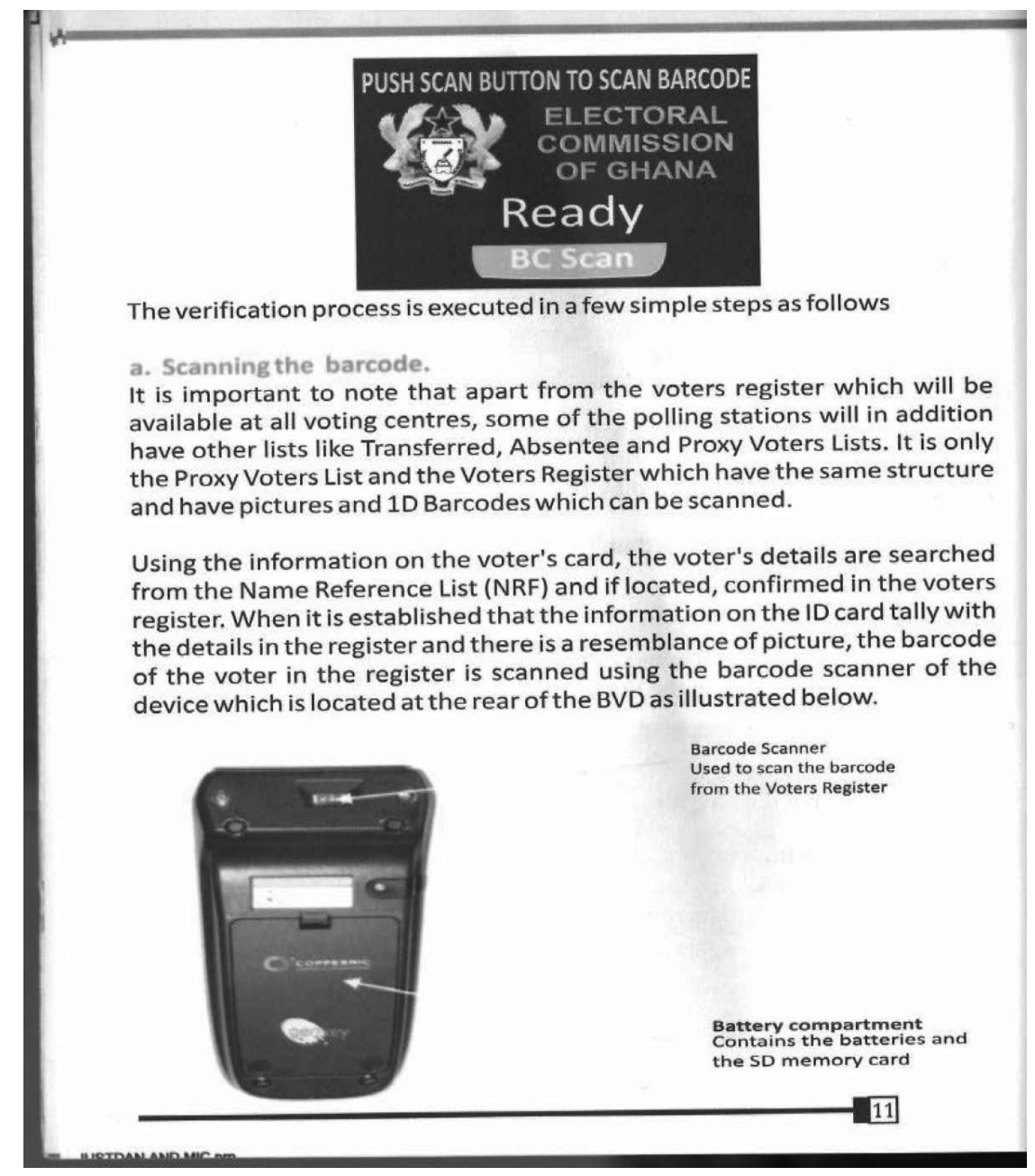

Figure 4.7: Instructions on how to scan the barcodes on register with biometric barcode. ${ }^{11}$

Language is very simple and it adheres to British English spelling style. Example are such words as "colour" and "centres." Sentences are very long. The examples above attest to this fact.

${ }^{11}$ Figure is from The Biometric Verification Device User Manual (p. 11), designed by the Electoral Commission of Ghana for the 2012 presidential and parliamentary elections. Republished with permission (See Appendix for documentation of permission to republish this material). 
More so, all four textbooks state that when writing instructions, it is necessary to state warnings clearly. Even though warnings are mentioned, they are not emphasized.

Sometimes it is hard to tell if they are warnings, and special sections not created for warnings. They are interlaced with the prose of the text. Much importance is not placed on warning signs, and they are not clear. For example, the warning that cautions "users of the barcode scanner..." in figure 4.8 (see Appendix A for permission letter) is too wordy and it is written in black ink; and the section does not present any sense of urgency:

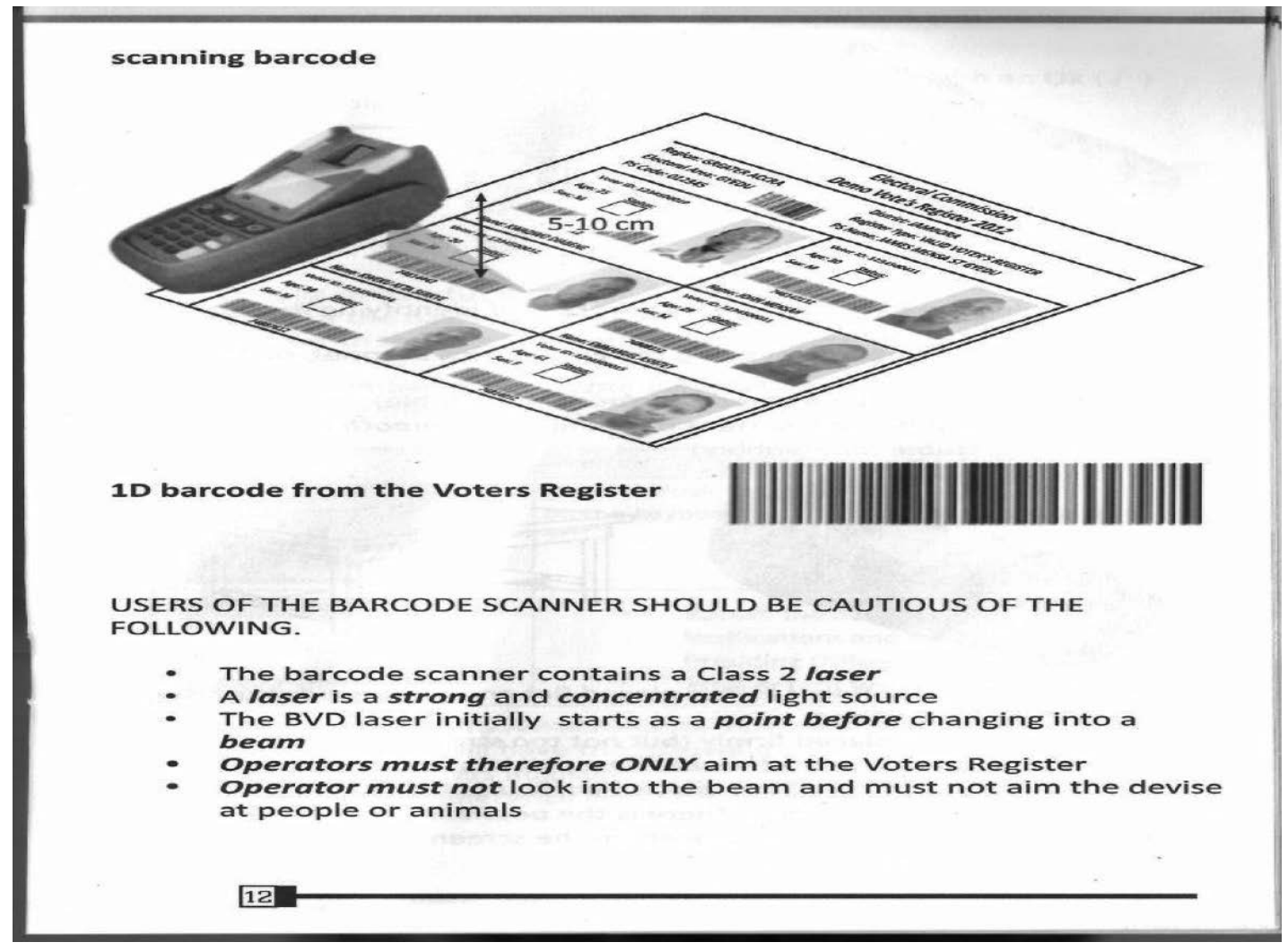

Figure 4.8: Instructions cautioning on staring at laser in the barcode. ${ }^{12}$

\footnotetext{
${ }^{12}$ Figure is from The Biometric Verification Device User Manual (p. 2), designed by the Electoral Commission of Ghana for the 2012 presidential and parliamentary elections. Republished with permission (See Appendix for documentation of permission to republish this material).
} 
Again, these sections "message requiring cleaning" (p.8); maintenance messages of the BVD” (p.6); "Low battery power" (p.6); and "sleep mode of the BVD” (p.4) captured in figures $4.3,4.4$ and 4.6 should be captured as warnings and cautions but they are not. Every sentence points to the BVD. What the manual is interested in is the biometric device and nothing else.

The user manual which accompanied the biometric device, I would argue, is a combination of what Seigel (2013) terms "system constitutive" and "system maintaining" documentation. By “system constitutive," Seigel refers to the tendency of a manual to “...argue for the future establishment of a technological system, or adoption of a technology, as a solution to an ideological, political, social problem” (p. 41). The user manual under discussion is system constitutive in the sense that it persuaded Ghanaians to have confidence in the device. Ghanaians were persuaded to believe it was necessary to adopt and use the device. If Ghanaians wanted a credible and accurate election results, then it was necessary to participate and engage in this technological enterprise. Also, the user manual could be categorized as a 'system maintaining manual' document because it works to condition users to behave in a certain way. That is, it keeps "users engaged with a particular technology or system rather than to critique or change that system" (Seigel, 2013, p. 71). These can be identified through the rhetoric that surrounded the biometric machine (more on this topic in the next chapter). By studying the manual, we get to understand why the country adopted the biometric technology, or better still, the context 
of use. It is also possible to conjecture through the analysis that users could not follow the instructions because the user manual at some point did not clearly state procedures. If an image comes without a text, as exemplified in figures 4.4 and 4.5 , it can lead to misinterpretation or miscommunication. The user also spends a lot of time trying to figure out what the image means and how relevant it is to the process. Such a manual is likely to be ineffective and irrelevant to the user. The user might want to take charge of the process by abandoning the manual. This action on the part of the user could lead to the breakdown of the technology. As I indicated in chapter three, one of the Electoral Officers I spoke with indicated that the biometric devices broke down because they identified that some Data Clerks did not follow the instructions that came with the biometric technology. Clerks would rather learn more about the system by doing than by referring to the manual. In the process, most of the machines broke down. The consequence of the breakdown was the extension of elections to the next day. This phenomenon somewhat confirms Johnson's (1998b) argument that in a lot of cases it almost impossible for users to read instructions because they "are actively engaged with a technology that is taking all of their concentration" (p. 44). The solution to this problem, he identifies, is to "have instructional texts that are visually sensitive to the users' needs as they negotiate the activity simultaneously learning the technology while "reading" the instructional text” (p. 44). 


\section{Manual as an articulation of rhetorical cultural patterns in a context}

An attempt to understand the manual leads to the recognition that rhetorical and cultural patterns of a context influence, in a way, how documents are designed. This confirms earlier studies that make similar claims. Scholars such as Thatcher $(2006,20011)$, Fukuoka et al (1999), Agboka (2012, 2013a), Boiarsky (1995) stress that documents reflect the rhetorical and cultural patterns of societies. Thus, how does this manual articulate a cultural and rhetorical value of a non-Western society? To respond to this, I turn attention to Thatcher's (2011) revelation that one of the ways to assess manuals for implicit cultural and rhetorical values is to describe the instructional manual based on "eight common human thresholds" (p.45); namely, levels of independence or interdependence among human groups (I/other); how cultures develop and enforce rules (rules orientation); definition of boundaries among what is public or private (private/public); variety of sources that guide behavior (sources of virtue and guidance); status and accomplishments; context in communication; how cultures deal with time (Time); and, how cultures deal with inequality (Power distance). These eight overarching thresholds reflect or reveal how cultures identify the self, ideologies or social values, epistemologies or thinking patterns and subjectivity, concepts I stated in chapter 3. More so, the thresholds identify how rhetoric acts upon culture in a context. Thus the thresholds enable an understanding of the dialogic and articulated relationship between culture and rhetoric; a revelation that helps understand how rhetorical-cultural methodology can be operationalized to conduct international technical communication research. Although all 
eight thresholds are relevant, I focus on how the user manual articulates four of these units: I/Other, norms or rules, status, context and power distance.

\section{Common human thresholds and their relevance to document analysis}

The I/Other threshold establishes the importance of human interaction. Essentially, it hinges on the idea that humans are social beings and thus interact with individuals or groups. This threshold, according to Thatcher (2011), "assesses the levels of dependence or independence among people" (p. 46). Basically, this threshold categorizes societies as either individualistic or collectivistic. In an individualistic society, individuals see themselves as independent and as a result, see the world through "individual identities and efforts." This sense of individualism is captured in their communication patterns, mostly, through the use of "I," "a strong bifurcation between personal and objective communication strategies; a dumbed-down readership level so as to un-complicate the interpersonal dependence of communicators; and an emphasis of personal achievement, self-creation, and reader-friendly document design patterns" (p. 47). In a collectivist society, on the other hand, individuals view themselves as dependent on others, and thus, define themselves as part of a group. In these collective societies, "communication patterns emphasize interpersonal relationships, social hierarchy, social leveraging, group identities, close personal space, and writer-friendly patterns" (p. 47).

As a born and bred Ghanaian, I can say that Ghana is a collectivist society. As Utley (2009) puts it, the social values of Ghana place importance on "social harmony and the well-being of others, not just of the individual" (p. 40). Growing up in Ghana, for 
instance, I have come to cherish the importance of the extended family and the community. Family in Ghana does not refer to mother, father and child but a close knit relationship between siblings, cousins, grandparents and other relatives. It is common for a Ghanaian child to grow up in a house that consists not only of their siblings but other relatives. I, for instance, did not grow up with my parents. At an early age, I was taken up and nurtured by my uncle who has four children. My uncle's wife also had a sibling living with us and constantly, family members from both sides visited. Therefore, at an early age, the notion that family is about people and not just siblings was drummed into my head. But how is this collectivist value reflected in the design of the user manual? As I stated in the preceding paragraph, the difference between collective and universalist values can be elucidated through assumptions made about readers or writer's rhetorical strategies. Documents are either reader-centered or writer-centered. Reader-centered writing patterns are linked up with universalist (individualist) cultures where communication relies "on overt visual designs such as headings, hanging indents, concise introductions and conclusions, lists, and other formatting devices that signal the content of instructions through visual design" (p. 288). Whereas collectivist cultures rely on "the complexity of the author's thoughts with little effort to revise the writing or design the document to accommodate different levels of audience knowledge and attitudes." (p. 289). Writer-friendly rhetorical patterns, Thatcher continues, draw “on the same tacit knowledge, non-verbal and contextual cues, and other rhetorical strategies and processes known by the in-group" (ibid). 
The user manual, I would say, is a combination of both reader-centered and writerfriendly approaches. At some point, the manual relies on overtly visual designs and visual cues, communication patterns of universalist cultures. There is the preponderant use of headings, lists and readers are babysat throughout the document. Almost every page of the document has some form of a visual cue. 19 out of the 23 body text pages has a visual cue of some sort. For example, visual cues that indicate the oblique view of the device (figures 4.1 and 4.9) (see Appendix A for permission letter): 


\section{The Biometric Verification Device (BVD)}

\section{DSERTMANOAB}

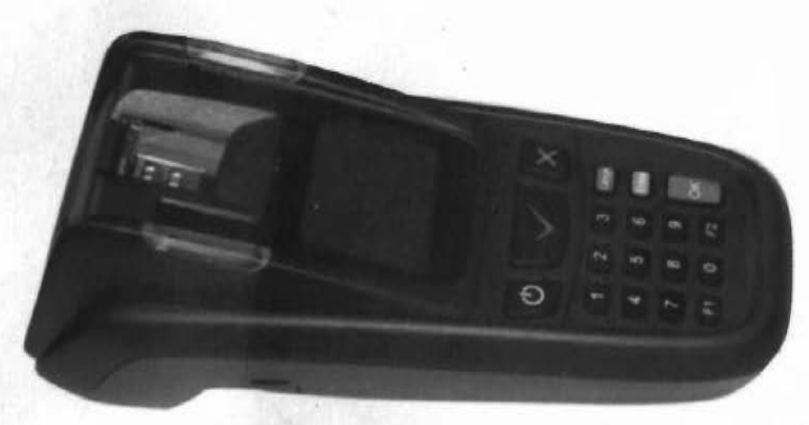

\section{Presidential and Parliamentary Elections}

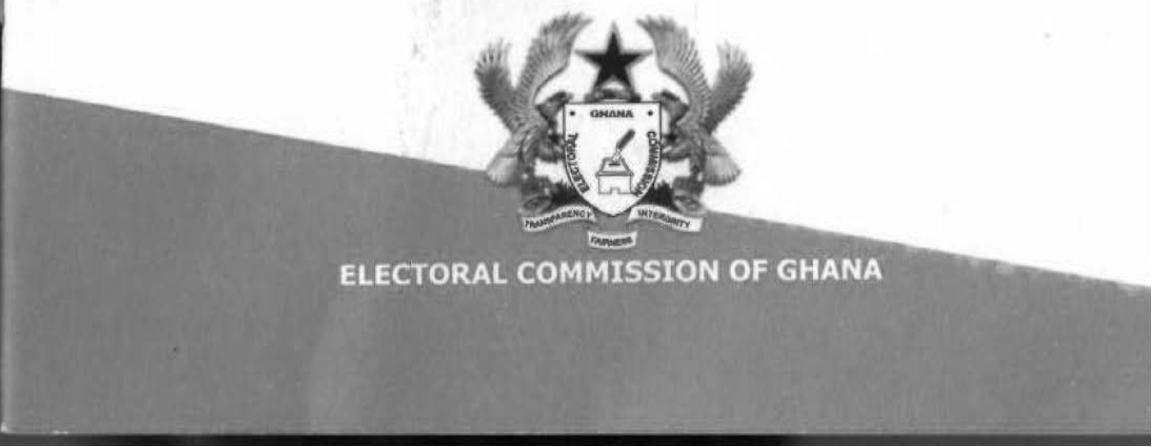

Figure 4.9: The oblique picture of the biometric device used during the elections. ${ }^{13}$

\footnotetext{
${ }^{13}$ Figure is from The Biometric Verification Device User Manual (cover page), designed by the Electoral Commission of Ghana for the 2012 presidential and parliamentary elections. Republished with permission (See Appendix for documentation of permission to republish this material).
} 
Or cues that indicate how an individual should place their fingers on the device. Example is figure 4.10:

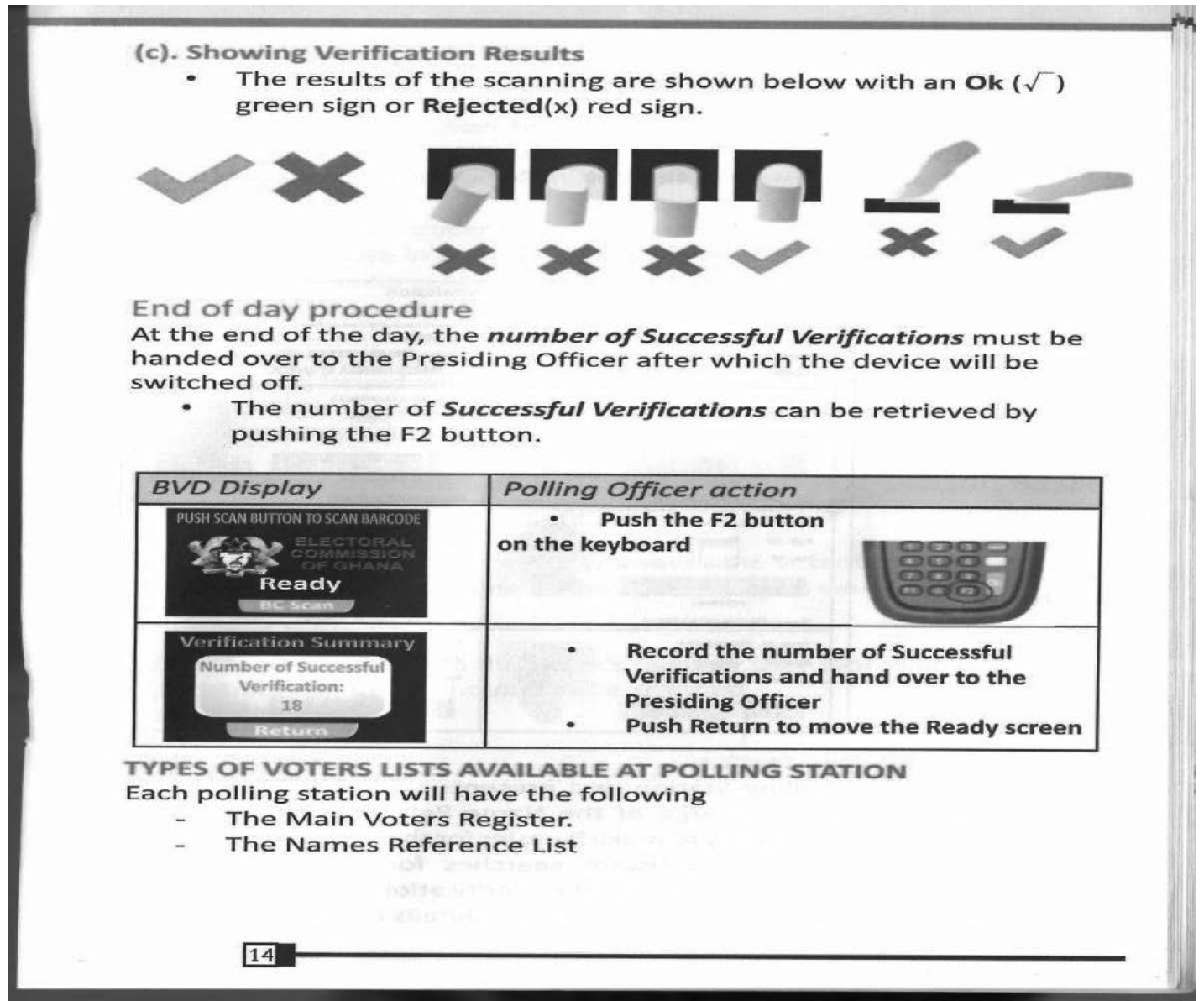

Figure 4.10: Instructions showing possible outcomes of verification. ${ }^{14}$

In essence, there is "sufficient information to accomplish all that is necessary..." (p.289).

\footnotetext{
${ }^{14}$ Figure is from The Biometric Verification Device User Manual (p. 14), designed by the Electoral Commission of Ghana for the 2012 presidential and parliamentary elections. Republished with permission (See Appendix for documentation of permission to republish this material).
} 
On another level, there are traces of writer-friendly communication approaches. For instance, the manual makes explicit statements about the audience of the document: operational staff, such as, key trainers, polling staff and stakeholders who will handle the biometric machine on Election Day. There are also instances where the manual adopts a conversational approach, indicating an oral form of communication. An example is figure 4.7 above. And in some sections, images do not come with texts that explain what those texts are (refer to figures 4.4 and 4.5 ).

The combination of collectivist and individualistic rhetorical forms gives an indication that there are instances where some cultures, such as Ghana, will adopt both Universalist and Collectivist values in their communication patterns. This, in a way, identifies the dynamic nature of the Ghanaian society.

"All cultures establish norms or rules," states Thatcher's second human threshold. But Thatcher is quick to point out that the manner in which these rules are laid out vary from culture to culture. Mostly, these rules or norms adopt a universal or a particular approach (p. 48). In a Universalist culture, laws and regulations adopt a more 'level playing field" approach. Regardless of the situation, laws and norms are enacted based on what is good and right for the society and not the social status of individuals. It operates under the dictum: all are equal before the law. Communication patterns include "strategies of fairness, justice, equality, and parallelism, and strong use of templates or branding” ( $\mathrm{p}$. 48). In a particularist society, however, rules depend on "relations and context." Common among particularist communication patterns are "emphasis of context and particular relationships; attention to exceptional circumstances; and consideration of social prestige 
and power relations" (p.48). Related to norms and rules is the fifth threshold: status. This threshold pushes us to understand how status is developed and communicated in a society. Here, scholars identify two approaches: ascription and achievement. In ascriptive-oriented cultures, status is derived from "social group, race, gender, age, ethnicity, and language" (p.55). The communication pattern of ascriptive societies is “operationalized through overt signs of ascribed status, power through people, and importance of context and history to the university" (ibid). In achievement-oriented cultures, however, status is not derived from where you come from, your family background, language etc. instead, an individual is okay as long as they can achieve their goals. Achievement-oriented cultures tend to emphasize mostly on what they have achieved when they are communicating. Achievement-oriented communication “emphasize action, change, statistics, and other observable and verifiable demonstrations of accomplishment" (p. 55).

It is not by mere coincidence that after the "forward" section is written, the Chair signs his name as Dr. Kwadwo Afari-Gyan. Most Ghanaians will attest to the fact that titles are cherished in Ghanaian societies. It distinguishes and creates hierarchy among individual members in the society, and it is "not unexpected for a society in which hierarchical relationships prevail” (Dong, 2007, p. 226). One of the cultural shocks I experienced when I arrived at Michigan Tech was the rate at which professors will ask students to refer to them by their first names. It is rare to see this attitude in Ghana. Friends have narrated stories where they have been asked to leave a lecturer's office because they did not address them by their proper title: "Doctor." The fact that the forward was written by 
the Chair speaks to the level of seriousness that needs to be attached to the user manual and the rules that have been laid out.

Issues of norms and status lead to a discussion of another threshold: "power distance." Developed by Hofstede (2010), this threshold pays attention to the various ways inequality is handled or revealed through communication. He identifies high power and low power distance approaches. High power societies use communication to reinforce and exemplify hierarchy in a society. There is, as Hofstede identifies, an "unequal, centralized distribution of power, acceptance of authority, high levels of overseeing, and top down communication styles" (Thatcher, 2011, p. 62). Communication patterns are usually top-down, strict, adhere to formalities and titles that indicate ones hierarchy in the society. In contrast, communication is less formal in a low power distance culture and it tends to ease off inequality.

I have discussed the preponderant use of visual cues and list in the user manual. Since I did not talk to users or observe them using the manual, I can only conjecture that writers assumed that by following the visuals and laid down steps, polling staff will be able to use the device to achieve set target. As indicated above, goal achievement is a trait in a Universalist approach to communication. Thus, it is believed that regardless of the educational or economic background of the polling staff, they will be able to use the manual effectively. The goal of the commission is to enable individuals to cast their votes on Election Day. Thus, every section of the manual gave information that is needed for the job to be done. As we can infer from most of the images above, the various processes and stages are broken down for the user to follow. For example figures 4.11 and 4.12 
below lay out the "general flow in polling station." These pages lay down what polling agents are to expect in regard to the flow of voters in order to help them to anticipate what work schedule will look like. They have to know what will happen and what they need at each stage of the process.

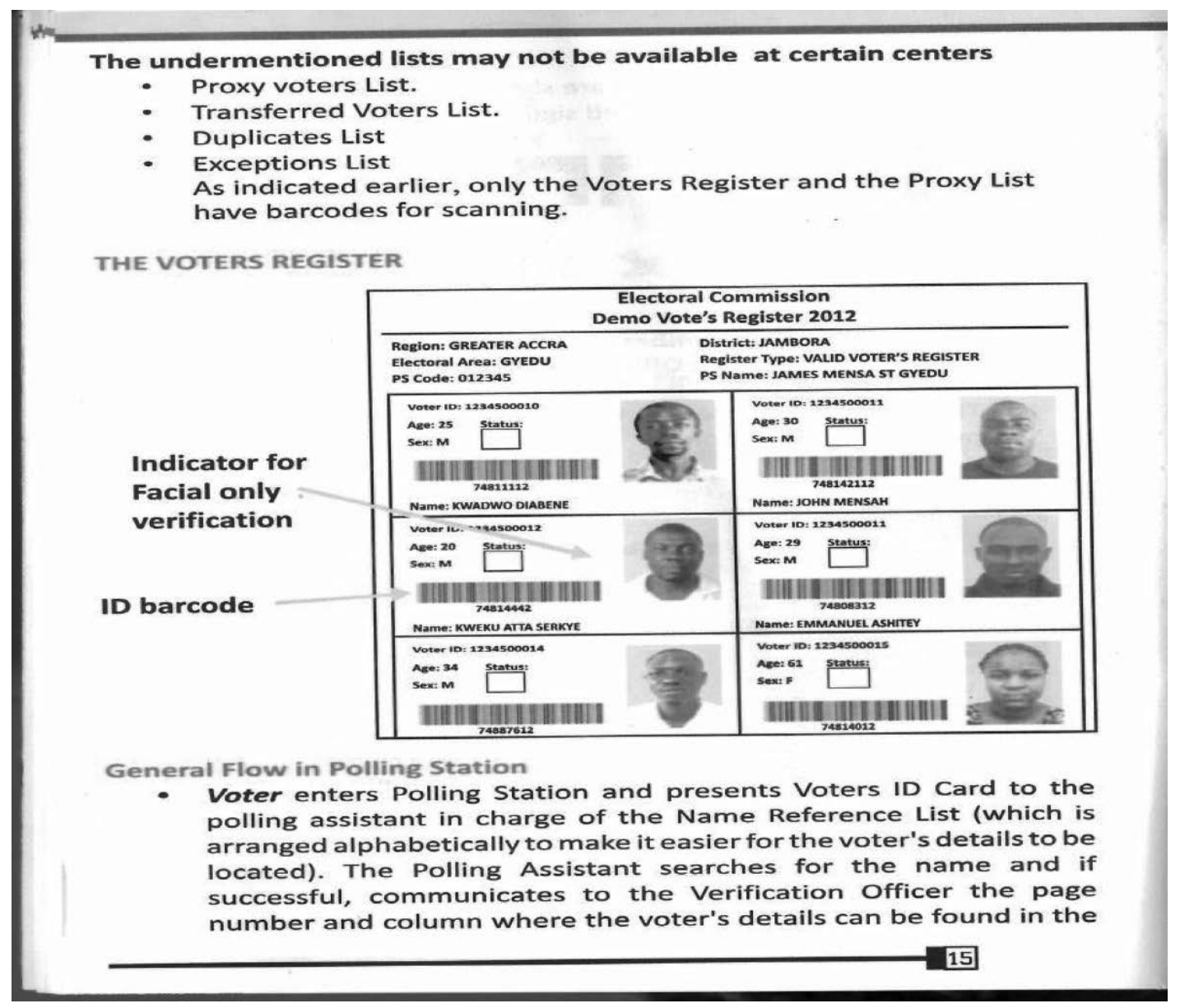

Figure 4.11: The voters register in view. ${ }^{15}$

${ }^{15}$ Figure is from The Biometric Verification Device User Manual (p. 15), designed by the Electoral Commission of Ghana for the 2012 presidential and parliamentary elections. Republished with permission (See Appendix for documentation of permission to republish this material). 
voters register. Polling Assistant then marks the voter's name on the list as having been found.

- The Verification Officer finds the entry in the Voters Register using the information provided by the Names Reference List, and the details on the voter ID card.

- The verification officer makes a determination of identity (picture on card, picture in register) and if the results are positive the barcode of voter is scanned after which the applicant's finger(s) is scanned.

- If the Biometric fingerprint scanning is successful, the voter is inked and issued with a ballot paper to vote. Verification officer then marks the voter's barcode in the register to indicate voter has been verified.

- If the Biometric Verification is not successful, the presiding officer will be alerted and he/she will take a final decision on the voter.

- In some instances the device will verify the voter by face only. This happens when none of the voter's fingers was captured during registration.

NB: It is only a barcode from the Voter's Register that should be scanned. Voter Identification Cards should not be scanned

Figure 4.12: Verification procedures for verification officers. ${ }^{16}$

I end this section with a caution: the fact that rules and norms are laid out for users to follow does not mean that the Ghanaian society follows a universalist approach at every instance. In some instances, the society adopts a particularist approach.

${ }^{16}$ Figure is from The Biometric Verification Device User Manual (p. 16), designed by the Electoral Commission of Ghana for the 2012 presidential and parliamentary elections. Republished with permission (See Appendix for documentation of permission to republish this material). 
The final threshold to discuss is the context in which communication occurs. Thatcher dwells basically on Hall's (1976) distinction of low-and-high-contexts of communication. Low context communication places emphasis on explicitly written protocols of communication rather than surrounding context. As Thatcher (2011) identifies, in low context communication societies, attention to detail is high, and communicates "all of the verbal signs and cues to carefully guide the reader through the message" (p. 56). High context communicators, on the other hand, depend on social cues to ascertain the meanings embedded in communication. "Good writing focuses on information that elucidates the influence of the social context on meaning..." (p. 57). High context communicators hardly rely on fixed guidelines. They tend to cherish non-verbal, indirect approaches to communication. Instances cited above demonstrate, again, that communication patterns of the Ghanaian society shift between high context and low context. For instance, every rule or norm necessary for a successful use of the biometric and a successful election is coded in the user manual. Aside from the steps and laid down procedure, polling staff are charged to disallow "a voter whose fingerprints are not recognized by the device." Meanwhile, "voters whose fingerprints are recognized by the device will be issued with ballot papers" to cast their votes (manual, p.1). However, there are instances where users would have to rely on the situation or external environment to make a decision. For instance, when a voter's finger print is rejected, do you send the person home instantly considering the fact that the person has been in a queue for close to 10 hours? It is important to stress that even though official voting starts at 7: 00am GMT, some voters wake up as early as 1:00 am to queue (some even start queuing a day before election). Will a polling officer have to ask someone who queued from 3:00am-2:00pm to 
go home just because the biometric device rejected the individual? When such situations occur, the "presiding officer will take a final decision on voter eligibility" (manual, p. 20) by asking voters around to ascertain the voters state. At this point, decision is made outside of the coded, written guideline. The idea here maybe that by using common sense or by depending on the context to make a decision, polling officers will be able to solve any problem they encounter during the electoral process.

These thresholds make us understand that "cultural [and rhetorical] differences are indeed a relevant factor to consider when addressing international audiences in any form of international communication," (Dong, 2007, p. 222). The thresholds could also be a way to understand why some of the sections deviated from the guidelines to instruction writing we teach in U.S technical communication classrooms. They provide a window to appreciate the essence of understanding how diverse cultural and rhetorical patterns shape document design. In this regard, when a document from another culture deviates from what we are familiar with, we are not quick to identify it as worthless. Such documents from other cultures help us to reflect on our encounter with technical documents from cultures different from ours. 


\section{Manual as an articulation of broader entanglements in a complex context of use}

In the sections above, I have worked to understand how a simple manual could not be piously followed and how a critical look at the manual leads to an articulation of the various ways that rhetorical and cultural patterns are entangled in a context. In my next section, I focus more on the second part of Seigel's statement; to be precise, I work to uncover what it means to be used by a technology such as the biometric device. As Thatcher (2011) indicates, by analyzing manuals, we can uncover assumptions societies make about technology. In my view, uncovering these assumptions will help us to articulate what it means to be used by a technology. But how can articulation help us to configure how technology uses us? In chapter two, I revealed how Slack and Wise (2005) make us understand that cultural studies approach to technology studies "considers the power of language in shaping our assumptions about technology, provides a more nuanced theory of how change happens and how agency works, ... considers the following dimensions that shape technological culture: agency, space, identity, politics..." (p. 5). To these scholars, the concept of "articulation draws attention to the contingent relations among practices, representations, and experiences that make up the world" (p. 120). More importantly, the scholars make us understand that technology studies from an articulation standpoint should open us up to discuss such issues as ideology, power, politics, gender and globalization. I add that articulation also lends to an understanding of such issues as localization, social justice, truth and subjectivity. For me these form the foundation to understanding what it means to be used by technology. To this end, in paragraphs below, I look at how the powerful use of language to represent 
and capture the magnificence of the biometric leads to an articulation of issues beyond the effectiveness and ineffectiveness of user manuals: localization, regimes of authenticity and ideology, technology disciplining body, subjectivity and identity and social justice.

\section{The user manual as it furthers knowledge on localization}

My analysis of the manual, in a way, demonstrates that such concepts as localization and user-centered design still remain at a theoretical level. Ghana uses a technology developed in a European country. There was no contact between the producer of the technology and the real users of technology. More disturbing is the idea that though the biometric technology was developed in Europe, the user manual that accompanied it was designed in Ghana by officials from the Electoral Commission and SuperLock Technologies Limited. These designers of the document may have not had any idea of how the biometric was even developed. At the mention of this, the first idea that comes up is Huatong Sun's revelation that there is almost always a disconnection between users and designers and Walton's (2013b) claim that "we still do not understand how best to design technologies to inform, connect, and empower people in resource-constrained environments" (p. 85). The core of Sun's scholarly works, for instance, contend that localization should lead to an understanding of use activities in a context. She makes us understand that a gap exists between the product designer and the user of the product. This gap is as a result of the existence of two levels of localization: localization at the developer's site and localization at the user's site. The tension between localization on the two levels should lead to the development of "an effective way to address cultural 
issues in IT localization and design well-developed products to support complex activities in a concrete context" (Sun, 2004, p. 2). In "The Triumph of Users," for instance, she admonishes us to make conscious efforts to study user localization, that is, efforts made by users to "integrate...technology into their daily lives and enhance their lifestyles" (Sun, 2006, p. 474). In this direction, Ghana's case becomes a useful way of thinking about localization because there is an incorporation of efforts that users make to localize the biometric. This is seen in how officials of the Commission claimed agency by designing the user manual that accompanied the technology. Ghana's case can best be exemplified graphically in the diagram below:

\section{Developer site (European country)}

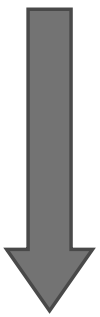

Adopted country

Real users of the biometric and manual

Figure 4.13: Levels of localization in Ghana's adoption process

In this diagram, we see a confirmation of Sun's argument that there is almost always a gap between developer sites and user sites. These two sites are never in interaction. The best way to resolve this is to link "use back to design." She contends that users 
understand their use situations more than anyone else, hence, localization should take into cognizance "users at the use phase or expanding the design process to users' sites" (p. 477). This way, we can understand "concrete use activities in local contexts while understanding cultural and structuring factors" (ibid). I agree. Similarly, Agboka (2013a) advocates a "participatory localization" in the design of documents and technologies in international or cross-cultural contexts. By "participatory localization," the author refers to the extent to which users will be involved in design phases. The user who participates in localization processes is not an isolated person, but he/she is involved as a member of a community (Agboka, 2013a, p. 42). He identifies that though technical communication scholarship is replete with ideas and notions of localization, little is done to account for user needs in unenfranchised and disefranchised cultural sites. Localization "often starts from the developer's site and trickles down to the users' site." As a result, "users are not cast as agents who initiate and implement change themselves" (p. 30).

We also have a glimpse of the role that power plays in a localization process. As the diagram above indicates, the user manual which intends to localize the biometric technology was designed by officials of the Electoral Commission. Polling officers who will use the document to help voters negotiate the voting process are never part of it. Polling officers are left out mainly because most of them are not permanent workers of the Commission. They are hired during general elections. Their jobs end as soon as elections are over. Thus the polling officer will almost always be sidelined in such design processes because he/she has a fluid identity. The interesting thing is that even though the Commission organized several training sessions for Data Clerks and other polling 
officials, most of them could not properly handle the biometric. Hence, the report that "the Commission had ... challenges such as the failure of some Data Entry Clerks to follow simple operational instructions regarding the usage of the biometric machines...." ${ }^{17}$ Ghana's case is one of the many situations where users will not come into contact with developers of the technologies they adopt and use. The gap between producer sites and consumer sites keeps widening especially when the user site is an unenfranchised cultural site that depends on donor agencies for economic support. This gap is especially problematic given the technological ideology articulated in the manual, as I discuss in the next section.

\section{Technology Adoption and Regimes of Authenticity and Ideology}

An analysis of the manual exposes the belief that the use of biometric $=$ free and fair elections. For instance, as I stated above, the Chair states that the purpose of the biometric is to detect and prevent impersonation and multiple voting. We can infer from this that the major problem that inhibits the electoral process of Ghana is impersonation. Thus, if that canker is eradicated, then the electoral process will be free, fair and incontrovertible. The Commission will thus be fulfilling their constitutionally mandated task of conducting free and fair elections. This belief that the biometric machine can correct an electoral process that has been historically, socially, politically, culturally, and legally marred by deep-seated malpractices if users piously followed laid down procedures about the system to the letter, I argue, is unfounded and an unexamined

\footnotetext{
${ }^{17}$ http://www.ec.gov.gh/news.php?news=116
} 
assumption; it is rooted in the belief that technology is a means to an end, neutral and also an efficient way of solving an age old problem in the electoral process. We are exposed to an "ideological complex based on a common sense belief in technology" (Selfe, 1999, p. xxii) and how such ideologies shape user or individual subjective identities.

"Ideology," Althusser states, represents the imaginary relationship of individuals to their real conditions of existence. It has a material existence. Mostly it refers to a system of representation and such systems of representations "always exist in an apparatus, and its practice, or practices" (1971, p. 28). To introduce a technology to "enhance the integrity of the electoral process of the country" and "to assist in the detection and prevention of practices of impersonation and multiple voting..." exposes the trust we have in technology. These statements create, in the words of Steven Katz, a technological ethos. Thus, the machine becomes the medium of truth and authenticity (Aristotle, 2014; Bazerman, 1998; Heidegger, 2014; Miller, 1978; Mitcham, 1994; Plato, 2014; Selfe, 1999; Wickman, 2012; Winner, 1977, 1986).

This belief that technology can capture truth and authenticity is questioned the more by incidents that happened during and after the elections in Ghana. For instance, at the Supreme Court of judicature, the Chairman of the Electoral Commission, Dr. Afari Gyan; the Secretary of the National Democratic Congress, Johnson Asiedu-Nketia; and the running mate of the opposition New Patriotic Party, Dr. Mahamud Bawumia accepted that incidents such as impersonation and over-voting occurred during the elections. Thus, the machine could not authentically capture impersonators. Re-presenting the biometric 
as authentic is a means of reproducing an ideology that connects biometric to safety or security. This is just a way to sell the technology.

It is interesting and disheartening to note that in spite of the positive way the device was communicated to the public, the Chair of the Electoral Commission admitted at the Supreme Court that some incidents of over voting occurred but the extent of such incidents were minimal that they could not affect electoral results (Judgement, p. 27). Or when, for the first time in the electoral history of Ghana, electoral results were contested at the Supreme Court of judicature. I can speak on authority that most Ghanaians still believe that the 2012 election was not fair, free and incontrovertible. For instance, in his concession speech after the Supreme Court ruling over the historic petition, the presidential candidate for the opposition NPP stated that even though he disagrees with the verdict, he accepts it (Group, 2014). By this, we get to question whether technologies really provide quick fixes or whether we can trust that a technology such as the biometric can deliver an incontrovertible election. Can technologies autonomously solve problems without human aid? Or does technology adoption guarantee a solution to a problem that is culturally, socially, politically and historically rooted in the fabric of social context? Can the use of the biometric really stop "macho" men from snatching ballot boxes and causing mayhems at polling stations? Can it stop coalition agents from changing figures? While users adopt technologies for good reasons, it is necessary to pay attention to the technologies because "when we fail to do so, we share in the responsibility for sustaining and reproducing an unfair system that...enacts social violence...." (qtd. in Selfe, 1999, p. xiv). The question is: how can technical communicators help users to pay attention to 
technology through the documents we design? As Seigel identified, most of the documents we produce are system maintaining and they offer little room for users to critically access the technologies that they document. How do we crossover to practices that enable the disruption of technological systems? That is, how do we work to give users the tools to "manipulate parts of the system, negotiate the systems, or change the system even in small, local way?" (Seigel, 2013).

Not only do we encounter a technological ethos, we are presented with particular forms of rationalities accompanying the biometric technology. Statements made about the efficiency of the machine in the user manual, such as, "the BVD internally checks its own status and issues messages when there is the need to perform maintenance" (p. 6) or " the BVD can perform a built-in functional self-test..." (p. 9) expose "our understanding of technology as a way of solving social problems" (Selfe, 1999, p. 116) and confirms Slack and Wise's (2005) assertion that "technologies in our culture are often linked with key values of the European Enlightenment of the eighteenth century: scientific objectivity, efficiency, and rationality" (p. 12). Though Slack et al tell stories rooted in North American culture, this assumption about technology is revealed in a non-Western society. The biometric technology presents a kairotic intervention to the age old problems bedeviling the electoral process in Ghana. These statements are forms of re-presenting the technology as a worthy tool to be trusted: it is fool proof. But is any technology $100 \%$ efficient? Little consideration is put to discuss the political nature of technologies and how technologies such as the biometric system can fail. According to Magnet Shoshana, technologies such as the biometric technology are subject to failure. She maintains that 
"the complex communicative acts between biometric scanners, individuals, and institutions are, like any communicative exchange, filled with error” (Magnet, 2011, p. 10).

\section{Technology disciplining and surveilling bodies}

Practices around the biometric technology confirm arguments made by scholars that technologies are not neutral: they shape and control the bodies of users. Langdon Winner and Judy Wajcman, for instance, contend that technologies are not neutral conduits. They wield some forms "of power and authority" (Winner, 1980, p. 121). In "Do Artifacts have Politics," Winner (1980) provides enough evidence to the effect that technologies do control, by which he implies that technologies shape and dictate the very ways that we live our lives. In my second chapter, I stated how the parkways designed by Robert Moses dictated who visited the recreational parks. Similarly, Winner's Autonomous Technology, raises the issue of control: who controls whom? What Winner presents in chapter eight of this book is the notion that though humans created technology, technology now controls humans. In an encounter between the creator and the created (monster/technology), the created tells the creator "you are my creator, but I am your master" (Winner, 1977, p. 311). The monster, in a way, is a metaphor of technology.

Even though Winner's metaphor represents technology run amok, I invoke the metaphor to indicate how technologies wield power or control over their users. The adoption of the biometric presents the metaphor of how technology controls, organizes and disciplines the body of the users. The biometric as used in Ghana scans the fingerprints of eligible voters. What is significant is the manner in which fingers are to be placed on the scanning 
machine. One cannot place their hands on the machine haphazardly. Figure 4.10 is a physical example of what it means to be controlled by a technology. What is captivating about the image is the way the machine dictates how voters can place their fingers on the machine.

Individuals going through the biometric verification system must position their fingers in a particular way. Thus there are several ways that registration could go wrong. If one positions the finger wrongly, the person will be denied access to register or access to vote. This mode of positioning, I would say, buttresses the legal code that gives the technology the power to accept who votes and who is denied access to vote. This way, the technology is shaping the positioning or the body of the individual.

By studying the manual, we also get to look at the way technologies structure our societies, especially the way we restructure our legal frameworks to make rooms for technologies. We are told that voters can only vote when they are identified by the technology. This means that one is disenfranchised if through no fault of theirs, technology fails to identify them. Since it is a constitutional requirement for a Ghanaian who is 18 years and above and of sound mind to vote, that individual becomes a subject of concern because they could not exercise their constitutional rights. We should investigate the various ways that technologies work to infringe on the rights of individuals. We must also work to critically expose legal proceedings that uncritically give too much power and authority to the technologies we adopt and use.

More so, the biometric device served as a mechanism for the "'panoptic' system of surveillance for a 'disciplined society"' (Longo, 2000, p. 80). French philosopher, Michel 
Foucault, invokes Bentham's panoptic architectural design 'the panopticon' to refer to the various disciplinary mechanisms enacted to control a society. The panoptic ensures that an individual under the surveillance system "is seen, but he does not see" (Foucault, 1977, p. 200); it is a "machine for dissociating the see/being seen dyad..." (ibid p. 202). As I have stated severally, the biometric was adopted on the premise that it was going to help curtail electoral malpractices. The device is not only to authenticate voters, it is also to control, manage and identify miscreants who intend to impersonate or cast their votes more than once because under the electoral laws of Ghana, it is considered an offence to "have your name in the voters register of more than one polling station;" or "To vote in the name of another person-living, dead or fictitious"(Electoral Commission of Ghana: A Guide to Candidates and the Agents, 2012, p. 18). It was to ensure the principle of "one man, one vote." Hence, the biometric as a disciplinary tool operates subtly as a "scare crow." The discourse surrounding the system points to the notion that whoever is not eligible will be identified by the system and the law will deal with such miscreants. In this sense, individuals who in one way or the other would have loved to disrupt the system are scared off because they do not want to face the legal consequences of their actions. The biometric induces in miscreants "a state of consciousness and permanent visibility" (Foucault, 1977, p. 201) and it is in this state of consciousness induced that reveals the powerfulness of the biometric over individuals. Hence, when the biometric exhibits its powerfulness over the individual voter, the voter is articulated as a subject to be controlled and identified by the biometric device. 


\section{Technology, subjectivity, identity}

Not only does the biometric device shape the body of users as I argued in the preceding section, it also determines the identity of the individual user. "Identity," by which I refer to who or what a person really is, occupies a central role in this discussion because the main purpose of the biometric device adopted is to assist in verifying the identity of voters. In Althusserian terms, I would say that individuals who present themselves for biometric registration and voting are interpellated or always already subjects to be controlled or identified by the biometric system. In this regard, the biometric becomes a technology that standardizes and normalizes who a citizen of Ghana is and who is not.

As I enumerated in chapter three, biometric technologies primarily work to answer two major questions: who are you? And are you who you say you are? It is through an analysis of data that has been collected and stored in biometric technology that we can respond to these questions. Even though issues related to identity: gender, race, class and ethnicity are relevant to a discussion of a biometric technology, I focus on citizenship as an identity marker. Thus, the biometric machine adopted in Ghana does not seek to clarify a person's gender, race, class or ethnicity. It worked to respond to these questions: are you Ghanaian? Are you 18 years and above? Are you of sound mind? These are questions tied to citizenship. The overarching question, therefore, is: "who is a citizen of Ghana?" Even though the 1992 constitution states categorically who a citizen of Ghana is, this definition is challenged by the biometric system. For instance, the biometric had a dual function in relation to this broad question. First it worked to authenticate the voter as a citizen. This is evident in the procedure involved in the registration process and the 
legal code binding both voters and electoral officers at the various stations. One of such legal codes is stated in the user manual: "a voter whose fingerprints are not recognized by the device will not be allowed to vote" (manual, p. 1).

The quote in the preceding paragraph indicates that the biometric worked to challenge an individual's citizenship as well. This is identified through some of the legal codes supporting the use of the machine. Ultimately, the machine must help the voter to respond to two questions that relate to their identity: first, who are you? This question is answered when the machine is able to identify or match the data that has been collected and stored in a database. Second, Am I who I really say I am? If the machine is not able to help respond to these questions then it means you are disqualified to vote. The machine therefore becomes not just an aid to a human activity such as voting, but also a powerful force that acts "to reshape that activity and its meaning" (Winner, 1986, p. 6) and the agents who does the activity. Individuals who are rejected by the system are denied access to vote. At that point, the individual's identity as a Ghanaian, who is eligible to vote is challenged. Thus, at this point, the voter suffers injustice. This development provides an avenue for us to discuss the social justice implications of technologies adopted and used.

\section{Technology adoption, social justice and the technical communicator}

Young (2011) advises that the first point of call in a social justice advocacy is to identify and interrogate domination and oppression (p. 16) in our various institutions. "Institutions," as used by Young, "includes any structures or practices, the rules and 
norms that guide them, and the language and symbols that mediate social interactions within them, in institutions of state, family, and civil society...." (p. 22). Here, I work to interrogate the structures and institutions that have a stake in the electoral process of Ghana. I also look at some laws that guide the electoral process in Ghana.

Per the definition provided by Young, the first point of call to interrogate is the Electoral Commission of Ghana as a state institution, enshrined by the constitution to organize elections in the country. If the biometric device was adopted to "enhance the integrity of the electoral process of the country" and "to assist in the detection and prevention of practices of impersonation and multiple voting..." ("The Biometric Verification Device User Manual," 2012, p. 1), then the implication is that there have been incidents of overvoting. I also do not discount the efforts being made to ensure that justice is served to all who have a stake in the electoral process of the country. But my main concern is to interrogate how we got to where we are, that is, how impersonation and multiple voting have become a common phenomenon. Thus, by paying attention to the content of the manual, we catch a glimpse of the history of elections in Ghana. Here, a document, such as the user manual does not only help users to achieve their goal, it takes us to a historical context. It helps us to question institutions and the roles they have played in ensuring free and fair elections. How can there be multiple voters even though the constitution of Ghana and electoral laws forbid individuals from voting or registering more than once? How did multiple names get on the register without officials noticing? How do multiple voters get to cast their votes? How have rules and laws governing elections been enforced? Who is to ensure that multiple names are not recorded in the register? 
Is the electoral commission the only institution to be blamed? As Young indicates, "institution," refers to a broad category of groups including civil society. Here, the individual and political parties as civil societies can be interrogated. How is it that an individual would want to register or vote more than once? Why do some people risk their lives? On another level, Young (2011) indicates that "the symbolic meanings that people attach to other kinds of people and to actions..." (p.23) must also be subjected to interrogations. Thus, in working to understand why the electoral process suffers from multiple voting, one would want to question the meanings that the Ghanaian electorate attaches to elections, to voting and to democracy. What meanings do electorates attach to these civic practices and how do these influence multiple voting? What social structures enable multiple voting? We also must bring under the microscope the role that political parties and social groups play in encouraging multiple voting. To say that the introduction of the biometric has resolved multiple voting is to belittle the whole concept of over voting because after the 2012 elections, the opposition New Patriotic Party (NPP) filed a petition to the Supreme Court of Ghana challenging the validity of the elections because they identified that over voting and other malpractices resurfaced ( Supreme Court Judgement, 3). Added to this is the more recent uncovering of " 76,000 foreigners found on Ghana's voter's register" (Daabu, 2015) by Dr. Bawumia and his team of researchers who sought to investigate the reason behind multiple and over-voting. The opposition has subsequently submitted the findings of their research to the electoral commission in furtherance of their claim that a new voter register must be compiled. This call for a new register or the cleaning of the voters register has been supported by political parties, civil society organizations, and the clergy. The calls made by the NPP 
and supported by other civil organizations give us enough cause to question whether the biometric alone can work to rectify errors when institutional structures are not strengthened and streamlined. More so, by uncovering institutional failures and calling for new voters register as a means of curtailing such practices as over voting is a social justice concern because "when people claim that a particular rule, practice, or cultural meaning is wrong and should be changed, they are often making a claim about social injustice" (Young, 2011, p. 34). The bigger question is: who benefits from over voting and who loses?

The statement captured in the user manual also implies that elections have not been clean, fair and incontrovertible. As Oquaye (2012b) states, "elections give meaning to the concept of political representation and the protection of all rights enshrined in the Universal Declaration of Human Rights and the Constitution of Ghana” (p. ii). It is unlawful for a voter to vote more than once. Thus, if an electoral system is fraught with impersonation and multiple voting, then it implies that over the years, elections in Ghana have worked to discriminate against individuals. It also implies that there has been a breach of the electoral laws of Ghana. In this case, if a candidate benefits from over voting and impersonation, then, concerns are that the said candidate was not elected on merit but through a dubious means. This leads to dishonesty. The electoral system becomes dishonest and the individuals involved become dishonest as well. Thus the machine was adopted so that justice could be served to the Ghanaian voter, the society, and the individual candidates who stood for elections. The system was meant to clean all forms of discrimination so that voters really get what they voted for. The adoption, in this 
regard, is laudable because it is a move towards "equality, respect, political and civil selfdetermination" (Sapp, Savage, \& Mattson, 2013, p. 2) in a postcolonial, dis/enfranchised cultural site.

It is captured in the user manual that "a voter whose fingerprints are not recognized by the device will not be allowed to vote: while voters whose fingerprints are recognized by the device will be issued with ballot papers and allowed to cast their votes at the polling station" ("The Biometric Verification Device User Manual," 2012, p. 1). This rule which is summed up in the phrase "no verification no vote," gives the machine the power to determine who a Ghanaian is and who is eligible to vote. Regrettably, even though this rule existed, "certain persons were selectively allowed to vote in certain polling stations without verification whiles in other places, those who failed the biometric verification test were turned away" (Oquaye, 2012b, p. 8). These forms of unequal treatment that accompanied the elections exposes the loose legal frameworks that guide the electoral process and the technology that is adopted for a specific purpose. Here, the technology, the law supporting the use of the technology and electoral officers worked in partnership to create a socially unjust election procedure. My take is that through a critical analysis of technical documents we can articulate these forms of discriminations that come with technologies we adopt and use. Through technical documentation, technical communicators can help users to critically assess technologies they use and the legal frameworks that shape their use. In this direction, scholars will be working to disrupt institutional processes that maintain systems that oppress or dominate individuals. 
In this chapter, I have demonstrated that user manual analysis proves useful in discussing and articulating broader issues. What this chapter shows is that scholars can analyze user manuals to articulate issues beyond the effectiveness or ineffectiveness of technical documents such as instruction manuals. Like Carolyn Rude, I make a case that documents have far reaching consequences than the delivery model (form): their analysis can elucidate broader cultural entanglements such as localization, social justice, ideology and the exercise of power. I do not discount the importance of analyzing documents to find out how effective or ineffective they are in hope of making them usable for the users/audience. My case is that when we focus solely on the form or usable nature of technical documents, we risk accounting for how they articulate broader social issues. More so, we risk accounting for the various ways that technical documents help to shape or articulate public policies.

In the next chapter, I will demonstrate how other set of documents - online video, parliamentary hansard, suite of posters - considered to be mundane, can articulate such issues as assumptions about technology; the consequence of technological mindsets to policy implementations. I will also articulate how the powerful use of language to represent the biometric technology can reveal issues about gender, cyborgism, somnambulism, and the political nature of technology in a context of use. More importantly, I look at how an analysis of technical documents can help technical communication scholars to participate in policies that shape technology adoption and use. 


\section{Chapter Five: Mapping the Biometric System in the Discursive-Material Practices of Elections}

In chapter four, I looked at how a study of the user manual that accompanied the biometric technology articulates knowledge about the historical, cultural, political and social justice implications of the technology that was adopted for the election. It also highlights the norms, values and assumptions cross-sections of Ghanaians have about the biometric technology. I emphasized the importance of the dualism captured in Seigel's definition of documentation: using and being used. I demonstrated that it is when we pay attention to the way we use technology and how technology uses us that we appreciate the importance of the dialogic relationship between rhetoric and culture. I further the same argument in this chapter but this time around, our attention is transposed from the user manual to three different technical documents: parliamentary hansard, online video and a suite of posters used to educate the electorate on the biometric registration process. I look at how the documents assemble to articulate users into accepting the biometric device, and how also, they open a window for us to articulate the biometric as a rhetorical artifact which has cultural significations. I share in Spinuzzi's and Zachry's view that "a genre analysis of a particular technological artifact can be useful for understanding how artifact is typically interpreted and used, but any given artifact is typically used in concerts with others: genres used in assemblages or complexes" (Spinuzzi \& Zachry, 2000).

I make two moves in this chapter: first, I look at the rhetoric of the biometric, that is, the powerful use of language to articulate the biometric in Ghana as the extraordinary 
technology that can "expose" electoral offenders, "provide transparency" in results, "prevent incidence of multiple voting" or "make it extremely difficult for a person to use the name and particulars of another voter." These words and phrases used, I contend, shaped the beliefs and expectations of Ghanaians about the biometric technology and the 2012 elections in general. The biometric technology is articulated as the "savior" or "the solution" to the electoral woes the country has experienced over the years. The success of the elections or democracy in Ghana is defined by the use of the biometric technology. In subsequent paragraphs, I will demonstrate that the representation of technology in such powerful terms or words casts a spell on users and it leads them to unreflectively accept technology. They become in the words of Winner, "somnambulists" who sleep walk through technological processes. More or less, such phrases prevent users from "questioning assumptions the media [or technical documents] present as common sense" (Kitalong, 2000, p. 292) about the technologies they adopt and use. For instance, even though it is a fact that minors register to vote, a catalyst of over voting, little was asked about how minors and non-Ghanaians were to be detected by the biometric technology.

By identifying the use of powerful language to represent the biometric, I perform an analysis of the "rhetoric of technology," by which I mean, “...the rhetorical productions that surround a material technology" (Bazerman, 1998, p. 381), the biometric. Important scholars I will dwell on are Carolyn Miller, Charles Bazerman, Steven Katz, Karla Kitalong and Amy Koerber. Through the documents analyzed, we identify that the biometric is articulated in a matrix of totalizing metaphors: success, hope, progress, truth, 
accuracy, efficiency, credibility and simplicity. Five threads of arguments extol the powerfulness of the biometric. The technology is articulated as:

- a very simple system to use;

- a credible source of information because it collects data that is connected to one person and no one else;

- the surest solution to the emerging challenges in the electoral system;

- a technology which can prevent incidents of multiple voting; and

- a technology which is able to expose perpetrators

My second move will look at how the articulation of the biometric provides a window for a fruitful discussion of the role that technology plays in human affairs and how a technology like the biometric shapes the material lives of its users. In a way, I take a critical look at the rhetoric surrounding the biometric. Here, I will dwell on such scholars as Donna Haraway, Michel Foucault and Judy Wajcman. In paragraphs that follow, I describe and discuss how these genres work in assemblage to articulate and rearticulate knowledge about how the biometric is constructed as a rhetorical artefact at the vortex of cultural entanglements. At the end of this discussion, some of our knowledge of the biometric will be destabilized or disarticulated.

\section{Online video: accommodating biometric to users}

The first genre under discussion is a 2 minutes online video: "Biometric System Voter Registration Process" developed by SuperLock Technologies, the organization that provided the biometric to the Electoral Commission. The goal of the video was to educate the electorate on the electoral process and how important the biometric was to the success 
of the elections. The video offers a widespread source of information about the biometric technology. It, in a way, "dumbed down" the process of verification and registration for the audience. Through the video we encounter "how to behave and what to think, feel, fear, and desire - and what not to" (Kitalong, 2000, p. 291) about the biometric technology. This video was a conversation between three voters: Kofi Ghana (an elderly man who seems to know more about the biometric) educating two voters; a man (no name) and a woman (no name) on the biometric registration process. I present the drama as it enfolded in the video:

Kofi Ghana (an elderly man), bedizened in a chiefly apparel walks to two voters who seemed confused about the biometric process. This is what transpired between these three characters:

Man: Kofi Ghana, what is this biometric registration all about?

Kofi Ghana: [laughs and says] oh it is very simple. Biometric registration is simply the collection of information that is only connected to you and no one else// like your finger prints and your photo graphs so that when we say it is you we know it is you.

Woman: Kofi so what do I need to register?

Kofi Ghana: Registration? Simple! First you must be a citizen of Ghana, eighteen years or older and you must present some form of identification like your old voters ID, National ID, passport, National health insurance card, driver's license or two guarantors to vouch for you.

Man: so how does the registration process work?

Kofi Ghana: oh...very simple. The registration process is in three stages. Stage 1 is to complete the form with all your personal details//like your name and age and so on...; stage 2 is where the registration officer enters all your information onto a laptop with your finger print capture using a finger print scanner, your photograph using a webcam and then a printer prints out all the details for your voters card; stage 3 is the final stage where your voters ID is prepared for you to collect, Simple!

Woman\& man: wow, so is really that simple!

Kofi Ghana: No biometric verification No vote. One man one vote that counts. 


\section{Online video as it articulates rhetorical cultural patterns}

The first point to comment on is the character Kofi Ghana. For me, the use of a character who bears a Ghanaian name and attribute is a way of localizing the biometric. By this I mean, the "process of creating or adapting an information product for use in a specific target country or specific target market" (Hoft, 1995, p. 3). The concept of localization, Hoft identifies, helps producers to balance business needs and cultural understanding of people who need to learn how to use high-technology products (p. 3). As global economies merge, it has become necessary for producers of technologies and artifacts to localize their products to meet the needs of users (Agboka, 2013a, 2013b; Hoft, 1995; Salvo, 2001; Sun, 2004, 2006, 2009a, 2009b, 2012; Thayer \& Kolko, 2004). Hence, a technology which was adopted from a European country is communicated in a way that will make meaning to the Ghanaian electorate. Kofi is an Akan name for a Ghanaian male born on Friday; and his surname (last name), Ghana, gives an indication that he comes from Ghana.

Another attempt to localize the technology is seen in the manner in which Kofi Ghana is dressed. He wears kente, a rich royal cloth worn only on special occasions such as festivals; a native sandal and a crown. These are symbols of authority and kingship in a cross-section of the Ghanaian society, especially those in the southern part of Ghana. We witness an attempt to accommodate technology through an elevation of one of the varied customs of Ghana, chieftaincy. A chief, as Utley (2004) posits, is an "amalgam of political head, religious head, judge, war leader, and advisor" (p. 64). Even though the chiefs' power has been lessened as a result of the practice of Western forms of 
democracy, he is still respected in the Ghanaian society. Thus, to use someone who epitomizes chieftaincy is in a way to first try to localize the technology and second communicate the credibility of the biometric technology. Here, Kofi Ghana, the epitome of the seat of traditional wisdom and power adds what Aristotle calls "ethos" to the biometric. In Rhetoric, Aristotle outlined the modes of persuasion. The first mode of persuasion depends on the speakers character; the second focuses on putting the audience into a certain frame of mind; the third provided by the words or logos of speaker (McKeon, 2009, p. 1329). In the first mode "persuasion is achieved by speaker's personal character when the speech is spoken as to make us think him credible" (McKeon, 2009, p. 1329). Aristotle believes that we believe good men readily, thus, speakers must be able to create impressions with what they say and not what people think of their character. Thus it was not mere happenstance that STL chooses a seat of authority as the accommodator of the technology to the electorate. When the speaker creates good character impression, it must stir the emotions of hearers (McKeon, 2009, p. 1330). As you can infer from the conversation above, the two listeners represented a cross-section of Ghanaians who were confused about what it means to be registered biometrically. Ghanaians, at that point needed a more credible authority to listen to. At this instance, the best person to be listened to is the chief, an epitome of truth, power and wisdom. The Akans of Ghana have a saying which goes "there are no bad chiefs, only bad advisors" (Utley, 2004, p. 67); this speaks to the trust and respect that Ghanaians hold for the traditional seat of authority. 
Kofi Ghana also, in a way, is cast in the "expert/novice" binary that Johnson refers to in his book User-Centered Technology, and the two compatriots are the "idiots" who need to be dumbed down with information about the biometric technology. The response they provide "wow, so is really that simple!" could possibly speak to the fact that not only the American culture (referring to Johnson's case) celebrates technological idiocy but also the Ghanaian user of technology is captured in a similar metaphor. The two electorates, possibly representing a cross-section of Ghanaians, are represented as not having any knowledge of the modus operandi of the biometric, hence, they needed to "have everything provided to them in an easy-to-use format that asks little of them in return" (Johnson, 1998b, p. 44). The interlocutors in the video, "not only present information and practical knowledge about [biometric] technology [as it is to be used in Ghana], but also creates, and sustains consumer's optimistic expectations" (Kitalong, 2000, p. 290). We become privy to the way the EC in Ghana and cross-sections of Ghanaians established norms, values and impressions about the biometric.

As technical communicators, by which I refer to those who help "accommodate technology to users" (Dobrin, 2004, p. 118), we could be tempted to cast users as idiots who know little or nothing about technologies and as a result "dumb" information down on them. It is as a result of this that we have been urged to help users of technologies to be critical of the artifacts they consume (Kitalong, 2000). This call by Kitalong is reechoed by Blake Scott's call for a critical scrutiny of the representation of technologies. As Kitalong (2000) contends, technical communicators can help consumers to pay attention to technologies by critically assessing the "magical terms," by which she means, 
an attention to use "optimistic discourses... [that] either deliberately or inadvertently imply that technologies possess transformative powers that require no human intervention" (p. 293). One of the reasons why we should do this, Kitalong states, is that technical communicators like several other users of technology are "interpellated — hailed or addressed" by discourses about technology. In another direction, technical communicators are also creators of technical discourses (pp. 290-291). While I agree with Kitalong that technical communicators play a dual role in Western techno-culture, I would want to add from the instant that this third reason must and should be extended because it is a factuality that the roles of technical communicators now extend beyond Western frontiers. So instead of making a case that technical communicators offer dual roles in Western cultures, I extend to include non-Western contexts. We must look at the various ways in which technologies are represented in non-Western contexts. These way, we are educated on how users outside Western societies relate to technology. It is by studying non-Western societies that our role in a globalized society can be felt the most. Also, as I discussed in my first chapter, an attention to non-Western society provides an alternative or a diverse perspective on literature about issues that expose the relationship between humans and technology.

In this video, we encounter the syllogistic argument that the use of biometric= fair and successful elections: biometric becomes an object of celebration. The biometric registration process becomes the means by which accurate information about voters and citizens can be gathered and stored for the purposes of verification, and more importantly a means by which electoral malpractices can be curtailed. In this regard, the designers of 
this online video, cast in what I will term "technology accommodators," perform similar roles as scientists who accommodate scientific information to non-experts. Fahnestock (1986) identifies that accommodators of scientific reports are "overwhelmingly epideictic; their main purpose is to celebrate rather than validate"(p. 333) by making "all references to the amazing powers and secrets" of the biometric technology through "wonder" appeals. Through the conversation among the three interlocutors, we can scrutinize the biometric "by picking apart the conjunction of the powerful discursive forces that create value for and give shape to technological developments and their uses" (Bazerman, 1998, p. 387). The biometric system becomes the embodiment of truth, accuracy, facticity and a means of control. We could identify from the above representations that the biometric system really "affected the technical imagination" (Miller, 1994) of a cross section of Ghanaians so "powerfully."

Also, the fears of Ghanaians were allayed and a faith about success of elections is built through biometric discourses. As I indicated in chapter one and as I will discuss later, a cross-section of Ghanaians had lost confidence in the electoral process owing to such malpractices as over-voting, electoral fraud, vote rigging, and impersonation; hence, to assure those who have lost confidence that a technology will ensure that no one can vote twice is to, in a way, increase their confidence in the electoral process. Thus, such phrases as "biometric registration is simply the collection of information that is only connected to you and no one else," "registration officer enters all your information onto a laptop with your finger print capture," "one man one vote that counts" instills confidence, faith, trust into the system. The voter is assured that only those individuals who are 
registered can vote. In essence, impersonators will be weeded out from the process and results will be accurate and reflect the free, fair and incontrovertible results that Ghanaians have been yearning for. Little though, was said about how the biometric will ensure that minors, that is, those under the age of 18 and non-Ghanaians will be prevented.

We also encounter notions of truth and authenticity in the rhetoric surrounding the biometric. The three stages that voters must go through enables the biometric technology to capture the image of individual voters. It is through the various images that have been captured that the biometric can prevent impersonators from voting because individual unique identities are established, coded and stored. As I indicated in chapter three, these processes enable the biometric and voters to respond to two questions that form the heart of biometric technologies: who are you? And are you who you say you are? Questions that supposedly lead to a truthful identification of subjects who present themselves to the technology. These questions in the words of Pugliese (2010) "underline the manner in which biometric technologies transmute a subject's corporeal or behavioral attributes into evidentiary data inscribed within regimes of truth" (p. 3).

The stages of registration also help us to understand the biometric not as a single device; instead, it is an articulation and assemblage between the biometric device, computers, scanners, electoral laws, voters, and electoral officers. Hence, it will be limiting to define technology as an object (Mitcham, 1994; Winner, 1977); instead, the notion of technology should draw "attention to the contingent relations among practices, representations, and experiences that make up the world" (Slack \& Wise, 2005, p. 120). 
Looked at from the perspective of articulation and assemblage, technology is not autonomous but integral to the context within which it is produced and used; culture is not separated from the connections that are made between technology use and production; and technologies emerge as part of the connections and within the various connections. We can thus talk about technology as a system. The articulations that accompany the biometric help us to understand Winner's (1977) statement that technology, "a concept that was once very specific in the way it was used has now become amorphous in the extreme" (p. 9). Technology has expanded in both denotative and connotative terms.

Finally, the use of phrases and words such as "very simple," "expose," "collection of information that is only connected to you and no one else" help us to understand how the ethic of technological expediency discussed by Steven Katz is employed in a nonWestern context. Dwelling on Aristotle's concept of ethos, Katz makes us understand that when we perceive of technology as an embodiment of objectivity, truth and power and thus make arguments for its adoption and use, then we fall prey to the ethic of expediency: "science and technology become the basis of a powerful ethical argument for carrying out any program" (Katz, 1992, p. 264). When this happens, technology becomes both a means to an end and an end itself. The impression we create is that technology is autonomous and deterministic, it is "its own raison d'etre and driving force in culture" (ibid p. 266). The consequence of technological expediency is that technology becomes a form of consciousness and our actions are exhibited in discourses that favor impersonality, closed-system thinking, narrow mindedness and non-responsibility 
(Miller, 1978, p. 235). We also think in terms of efficiency and mathematization. More so, we are "enframed" and become "standing reserves," Heidegger expounds.

I am not making a case that the ethic of expediency that was operationalized in Ghana so that the public will accept the biometric system is similar to the ethic of expediency used by Nazist Germany (see Katz, 1992), I am saying that the decision to adopt the technology was based on the assumption that technology can solve the problems that underpinned our general elections. This assumption could be problematic because technology is not always objective, efficient and neutral. The consequence of placing too much faith in the powers of the biometric was the eight months legal tussle at the Supreme Court over the veracity of the electoral results; and the current impasse over the state of the voters' register. As I stated in chapter four, political parties and some civil societies presently doubt the credibility of the voters' register. This lack of trust in the voters' register has increased following the opposition NPP's uncovering of 76000 nonGhanaians on the voter roll. As it was indicated throughout the electoral petition and as I will indicate later, technologies are subject to breakdown, as much as they are subject to manipulation by users. When we place all our hopes and desires in technology, we run a risk of making erroneous decisions. It testifies to the fact that ethic of expediency is not only predominant in Western cultures, as Katz insinuates, but also, it is predominant in a non-Western society. I argue that the ethic of expediency was adopted and used to represent the biometric to Ghanaians.

As I have indicated in the above discussion, the language used to describe the biometric in this video leads to the examination of discourses and "patterns of thinking...concerned 
with the development, production, and marketing of artifacts and practices" (Miller, 1994, p. 92). These discourses also provide "a tool that facilitates meaning making about technological aspects of the world" (Koerber, 2000, p. 59). We come to understand that technologies are always already rhetorical because we develop technologies to meet the needs of humans and they are always "part of human needs, desires, values, and evaluation, articulated in language and at the very heart of rhetoric" (Bazerman, 1998, p. 383). More so, technologies must go through several publics for approval before it becomes a material reality. We can infer from the discussions above and subsequent discussions that rhetoric of technology is about discourses that make users develop faith in a material object. I would want to add that not only is it about discourses that make technologies come to be, it is also thinking about the ways that we make these artifacts come to exist in the world. Bazerman, Miller and Koerber make us understand that technologies must be accepted by intended users before they become a material reality. Hence, there must be arguments made for the value of these technologies at different levels. As we have identified, different arguments were made at different levels for the biometric technology. The biometric as used in Ghana becomes the medium through which we can discuss issues such as truth, authenticity, and even the relationship between humans and technology - a subject that will be elaborated in the next section.

\section{Biometric as a cyborg technology}

Here, I critically assess the relationship between the biometric technology and material lives of voters. I discuss the biometric as an example of a cyborg technology. In chapter 1, I defined the biometric technology as a system which "scans a subject's physiological, 
chemical or behavioral characteristics in order to reify or authenticate their identity" (Pugliese, 2010, p. 2). This definition is well exemplified in Kofi Ghana's statement that the biometric is "simply the collection of information that is only collected to you and no one else// like your finger prints." These two definitions make an explicit statement about the biometric: it is a fusion between a part of the human body and a technical device. In other words, it is an intimate, complex and dynamic relationship between the human body and a technology. The various stages of verification and authentication blur the boundary between technology and humans. According to Haraway (1991), a cyborg is a "cybernetic organism, a hybrid of machines and organism, a creature of social reality" (p. 149). A cyborg intermingles organisms and machines, "each conceived as coded devices" (ibid p. 150). Hence, embodiment plays an important part in biometric discussions. In biometric systems such as the one Ghana used for the election, "the body...itself becomes a most engaging being" (ibid Haraway, 1991, p. 199). The biometric becomes what I term a "biocyborg" because it needs a part of the body to function and biological information, in turn, finds a permanent dwelling in the algorithms generated by the device: a symbiotic relationship, I would argue. It is through this symbiotic relationship that we encounter the political nature of technologies (topic for next section) or the various ways that technologies such as the biometric control.

The point, thus is, cyborg ideas cannot be applied to only Western societies. In a globalized world where technologies are constantly being transferred from one context (usually Western societies) to the other (mostly unenfranchised cultural sites), such ideas as cyborg move along with the technologies. Thus, Ghana's case becomes a tacit point to 
look at how technologies that are adopted exhibit tendencies that are similar to or different from how biometric functions in a Western society. Through the concept of cyborg technology, we encounter biometric as "the complex intersection of bodies, subjects, technologies and power" in both non-Western and Western societies.

Not only is the biometric a cyborg technology, the voters are implicitly interpellated to be part of the cyborg world: they are always already cyborg citizens. As part of its modus operandi, the biometric as a cyborg, theorizes and maps the body "as a coded text whose secrets yield only to the proper reading conventions" (ibid p. 206). When the voter goes through the various stages of registration; when the voter's finger prints are captured and when the biometric machine processes the captured image into codes, the voter's body is "thoroughly denaturalized" (p. 208); the body becomes "a coded text" that can be ordered, structured and interpreted. More so, the body becomes a raw material that is “...appropriated, preserved, enslaved, exalted" (ibid p. 198) and turned into codes by the biometric cyborg. The body is reified in the process. As Haraway (1997) puts it, "the moment of reading and scanning, of being read and being scanned, is the moment of vulnerability through which new articulations are made" (xiv). As we shall encounter in the next section, it is through vulnerable moments; through the process of reading and being read; scanning and being scanned; it is in these dualisms that technologies exhibit their control and their political nature.

\section{Biometrics and the politics of technology}

In the case of Ghana, the biometric technology becomes the means by which the country can record a free, fair and incontrovertible elections. As Kofi Ghana tells us "No 
biometric verification No vote;" or as it will be discussed later, the biometric will "expose" perpetrators. Ultimately, the biometric technology, "a techne, has become politeia" (Winner, 1986, p. 55); that is, the biometric has become political in the sense that it has become "a way of settling an issue in the affairs of a particular community" (ibid, p. 22 ) such as Ghana. Ghana's case provides two senses for us to discuss the political nature of the biometric technology. First, it intermingles with the human body in order that accurate information about individuals are gathered and stored for algorithmic codes. As we have realized from the preceding discussion, "if there is no body, then there can be no biometric as such," (Pugliese, 19). In this regard, through an analysis of the biometric system we can even diffuse the notion that there is a binary between body and technology. There is, as Pugliese states, "an inextricable relation between bodies and technologies" (p. 20). Second, it decides who may vote and who may not vote. This idea is captured in several ways. In chapter four, for instance, I revealed how operation officers were legally bound to turn away "a voter whose fingerprints are not recognized by the device...: while voters whose finger prints are recognized by the device will be issued with ballot papers and allowed to cast the votes at the polling station" (manual, p. 1). In Kofi Ghana's narrative, we are told that "no biometric verification, no vote;" and in the Parliament of Ghana, members of the House agreed that "voters shall go through a biometric verification process to cast their votes" (Hansard, p. 786). In essence, the biometric assumes a very political position. It becomes not just a part of an activity such as voting, it shapes the entire electoral and legal processes circumscribing the use of the biometric. To this end, we can discuss the biometric not only as a manifestation of a cyborg technology, but also, in terms of biopower. 
By biopower, I draw on Foucault's (2009) concept of biopolitics referenced in his lectures on security, territory and population as a "set of mechanisms through which the basic biological features of the human species became the object of a political strategy, of a general strategy of power, or, in other words, how starting from the eighteenth century, modern Western societies took on board the fundamental biological fact that human beings are species" (p. 1). And exemplified by Haraway (1997) as "the practices of administration, therapeutics, and surveillance of bodies that discursively constitute, increase, and manage the forces of living organisms" (p. 11). Biopower, for Foucault becomes a technique used to control people or populations. It is in a sense the ability to exercise power over bodies so that truth about individual voters are captured. This way, it is believed, results will be transparent because there will not be multiple voters.

Even though Foucault's biopower makes explicit reference to Western societies, discourses generated about the biometric in Ghana, a non-Western society, make tacit reference to ideologies inscribed in Foucault's biopolitics. For instance, Kofi Ghana tells us that when voters go through the biometric verification process, "information collected" will be connected to "you and no one else." Hence, the quest to achieve a free fair elections will be met and results will be "transparent." In this direction, the biometric becomes a technology that enhances truth and accurate results. In chapter four and later in this chapter, I refer to this belief in the biometric as an ideology. Thus, I refer to the biometric as a biopolitical technology because it served as a mechanism that restricted miscreants from voting or registering twice. The biometric ensures "one man one vote." I must also say that even though the biometric could be used differently at different places, 
its use no matter the context, establishes a truism: the binary between technology and humans is becoming blurred and increasingly, humans are becoming over dependent on technology.

\section{Biometric as the articulation of gendered patterns ${ }^{18}$}

Ghana's adoption of the biometric helps to advance a case that increasingly, as technologies such as the biometric are advanced, societies will depend solely on these technologies to explain or define who they are and what counts as truth. Hence, technologies such as biometrics will be able to speak humans and assign meaning to who we are or what we are (Koerber, p. 66). An example of a technology speaking human can be identified in the processes voters in Ghana would have to go through before they cast their votes. As I stated in chapter four, one of the major laws that backed the biometric stipulates that voters can only vote when biometric recognizes the fingerprint of the voter. This is exemplified by the stages laid out by Kofi Ghana in the video I analyzed and made more concrete by Parliament's institutionalization of a Constitutional Instrument that ensured that "voters shall go through a biometric verification process to cast their votes" ("Parliamentary Debates: Official Report (Emergency Meeting)," 2012, p. 786). If the biometric fails to recognize finger, that individual is not allowed to vote. Thus, the biometric becomes a speaker of an individual voter's identity. It must confirm that you are you before you can vote. These practices of going through different stages to be scanned, identified, verified and registered are forms of what Scott calls "disciplinary

\footnotetext{
${ }^{18}$ I owe the development of this section to Dr. Gerald Salvage. When he reviewed a paper I submitted to a journal for publication, he pointed out how the phrase "one man one vote" can lead to the discussion of the biometric technology and gendered nature of democracy in Ghana.
} 
rhetorics." These disciplinary rhetorics work to shape "people as particular kinds of subjects and subjects them to various exercises of power" (Scott, p.7). This is a notion I elaborated on in my previous section and will return to as I advance my argument in this chapter.

If we are becoming dependent on technology, and if technology speaks about us, through verification and identification, then Koerber (2000) admonishes us to pay attention to the various ways that technologies become "speakers of meanings assigned to...gender" (p. 66); a reiteration of Durack's (1997) assertion that technology may have gendered meanings. I state that we could, somewhat, read a gendered meaning into the biometric usage in Ghana. As is stated in the video, the biometric ensures that "one man one vote that counts." Why should it be "one man, one vote" and not a different statement? Are women not allowed to vote in Ghana? Perhaps, we may say that this statement was made because of a cultural blinder that makes it difficult to filter the various ways that discourses about technology or technology use come pregnant with gendered meanings. It could, perhaps be an example of what Durack terms an "unintentional bias" or a neutral statement, but no matter the direction we take it, whether it is literal or not, the phrase confirms statements by some feminist scholars that technologies are gendered and mostly come clothed in masculine terms (Durack, 1997; Haraway, 1991; Koerber, 2000; Wajcman, 1991). This statement reflects Koerber's (2000) elaboration of critiques feminists have leveled against technology: first, technology is intrinsically linked to masculine ideology; second, technology shapes the way we think about gender and humanity; and third, technology is perceivably neutral and objective (pp. 63-68); and 
Wajcman's (1991) claim that "the very language of technology, its symbolism is masculine" (p. 19). This intricate relationship, Wajcman argues, is not inherently biological but it is as a result of how gender has been culturally and historically constructed. As innocent as the statement made by Kofi Ghana may be, it is, I would argue, one of the instances where the role that women play in technological or political discourses are sidelined. The man is technological, the woman, a passive, private, sidelined consumer of an artifact.

Even though these feminist arguments are made in regard to the relation between gender and technology in Western societies, I make a case that it becomes relevant in a nonWestern society because it provides avenues for scholars to interrogate the various ways that technologies that are adopted by non-Western societies carry the stigmata of Western cultural ideologies. It paves a way to, as a matter of urgency, investigate the ways "gender affects both access to technology and the practices of users of technology" (Wells, 2010, p. 151) in a non-Western society. We can also begin to interrogate how women in non-Western societies, such as Ghana, have been represented in technological and democratic discourses. The ultimate question to ponder over is does the representation of the biometric as a technology which ensures "one man one vote" reflect the cultural, historical, rhetorical and political relationship that have existed between men, women and technology in the Ghanaian society in general? Does this phrase reinforce Wajcman's (1991) claim that technology “fundamentally embodies a culture?” (p. 149). Or does it reflect statements made by Wajcman (1999) and Reed (2014), for instance, that technologies do carry imprints or biases of their creator? Since the 
biometric was not developed in the country, can we make a case that the device carries a bit of the cultural bias of the production country? To an extent, I will respond to these questions I pose in the affirmative. The idea that the biometric ensures "one man one vote" cannot be taken lightly. It provides a way for technology accommodators to think critically about the language they use to represent technology to users or customers.

The statement I have been commenting on, "one man one vote that counts," provides an avenue to discuss gender, technology and democratic culture in Ghana because even though the call for the participation of women in national governance began half a century ago, response to this call has been snail paced. For instance, the number of women in Parliament decreased from 25 in 2008 to 19 in 2012. This retrogression made Oquaye, for example, wonder what the number will be in 2016 (Oquaye, 2012a). The diagram below curled from Manuh (2011) graphically represent women's participation in democratic governance in Ghana.

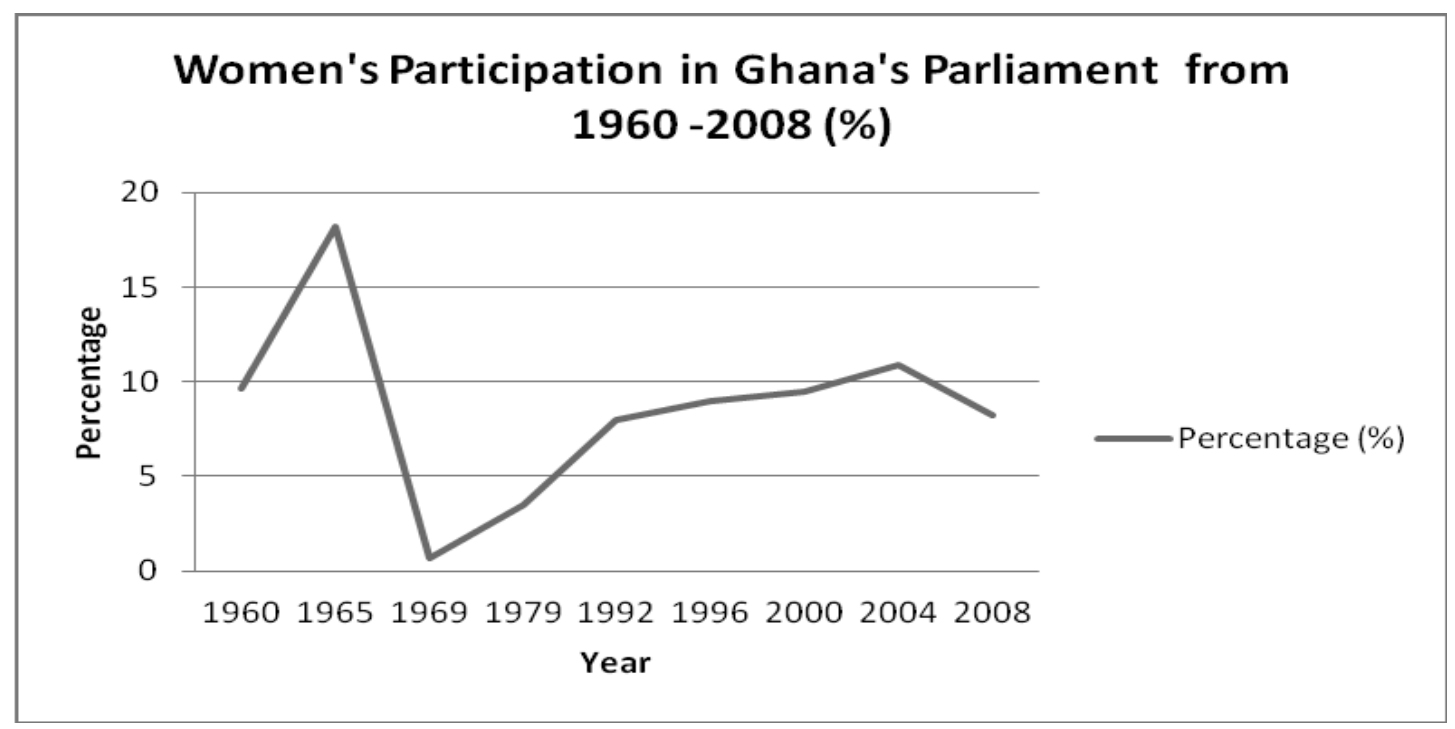

Figure 5.1: Women's Participation in Ghana's Parliament from 1960-2008 (\%) 
Table 5.1: Women in Parliament in Ghana. The table below was curled from Oquaye's "Reserving Special Seats for Women in Parliament"

\begin{tabular}{|c|c|c|c|c|c|c|c|c|c|}
\hline Year & 1960 & 1965 & 1969 & 1979 & 1992 & 1996 & 2000 & 2004 & 2008 \\
\hline No. of seats & 104 & 104 & 140 & 140 & 200 & 200 & 200 & 230 & 230 \\
\hline $\begin{array}{l}\text { No. of Women } \\
\text { in Parliament }\end{array}$ & 10 & 19 & 1 & 5 & 16 & 18 & 19 & 25 & $20^{19}$ \\
\hline $\begin{array}{l}\% \text { of Total in } \\
\text { Parliament }\end{array}$ & 9.6 & 18.2 & 0.7 & 3.5 & 8 & 9 & 9.5 & 10.8 & 8.7 \\
\hline
\end{tabular}

This call for women to be part of democratic processes is on the ascendancy in Ghana because even though the participation of women in "national governance" is "a requirement of democratic governance and a condition for achieving the Millennium Development Goal" (p. 1), their participation still linger below the minimum $30 \%$ the UN system has proposed. Factors such as "increasing monetization of politics and political campaigns, and growing political violence and intimidation, creates insecurity for women and builds resistance to their participation..." (Manuh, 2011, p. 2). According to Oquaye (2012a) "military intervention in politics inflicted a lethal wound on women's political emancipation as the process of development through political parties was arrested in the face of machoistic male-dominated militarism;" a historical incident which worked to

\footnotetext{
19 "Reduced to 19 when the female MP for Chereponi died and the seat was won by a man" (qtd. Oquaye, 2012a, p. 2)
} 
prevent women from fully participating in the public sphere. This has led scholars to propose several short-term or long term goals to mitigate the development. One of such affirmative actions is the quota system which requests that a number of seats should be reserved for women in parliament (Oquaye, 2012a).

The point of my argument is that political, religious and social organizations can garner all the resources and legal amendments they could but if discourses are couched in masculine terms, the woman could be sidelined. Kofi Ghana helps us to identify that it is not enough to adopt a technology, it is paramount to avoid representing technologies in masculine terms. If discourse about technologies that are to enhance democracy, such as in Ghana's case, are couched or discussed in masculine terms, we articulate and rearticulate incidents that prevent the participation of women in Parliament. It is not surprising therefore that an affirmative action policy enacted by the opposition NPP to encourage the participation of women and to allow female MPs in the party to contest for national elections unopposed was met with disaffection from, mostly, some male aspirants. The consequence of the disaffection was the redraw of the policy (MyJoyOnline, 2015). I contend that these oppositions to affirmative actions will be encountered the more when we do not work to counter and silence the representation of elections in Ghana as the preserve of males. I agree with Ocquaye (2012a) when he proposes that "...the perception that politics is the realm of men should be removed by conscious efforts in advertising, symposia, debates, plays, films, etc" (p.6). The representation of the biometric as a technology that ensures "one man one vote," I contend, should not be encouraged in the domain of politics or democracy in Ghana. The 
advert, though it informs the populace about the biometric, also implicitly carries an agenda that pushes the idea that technology use or elections in Ghana is masculine. This advert, I propose, must not be used in any of the Electoral Commission's information sessions; neither should it be encouraged by any organization that educates the electorate on electoral processes. It carries with it a rhetorical and cultural bias that reinforces gendered politics, a force that works against the participation of women. Hence, we can argue that the biometric technology carries the cultural bias of its creators and those who adopt them.

\section{Parliamentary Hansard: Deliberating on the Biometric Law}

In this section, I discuss the parliamentary hansard, that is, "the official nearly verbatim report of proceedings of the House. It is a repository and reflection of the legislative activities of Parliament." ${ }^{20}$ The parliamentary hansard provides an avenue for us to discuss how technologies are discussed and talked about in technical documents, such as a report. Basically, Parliamentary proceedings defined the electoral process as at risk or Parliamentarians reinforced the perception that the general election was in crisis and that it needed to be saved through biometric verification. The biometric, it was hoped, would provide a moment of change in the electoral process of Ghana. For the biometric technology to be effective, it needed a legal backing and Parliament, the constitutional

\footnotetext{
${ }^{20}$ (http://www.parliament.gh/publications/).
} 
arm of government enshrined to enact laws made this possible. Through Parliamentary deliberations, we encounter how a technological mindset affected the laws that were enacted to see to the successful use of the biometric technology. We realize that sometimes technological mindset encourages "somnambulistic" laws that stymie critical questioning of the technologies we adopt and use. I will argue that the consequence of the somnambulism that was exhibited during the legal process contributed to the turmoil that almost plunged the country after the 2012 election.

The parliament of Ghana forms the legislative arm of government. The 1992 constitution of Ghana enshrines the Parliament of Ghana with powers to "make laws" which "shall be exercised by bills passed by Parliament and assented to by the President" (p. 72). The legal mandate of Parliament was expressed fully in the hansard as several of the Parliamentarians who contributed to deliberations about the Constitutional Instrument emphasized they were giving "a legal effect to the introduction of the biometric registration and verification of registered voters;" or that they were giving a "legal teeth to the biometric." Hence, the hansard, the official records of parliament, recorded deliberations about the role of the biometric technology in Ghana's elections. The hansard I analyze is a 30-page document which contains proceedings of September 25, 2012. Titled "Parliamentary Debates: Official Report Emergency Meeting," this document captures several motions tabled on September 25 but of importance to this project is the motion: "Public Elections Regulations, 2012 (C.I. 75). The motion was a report submitted to the House of Parliament by the Subsidiary Legislation Committee on the Public Elections Regulations, 2012 (C.I. 75) by Honorable John Tia Akologo on 
behalf of the Chairman of the Subsidiary Committee. The focus was to enact a law that will enable the EC to "make new Regulations to replace the existing C.I. 15 in order to...give legal effect to the introduction of the biometric registration and verification of registered voters..." (p. 785). Through deliberations we identify that the EC of Ghana, since 1996, has embarked on reforms that will address issues that undermine the integrity of elections in Ghana. One of such reforms was the adoption of the biometric technology.

\section{Parliamentary Hansard as it articulates broader rhetorical cultural entanglements}

I begin my discussion by asserting that Parliamentary deliberations enable an understanding of how concepts advanced by such scholars as Carolyn Miller and Langdon Winner become operational in a non-Western society. For instance, we will encounter a tacit example of Miller's “technological forecasting," kairos, and Winner's "somnambulism" and how old structures change to accommodate new structures. In essence, through an analysis of the hansard, we encounter how the biometric system really "affected the technical imagination" (Miller, 1994) of the Parliamentarians. More importantly, this section seeks to uncover how assumptions about the biometric technology guided legal and educational policies in the Parliament of Ghana.

\section{Somnambulism as a Consequence of "Technological Mindset"}

As I stated above, the main purpose of Parliament is to "make laws." Hence, the primary stasis question of the parliamentary debate about the biometric technology was procedural: how can we give "legal teeth" to the biometric technology? This was necessary because the existing Constitutional Instrument (C.I 15) did not make any room 
for the biometric to operate. C.I 15 was the Public Elections Regulations that was used to regulate Public Elections since 1996 (periods before the adoption of the biometric technology). Thus, with the adoption of the biometric, it was necessary to replace it with another Constitutional Instrument (C.I. 75) so that the biometric can be operational. During this procedural moment, several of the members of parliament represented the biometric as the kairotic intervention to our risky electoral process. The biometric, to an extent, becomes a "desperately needed tool for intervention and control of an epidemic that was out of control" (Scott, 2003, p. 208): electoral malpractices.

The representation of the biometric in the hansard as a technology that has a "teeth" (p.791) which can bite or a technology which will make it "extremely difficult" for impersonators to vote exemplify Miller's notion of "technological forecasting," that is "a discourse in which the characterization and construction of moments in the present are crucial to the projection of the future." "The characterization and construction of moments", captured in rhetorical terms as Kairos, plays an important role in discussions about technology. As Miller indicates in "Opportunity, Opportunism, and Progress," Kairos provides an opportune moment for rhetors to "find an opening."

Parliamentary deliberations provided a moment, an opening or a situation that needed a timely intervention. What was the moment that required intervention: there were "emerging challenges in the country's electoral system" (p. 785) and that it was necessary to adopt measures that will curtail the challenges. At this point, the electoral process becomes a risky endeavor. Defining the electoral process as at risk or the perception that elections in Ghana had experienced crisis moments provided a kairotic moment for the 
introduction of the biometric. The biometric, it was hoped, would provide a moment of change in the electoral process of Ghana. The biometric will provide an intervention in the sense that it will make it "extremely difficult for a person to use the name and other particulars of another person to vote" (p. 788). Defining the moment, in this regard, also helps to identify the cause of the electoral woes of the country: people vote more than ones. Thus, with the biometric, the country will, ipso facto, seize the moment, it will go through a credible and reliable electoral process that will yield accurate results. In this regard, the biometric becomes the "saving grace" of our electoral process.

The hansard makes us understand that both internal and external forces pushed the country to look for ways to make elections better in Ghana. For instance, Honorable Justice Appiah did not mince words when he lamented that "the political temperature in this country is rising..." (p. 796) and Honorable Ntow states "I am only praying that everything will go on smoothly for this election to be very successful and that at the end of the day, each one of us will be satisfied with the results and accept it in good faith" (p. 795). These statements by honorable MPs capture the internal tensions that have gripped the electoral process over the years. Internally, Ghanaians wanted a safer and credible electoral process: elections bereft of over-voting, electoral violence, vote rigging and other malpractices. The electoral system needed to be strengthened. Ghana needed a system "which will put results beyond dispute" (Oquaye, 2012b, p. ii). This feeling of insecurity of the polls reached its magnitude when in 2008 Ghana came close to experiencing post-election conflict. Oquaye (2012b) states categorically, and I quote extensively for the sake of the argument I intend to make. 
Ghana was at the brink of conflict in the month of December 2008. The NDC complained that it had unveiled a conspiracy between the NPP and the EC to rig the elections. Candidate Prof. Mills warned that a Rwandastyle civil war was imminent. Macho men became part of the process as candidates engaged them. Deaths occurred, several people were maimed. Some Ghanaians looked for their passports and sought solace abroad, as many stored food against the expected "war". Churches and mosques were filled with panic-stricken prayer warriors. As the final results were being awaited, NDC youth armed to the teeth invaded the EC Head Office and burnt vehicle tyres. War was invoked. Rwanda was rehearsed in the city of Accra. In 2012, the panic scenario was repeated. A foreboding doom clouded the hemisphere as once again, the prayer warriors congregated for God's intervention (ibid p. ii).

External forces cannot be underestimated. As I stated in chapter 1, in Africa and beyond, Ghana has been hailed as the beacon of Africa in terms of democracy. This prestige was reinforced by Honorable Justice Appiah “'Ghana is the beacon of hope for Africa.' It is true. So, if you want this thing to stay, we have to exhibit decency in our politicking." (p. 796). Indeed Ghana has been the hope of Africa. Until the recent electoral success of Nigeria in 2015, Ghana was the only country in Sub-Saharan Africa that had witnessed peaceful transitions of governance between the two major political parties in Ghana both in 2000 (when the opposition New Patriotic Party unseated the ruling National Democratic Congress) and in 2008 (when the opposition National Democratic Congress unseated the ruling NPP). The country, in a way, wanted to live up to this positive external image. More worrying was the fact that elections had plunged nations such as Cote D'Ivoire, Zimbabwe, Kenya, Togo, and Benin into post-election conflicts. Hence, there was "the need for reasoned action in the face of uncertainty" (Miller, 1994, p.91). Measures needed to be taken to avoid a repeat of what happened in 2008. Well, if the biometric was adopted to put results beyond dispute, as Oquaye avers, then I must say that the biometric system failed woefully because the results of the 2012 election was 
contested in the Supreme Court of Ghana, an unprecedented occurrence in the political history of Ghana. The important point is that these rhetorical moments which were created through discourses around the biometric reemphasize the pushmi-pullyu dyad that Miller identifies as the forces behind technological changes. These dyad identifies that societies are either pulled by internal or external forces to adopt and use technology. As I have indicated in this paragraph, the country was pushed by internal and external forces to adopt a system that enables "each one of us [to] ...be satisfied with the results and accept it in good faith" (p. 795, parenthesis mine).

At the mention that a new Constitutional Instrument (C.I. 75) was to replace an old one (C.I. 15) so that the biometric could be effective, we encounter Winner's (1986) argument that "adoption of a given technical system actually requires the creation and maintenance of a particular set of social conditions as the operating environment of that system" (p. 32); or that the structures, processes and alterations of technology "enter into and become part of the structures, processes, and alterations of human consciousness, society and politics" (Winner, 1977, p. 6). If you may recall, in chapter two, I narrated how Wajcman (1991) and Cowan (1983) also stated how the introduction of new technologies structured and shaped activities in the workplace and in the home respectively. Through Parliamentary proceedings, we encounter a characteristic of the biometric technology: it restructures existing laws. Parliamentary proceedings, in a way, confirm these statements that technology works to restructure existing laws and structures and activities. It is through these restructuring that we see the political and powerful nature of technologies. Hence, elections in Ghana becomes an appendage of an 
instrumental regime and the biometric becomes in the words of Winner (1986) "forces of democratic decision making" (p. 55).

To rhetorically establish the ethos of the biometric, some members discussed how

with the introduction of the biometric registration and verification in the voting process it will be extremely difficult for a person to use the name and other particulars of another person to vote ("Parliamentary Debates: Official Report (Emergency Meeting)," p. 788).

We gather from the extract above that the country's electoral process suffers from impersonation and the biometric becomes a way of solving this anomaly. The biometric offers a possibility because as the video I analyzed above indicates, information about individuals are captured into a database for verification and identification. In the process of verification, a presiding officer is required to deliver "a ballot paper to a person to vote" (786) after the officer has verified by "fingerprint of facial recognition that the person is registered voter whose name and voter identification number and particulars appear in the register" (ibid). In essence, the new Constitutional Instrument stipulated that "voters shall go through a biometric verification process to cast their votes" (ibid). By enacting this law, we encounter how the legislative body of the country gave power to the biometric to decide who to vote and who not to vote. As I stated in chapter four, this power enshrined to the biometric, in a way, speaks to the trust the legislative body had in the biometric. The biometric also becomes a powerful tool shaping the electoral activity in the country. Election 2012 is structured and organized differently from the previous elections held in the country. It is saddening, however, that even though this law existed, in some polling stations, "certain persons were selectively allowed to vote in certain polling stations without verification whiles in other places, those who failed the biometric 
verification test were turned away" (Oquaye, 2012b, p. 8). More so, although the new Constitutional Instrument imposed "penalty on Presiding Officers who contravene the laws and regulations governing the conduct of elections..." (p. 788) some Presiding Officers flouted electoral laws. For instance, it was established at the election petition that there were instances where some pink sheets in addition to other electoral documents were not signed ("Supreme Court Judgement on the Presidential Election Petition, Akufo-Addo V. Mahama and Others," A.D 2013, pp. 71-72). The failure to sign pink sheets and other documents, was in the words of Justice Ansah, "a monumental irregularity unmitigated by any circumstances" (p. 73). The issue therefore lies not in the enactment of laws to make technology fit into local activities but how these laws will be enacted to ensure that there is justice for all. The fear is that when we focus on enacting laws that will fit technology into local lives, we barely consider how the technology will be used by others to perpetrate acts that violate the laws that have been passed. To this end, we become "somnambulists," that is "we sleepwalk through the process of reconstructing the conditions of human existence" (Winner, 1986, p. 10).

It is important to realize that through statements made by some members we encounter ways that power works in electoral processes. For instance, Honorable Yaw Baah cautioned fellow members not to intrude into areas which EC officials are mandated to take charge. In his contribution to the deliberations about the law that will give legal effect to the biometric, he stated, "Mr. Speaker, those of us in privilege positions and by so, I am saying, those belonging to the Legislature... we ended up intruding into an area which is the preserve of the EC and I think it is not the best...there were series of 
reported matters where the EC was obstructed in its working by some of us, including my good self...” (p. 793). We can conjecture that electoral success does not merely rely on adopting a biometric technology that will curtail impersonation. There should be regulations that limit those in privilege positions from intruding and disturbing electoral processes. As I acknowledged in chapter four, power or status is one of the traits used to distinguish societies. The words by Honorable Baah send a signal to how people of power somewhat get their way around rules and norms that are established for peaceful existence in a society. Thus, to work towards an incident free elections is, in a way, to work to limit the extent to which power is exercised. He in a way hinted that the biometric cannot do it alone. More so we identify, in the words of Honorable Yaw Baah that the deliberation about the biometric was to give "the legal teeth to the biometric registration...that we are giving the legal effect to this, so that the verification aspect, that is what is contained in this biometric registration, could be implemented" ("Parliamentary Debates: Official Report (Emergency Meeting)," 2012, p. 791).

\section{Critical access to technology: Questioning the technological mindset}

In this section, I focus on Honorable Dr. Akoto Osei's contribution to parliamentary deliberations on the biometric technology and how he helps us to understand what it means to be critical of technology; a standpoint my research advocates. Of all the conversations captured in the report, only Dr Akoto Osei shifted the stasis from procedural one to evaluative: how do we critically ensure that the biometric we imported would work accurately? He shifted the argument from procedural to evaluative based on 
his experience with the technology. He cautioned against unanticipated consequences and potential frustrations voters could go through. He stated:

just a caution to the EC. This weekend, I was in my constituency and having lost my voters card, I was attempting to replace it. I put my four fingers on the machine and the machine only took two. So, as I speak, if I am not careful, I will not be able to vote....So the EC should pay attention to verification instruments that they are importing ("Parliamentary Debates: Official Report (Emergency Meeting)," 2012, p. 797)

...Two hours, Mr. Speaker-Sunday, I stood there for two hours and I gave up. So I think the EC is experiencing some difficulties ("Parliamentary Debates: Official Report (Emergency Meeting)," 2012, p. 799).

Dr. Osei’s submission was buttressed by the First Deputy Speaker:

I agree. I would want to hear from the Chairman of the Committee...This is because when we were even doing the registration, the machine will not even pick your five fingers at go. At times, you have to be trying, trying before it picked...So what happens when a registered voter goes, he is carrying his card, his picture is there, he can be identified that, that is his card, his name is on the biometric register and yet there is a technical problem with the machine. What happens? ("Parliamentary Debates: Official Report (Emergency Meeting)," 2012, p. 798).

More so, Reports from observers of elections 2012 indicate that several errors occurred during the elections. For instance, the African Union Elections Observation Mission report on the 2012 elections in Ghana indicated that three problems emerged with regard to the functioning of the biometric technology. The observers noted that:

in some polling stations, the machines could not read the finger prints of some voters and there were also cases of incompatibility between the BVR data and the data contained in the verification machine...The Mission equally noted that some EC personnel did not follow instructions given to them with regard to the handling of the machines which caused undue delay in some polling stations. As a consequence, the machines faced technical hitches that led to the malfunction in some polling stations... the 
delay caused interrupted voting in some polling stations that lasted for up to four hours, necessitating the extension of voting to 8 December, 2012 to avoid disenfranchising voters in the affected areas ("African Union Observation Report: Ghana," 2012, p. 18).

Subsequently, the Coalition of Domestic Election Observers (CODEO) reported that the biometric machine failed "at some point at 19\% of polling stations during voting" ("Final Report on Ghana's 2012 Presidential and Parliamentary Elections," 2013, p. 3).

I would like to point out that the question posed by Akoto Osei: what happens when biometric fails to operate on the Election Day provides a framework to discuss what I refer to as a critical engagement or Banks" idea of "critical access" to technology. According to Banks (2005), it is not enough to provide a technology to users; instead, it is paramount for individuals in a particular community to develop an understanding of "the benefits and problems of any technology well enough to be able to critique, resist, and avoid them when necessary as well as using them when necessary" (p. 42). Hence, through Akoto Osei's narrative, we can defuse the notion that biometric technologies are error free. In fact, they are not error free and they are subject to breakdowns. Like the breakdown and failure narratives presented by Akoto Osei and the Deputy Speaker of Parliament, Magnet (2011), identifies that the biometric system is subject to three errors: false acceptance rate; false rejection rate; failure to enroll. False acceptance rate occurs when a person who is not you is accepted as you; false rejection occurs when you are not accepted as you; and the failure to enroll error occurs when the system fails to enroll someone (p. 22). As the failures above indicate, the biometric technology did not always function in a straightforward way as purported in the documents I have analyzed. I 
conjecture that this is the kind of breakdowns we encounter when we ascribe to the notion that technologies are fool proof and cannot breakdown. When we submit to the internal logics of technologies we risk being critical of the technologies. More importantly, we risk asking questions that will help to ensure the successful use of a technology. In essence, when we submit to internal logics of such technologies as the biometric, we fail to "examine critically the nature and significance of artificial aids to human activity" (Winner, 1986, p. 4). These stories by politicians and election observers destabilize our notion of the biometric as a technology that is not subject to failure; the biometric is not a perfect tool after all.

\section{Suite of Posters: Educating the Populace on Biometric Registration}

In previous sections, I looked at how language was used powerfully to represent the biometric in an online video and in a Parliamentary report. I argued that the use of language to represent the biometric as an extraordinary technology lends to a discussion of issues such as ideology, assumptions about technology, power, and human-technology [biometric] relationship. In this section, I look at how the biometric was represented in a mundane document like a poster. This document consists of nine posters bound together. Its design makes it suitable to be hanged on walls like one would hang a calendar on a wall. The purpose of this document is to educate the populace on the biometric voting system. It is targeted towards a heterogeneous audience considering that the Ghanaian electorate comprises of either literates, those who can read and write English, semiliterates or illiterates, those who have not had any form of formal education. In a way, 
this document reinforces arguments made in the online video. The first page, for instance, defines what biometric registration is, what the biometric technology is and the purpose of the biometric. In this document, biometric registration is defined as "the capturing of some biometric features of voters during the registration process." Biometric technology is defined as "the use of computers to identify persons by means of their unique physical or behavioural features; such as face, iris, palm, fingerprints, voice...;" We are told that in Ghana's case features will be limited to fingerprints and photographs of the applicant. Also, the first page tells us the purpose of the biometric: "to prevent incidence of multiple registrations;" to serve as a foundation for establishing a continuous voter registration."

The second page of the document establishes the similarities and differences between old system and new system of registration.

\section{Table 2: Differences between old and new system}

\begin{tabular}{|l|l|}
\hline Old system & New system \\
\hline Direct data entry & Scanning of data previously \\
\hline No biometric & Biometric technology \\
\hline
\end{tabular}

Some other important items stated in this poster include: Qualification for registration; Evidence of eligibility; Registration process; process of challenging an applicant's registration; General advice; Importance of voters' register. Worthy of note are statements such as the biometric technology "provides transparency in the verification of 
Election Results" and the general advice to electorates to desist from "multiple registration, since the Biometric voter registration system will expose" them.

\section{Biometric and the articulation of cultural entanglements: Governmentality, Ideology, Subjectivity and Technologies of the Self}

I argue here, just as I have done in other sections in this chapter, that when studying technology and its issues, one can look to such technical documents as posters. In this section, I look at how phrases and words used for the purpose of educating the Ghanaian electorate about the biometric verification provides an avenue to further understand such concepts as "governmentality," ideology, truth, subjectivity and belief systems that technologies like the biometric enable. Like the online video I analyzed above, we catch a glimpse of how the biometric adopted functioned: it captured finger prints of voters. In these posters, biometric registration is defined as the "capturing of some biometric features of voters during the Registration process;" and the biometric technology defined as "the use of computers to identify persons by means of their unique physical or behavioural features; such as face, iris, palm, fingerprints, voice and so on." Here again, we encounter the relationship between the human body and technology. These expressions reinforce some ideas that I have highlighted throughout my discussion.

First, we encounter the relationship between humans and technology. This relationship as I argued earlier helps us to identify the biometric as a fulfilment of Donna Haraway's cyborg technology which foretells the intricate relationship between an organism and a machine. Although, Haraway uses cyborg technology to refer to the Western mode of existence, I argue that cyborg ideas cannot be limited to Western societies anymore 
because the forces of globalization enable bodies, goods, technologies and forms of knowledge to cross boundaries to non-Western societies. Through the adoption of technologies, we can say that cyborg is now a universal concept.

Second, through this cyborg relationship between humans and technology and the belief that the biometric will expose impersonators, we further discuss how the biometric enables a discussion of such issues as power, discipline, truth, managing bodies, or what Foucault terms biopower in a non-Western society. We identify that the biometric technology becomes a means by which bodies of individuals are managed and identified for the sake of accurate and transparent electoral results. In this regard, human behavior becomes something that can be "regulated, controlled, shaped" (Dean, 2010, p. 18) by the biometric technology and rules that have been established. These ideas that are expressed by statements made about the biometric technology exhibit tendencies of Foucault's (2010) concept of "governmentality," that is, the study of "the rationalization of governmental practice in the exercise of political sovereignty" (p. 2). According to Dean (2010), governmentality entails two notions. One of such notions is the definition of "governmentality" as the "emergence of a distinctly new form of thinking about and exercising power in certain societies" (p. 28). This form of government is more concerned about populations, the basis for discussing biopolitics - the process in which state power is exercised over subjects or populations. For example during the 2012 elections in Ghana, the Electoral Commission, with its constitutional power to organize free fair elections, exercised power over the individuals by using a technology that could "expose" violators of electoral laws, "make it extremely difficult for a person to use the 
name and other particulars of another person to vote," "provide transparent" electoral results and "prevent incidence of multiple registration." In its quest to achieve this goal, the bodies of individuals were to go through verification and identification before they could cast their votes as citizens of Ghana. To this end, we can say that the biometric as used in Ghana did not only work to ensure a supposedly free and fair elections; among other things, it provided a regime of practice that enabled bodies to be organized, controlled and punished in some instances by the Electoral Commission and the government of Ghana. Governmentality, thus, helps us to trace the history of election management in Ghana and how the Electoral Commission, has exercised state power in its bid to live to its constitutional mandate. Through the use of the biometric registration, we identify how human behavior during elections such as over-voting and impersonation are coded and perceived as risks which needed to be controlled, managed and administered for the sake of a successful elections. This act by the Commission which was supported by the Parliament of Ghana and the Executive reinforce how in a nonWestern society Foucault's biopower, captured in the adoption and use of "technologies of power that address the management of, and control over," (Nadesan, 2010, p. 2) the voting experience of Ghanaian electorates.

More so, by defining the biometric as a technology that uses "computers to identify persons by means of their unique physical or behavioural features; such as face, iris, palm, fingerprints, voice and so on," the designers of the document reinforce my assertion that the meaning of technology has now shifted from a single object to an articulation of bodies, objects, structures, humans and laws. Thus, my claim that we can 
talk of technological systems instead of a technology is sustained. At the core of the biometric is "communications systems, texts, and self-acting, ergonomically designed apparatuses" (Haraway, 1991, p. 1). If we acknowledge that the biometric represents a complex communication system, then we can argue that like any communication system, the biometric technology is subject to failure.

We are also exposed to the idea that individuals are unique and that they have unique features that are peculiar to them and no one else. Thus, to be a human means having a unique feature. This reinforces the notion of difference. One human is different from the other based on the unique features they possess. This notion of difference leads to the logic that because individuals are unique, the biometric can capture imposters who impersonate the identity of other voters.

We also encounter belief systems that the biometric embody. The essence of the adoption, as I argued above, was to help build faith in the electoral system since most Ghanaians had become disillusioned about the electoral process and the future of democracy in Ghana. The only way to build faith is to assure the electorates that the biometric will expose miscreants and ensure transparency although implicitly, the technology also worked to mark individual voter identities.

As I identified in chapter four, the image of the biometric as a "scare crow" is repeated in the idea that the biometric will "expose you." To say that the biometric will "expose" anyone who attempts to vote multiple times, for instance, is to make a case that the biometric technology has a powerful "vision" that can identify impersonators. The machine, to say the least, "is the gaze that mythically inscribes all the marked bodies, [it 
has the] power to see...to represent" (Haraway, 1991, p. 188). Also, this implies that the biometric technology provides a sense of security or a means by which individuals can be apprehended and punished. It embodies particular sets of values which will ensure that impersonators are apprehended.

Finally, to say that the biometric "provides transparency" is to assume that the biometric is an embodiment of truth, neutrality and success. I have argued earlier, mostly in my fourth chapter and paragraphs above, that these are ideologies and assumptions that come with the biometric. It does not necessarily mean the biometric ensures truth and accuracy; neither does it mean that in reality the biometric is neutral, since as I discussed above, the biometric forms a communicative system. The biometric, as I have argued throughout this project, IS POLITICAL. To this end, I agree with Banks (2005) that “... all technologies come packaged with a set of politics: if these technologies are not inherently political, the conditions in which they are created and in which they circulate into a society are political and influence their use in that society and those politics can profoundly change the spaces in which messages are created, received and used" (p. 23). Therefore, as critics or accommodators of technology, it is necessary for us to be critical of technologies we communicate about, that is, we must "unblackbox" language used powerfully to shape our assumptions about the technologies we accommodate. 


\section{Chapter Six: Importance of 'Unblackboxing' to the Technical Communicator}

In this concluding chapter, I want to define the phrase unblackboxing technology as I have used it in my title and how my goal to unblackbox the biometric technology through the documents that articulated it to Ghanaians has led to a dissertation project that has produced meaningful contribution to research, practice and pedagogy in the field of (international) technical communication. I have not treated research, pedagogy and practice as discrete sets, but instead, I see these three constituents as constantly in interaction. Hence, my conclusion stresses the need for research to influence practice and pedagogy. I also stress the need for technical communicators to engage in civic activities that can enable them to identify and intervene to solve local and global problems. My main take in this research is that, technical documents do not merely "accommodate technology to users" (Dobrin, 2004); Or that when we are engaged with an analysis of a document, we are not merely dealing with the texts in the document; rather, we are dealing with broader historical, social, political, power, economic, legal and ideological issues that circumscribe the document. We have to, therefore, open up to the various ways that texts open us to these broader issues. It is by opening up that we will work towards achieving the goals of unblackboxing. What does it mean to unblackbox technology? How did unblackboxing enable me to conduct a meaningful research, that is, how have I been able to respond to the questions I asked in chapter 1? What contributions have I made through unblackboxing? What else can I further? Lastly, what are the limitations of my work? 
I use the term "unblackbox" to refer to the study of technology from a critical stand point. I hold that technology is not neutral and that it is necessary to open it up in order to identify the various ways it operates among human lives. Technologies, I maintain, are black boxes; by which I mean, they appear to be complex, neutral, compact, but if we take our time to study it, to open it, we can understand the various ways using them can uncover issues. In this regard, I agree with Latour's reference to technoscience as a "Pandora's black box," that needs to be opened up. Technology, such as the biometric, is a "black box" in the sense that it is a machinery that is "too complex," it operates on "complex set of commands" and it comes to users as a compact technology. Because of its complexity, we might think it is “discrete, coherent” (Scott, 2003, p. 22). A critic's job "is to reopen the black box... by treating it as a messy and dynamic enterprise..." (ibid). We do not only have to account for the good of technology but also how their usage lead to a discussion of broader issues such as social justice, localization, power, ideology, discrimination and control. We need to find ways that technologies, such as biometrics, shape (not always in a negative fashion) the identities of users and structure their material lives. As Latour (1987) states, we need to "enter facts and machines" (p. 13) in order to "open the black boxes so that outsiders may have a glimpse at it" (p. 15). As I have demonstrated in preceding chapters, entering facts and machines becomes for me, the way we can study arguments about technology—both implicit and explicit. We need to understand both implicit and explicit arguments about technology because a technology, such as the biometric, "cannot convince anyone because of its good working order. It is only after endless little bugs have been taken out, each bug being revealed by a new trial imposed by a new interested group, that the machine will eventually and progressively be 
made to work" (p. 11). Taking out little bugs, I believe, is the task of the person who studies technology from a humanistic perspective. Such is the purpose I have achieved in this project.

In my quest to unblackbox the biometric technology, I traced arguments made about it in parliament and the user manual that accompanied it as well as how the complex operations of the biometric was translated or adapted to a more heterogeneous audience in a suite of posters. By opening the biometric I have worked to respond to these questions:

- Why will a "simple" instructional manual not be effective?

- How does the adoption enable scholars to examine the relationship between rhetoric, technology, technical communication/writing in cross-cultural contexts?

- Of what benefits will studying technology in international context bring to research, pedagogy and practice in the field?

By responding to these questions, I have made several contributions and proposals. In chapter 1, I unblackboxed the use of the term "international" in the field of technical communication. I identified that in our bid to define or interrogate "international," we have used it synonymously with "intercultural," an association which pushes us to dwell on concepts relevant to intercultural communication. I argue that when we define "international" to reflect the dynamic relationship between rhetoric and culture, we might adopt interdisciplinary approaches that shift attention from the over concentration on "culture" as the core element of international technical communication research. I have proposed that one of the ways to study how culture acts on rhetoric and vice versa is to adopt Blake Scott's rhetorical-cultural methodology. As I discussed thoroughly in chapter 
three, this methodology provides a flexible analytic and data gathering approach for studying international contexts.

The important point to note is that rhetorical-cultural methodology enables scholars to shift attention from studying 'large cultures' to small subcultures, such as elections and how individuals negotiate their situatedness in their quest to claim agency. For instance, by studying the electoral culture of Ghana, we realize that the country has adopted several means in its quest to conduct free fair and incontrovertible elections. The structures in place during the 1992 elections have gone through drastic changes. Thus, we see a sense of dynamism in the Ghanaian electoral process. By studying electoral culture and small cultures, we can perceive culture as dynamic, ongoing process subject to articulation and rearticulation. Electoral culture in Ghana is not stable, it is in a state of flux. As one of the Chief Justices commented after the historical petition and as it was reiterated by the presidential candidate of the NPP, thus, "elections in Ghana will never be the same" (Group, 2014). Hence, to ascribe a cultural notion to Ghana is to prevent us from identifying the various processes that subcultures in Ghana are constantly undergoing changes. Elections in Ghana is almost always in the "process of adjusting and becoming" (LuMing Mao, 2005, p. 429).

My work demonstrates that there are similar ways of representing technology in both non-Western and Western societies. Or we can say that there are universal assumptions about technologies in both Western and non-Western societies. Under "biometric as the speaker of gendered patterns," I identified how the representation of the biometric technology as a technology that ensures "one man one vote," reinforce ideologies that 
inscribe masculine tendencies to technologies. As I indicated in chapter five, Western feminist scholars such Wajcman, Durack, Koerber have discussed the gendered nature of technologies. In as much us we would want to think that the representation of the biometric technology is shaped by Western forms of thought and logics, we would also want to consider or study non-Western forms of representing technology in their own terms. That is, we must acknowledge what Haraway terms "situated knowledge" about the biometric technology. In this direction, what is necessary to consider is Kenneth Pike's etic (insider) and emic (outsider) influences. The emic approach enables us to acknowledge the importance of local based knowledge. For instance, Kofi Ghana, the expert user in the video I analyzed represents a local authority who makes knowledge about the biometric in his bid to educate his fellow electorates. Meanwhile, etic approach enables us to recognize that there are similar universal forms of knowledge making. Thatcher (2010) stresses the importance of combining both etic and emic forms. Etic, he states, hinges the notion that there are "common human thresholds" whereas emic emphasizes the ways cultures conceptualize and operationalize these common human thresholds" in unique and dynamic ways (p. 13). As Mao (2003) indicates, etic and emic approaches direct our attention "toward materials and conditions that are native to these traditions and so that appropriate frames and language can be developed to deal with differences as well as similarities between different traditions" (p. 418).

What we make of etic and emic frames is that it is relevant to pay attention to local situations and external influences. As I have indicated in chapters four and five, the various documents I analyze enable an understanding of the local situation that called for 
the introduction of the biometric technology. Through the analysis of documents, we identify that Ghanaians understand the need to persuade users of technology; they understand that we can use technology to solve complex problems and they also understand that rules and structures must guide technology use. Thus, as professional communicators interested in technology studies, it is necessary to pay attention to local material conditions that call for technology adoption and use. We need to analyze those conditions on their own terms before we can apply Western theories because "while nonWestern... practices should be studied on their own terms, it does not mean that they remain on their own terms forever. In fact they cannot... because the 'here and now' will always be exerting pressure on these emic accounts, and the 'etic' moment will always be intruding on them" (Mao, 2003, p. 418).

To technical communicators studying technology in international contexts, these etic and emic frames will not only improve "the logics, fairness, and validity of the research" as Thatcher (2010, p. 13) indicates, it will yield " reflective encounters" (Mao, 2003, p. 418). Reflective encounters enable "creative understanding of different rhetorical traditions" (ibid). Although Mao was addressing rhetors, I find this call for a reflective encounter between emic and etic frames a worthy step. The encounter will enable fruitful cohabitation between traditions and ways of knowing. More importantly, reflective encounters "renounce domination, adjudication, and assimilation, and they nurture tolerance, vagueness, and heteroglossia" (ibid p. 418). In my case, I used Western rhetorical and cultural theories to study a non-Western context not because I feel Western forms of knowing are superior and more worthy than non-Western concepts but because I 
acknowledge the dialogic relationship between the local and the global. In any case, the biometric technology is Western technology and Ghanaians practice a Western form of democracy. Thus, it will not be out of place to use a Western lens to understand a nonWestern situation. What is necessary for international technical communication scholars is a sense of reflection on the encounter between the theories they use and how they represent the material conditions they are studying because "...being local is not only about physical and temporal locality; it is also about the perspectives, the language ideologies, the local ways of knowing, through which language is viewed. The local should not be confused with the small, the traditional, the immutable, since it is also about change, movement and the production of space, the ways in which language practices... create the space in which they happen" (Pennycook, 2010).

More so, we will begin to reconsider received knowledge about the purposes and uses of technical documentation. As I demonstrated in chapter four, the user manual did not only aid Data Clerks to use the biometric machine, its analysis reveals the social justice implications of technologies that are adopted and used. The user manual becomes an avenue to discuss concepts such as ideology, identity construction, subjectivity, law, local logics and the various ways that technologies control us. Further, the study reveals the various ways that "rhetoric can function as biopower, wrapped up in larger power alignments that shape bodies and forms of embodiment" (Scott, 2003, p. 229). I point out in chapter five that it is necessary to study the rhetoric around technology, but it is not enough to limit such a study to just the rhetorical productions. It is paramount to understand how such rhetorical productions lead to a discussion of broader cultural 
entanglements. I demonstrate this by operationalizing Foucault's biopolitics and disciplinary technology and Haraway's cyborg theories as windows to understand the biometric as a tool that works to articulate such issues as gender and technology; technology and politics; the increasingly blurring boundaries between technologies and humans; technology and security; technology and ideology and; technology and identity construction. I also touched briefly on the question of citizenship and voting.

Subsequently, as my work indicates, it is necessary for technical communicators to become political. I do not mean to say that all technical communicators should aspire to become senators, governors, parliamentarians or presidents. What I mean is we should "examine the way $[\ldots]$ present conditions come about and are maintained for the purpose of understanding, critiquing, and changing them" (Blyler, 1998, p. 36). In chapter four I dwell on Marion Young's concept of justice to enable an understanding of why elections in Ghana experience such malpractices as over-voting. I point out that to answer this question, we have to work to study the various institutions charged to handle elections in Ghana. We also have to interrogate activities of political parties' and stakeholders and how their activities disrupt fair elections. In essence we have to aspire to intervene in local and global situations. One of the ways to do this is to cultivate an interest in the public sphere. To an extent, we must aspire to become what Johnson (1998b) refers to as "participatory citizens." A participatory citizen acknowledges that he/she is "a member of a larger social context" (p. 62). If we consider ourselves as citizens who have to participate in the affairs of a larger society, then, we will be able to carry the knowledge we acquire into the political arena, the space created for decision making. In the political 
arena, Johnson states, we are invited to participate and we, in return, should respond to the call of participation by contributing to the common "good of the community." Our engagement must not necessarily be aggressive as we see in our daily political debates and contests. It can be peaceful, less provocative, metistic and nonviolent. My project demonstrates that as technical communicators, we can in our small ways help find answers to the problems we encounter in our societies (p. 66). We need to apply our "specialized knowledge" in service of community (Bowdon, 2004, p. 329). It is when we engage in civic activities and write about them that we can respond to the "political turn" of writing. We become public intellectuals.

My work does not only instigate political activism. It also contributes to discussions about civic engagement (Bowdon, 2004; Cushman \& Grabill, 2009; Dubinsky, 2004a; Flower, 2008; Grabill, 2001; Grabill \& Simmons, 1998; Rude, 2004; Simmons \& Grabill, 2007) in the sense that it engages in issues relating to the politics of Ghana. My major aim is to help Ghanaian electorates to think about the role they want technology to play in the electoral process and integrate the biometric properly so that what occurred after the 2012 election will not happen again (I am making reference to the electoral petition). I have expressed my civic responsibility by discussing issues that can lead to ways that technology can be integrated into the electoral process of Ghana. Even though I focus on textual documents, I do not limit analysis to the text only, but instead, I discuss broader issues such as deliberations in Ghana in regard to elections. I also interrogate the issues that led to the adoption of the biometric technology. More examples of the relationship between technical communication and civic engagement can be found in the Fall 2004 
special issue of Technical Communication Quarterly devoted to civic engagement and technical communication. In this issue, Dubinsky (2004), the Guest Editor, stresses the age long argument that education should prepare students for civic engagement, meaning, students should be given the tools to "exercise political power by pursuing goals concerned with 'human life and conduct"'(p. 245). The scholars who contributed to this issue identified the varied roles technical communicators play in the public sphere. One of such scholars is Bowdon. In the article "Technical Communication and the Role of the Public Intellectual,” Bowdon (2004) tells a story of her involvement with a local AIDS prevention program to exemplify how technical communicators can act as public intellectuals. According to Bowdon, with our understanding of language as an ideological paradigm and genres as socially and politically situated, we can contribute responsibly in the public sphere by bringing our "specialized knowledge to serve as a liaison" (p.329) among stakeholders in our communities. Though she was only invited to this AIDS project as an editor of technical documents, she realized that she was involved with something larger that "just editing." Through the narration of her participation in this project, she helps us to understand that as public intellectuals, the onus lies on us to: "make our work part of the public sphere;" "recognize the democratic functions of our work as educators;" "create positive changes in our communities by recognizing kairotic moments for intervention;" and "recognize our own situatedness within work contexts" (pp. 325-326). It is necessary to expose students and ourselves to ways that they can initiate local action to effect changes in their communities (p. 326). 
Thus, as I have indicated elsewhere (Bowen et al., 2014), and as I have demonstrated in this project, civic engagement or the "public turn" of rhetoric and technical communication moves rhetors from their ivory towers on university campuses to communities around them. "Public turn" of rhetoric helps us to bridge the age-old binary between theory and practice. We bring theory to practice and practice to theory in service of our communities; we become agents of change. The "public turn" of rhetoric is not only interested in academic conversations, it gives rhetors the tools to apply practical judgment (phronesis) to solving community problems. We are ambassadors of change. Reflection and social action are the core tenets of community literacy and rhetoric. The public turn, for me, becomes a moment of engagement with the community around us in order to explore issues of concern and a moment of helping one another in order to solve complex problems. Rhetoric becomes the medium of exploration and a tool for inquiry.

I have demonstrated what the scholars have discussed not only through this project but through my teaching. As someone who is interested in civic engagement, I have found it necessary to create a dialogue between my research and my teaching. I have not left my students out of the projects I engage in. Mostly, I tell stories about my research and how that demonstrates how technical communicators can be effective in their societies. For instance, my HU3120 Professional and Technical Communication students are engaged in the preliminary process of revising the user manual that accompanied the biometric technology. Dubbed "the big project," this assignment requires students to revise and design a user manual that accompanied the biometric verification device that was adopted by Ghana in 2012 for its presidential and parliamentary election. 
The assignment extends civic engagement beyond local contexts to international and global contexts. As Walton (2013a) and other scholars have identified, even though our societies and workplaces have become a globalized environment, most civic engagement activities in the academy are limited to local communities in which universities are located. Walton (2013) argues, and I agree, that the appropriate way to prepare our students to embrace the kind of globalized environment that we live in is to "seek civic engagement opportunities within not only local contexts, but global as well” (p. 148). Through the "Big project", students come to appreciate that globalization is about "cultural blending, hybridization, glocalization, and cross-border flow of rhetorical and cultural patterns" (Thatcher, 2011, p. 42). They learn how to appreciate the history, culture, politics and rhetorical patterns of societies that are miles apart from their own. For example, while they work on the project, they ask questions about the currency of Ghana, political system, how to design a budget for an audience that is different from theirs. I appreciate and admire how they struggle to convert dollars to Ghana cedis, and how they eagerly read about the Electoral Commission of Ghana. More importantly, they learn how to analyze audience, collaborate with peers from diverse disciplines and how to present information to diverse populations. In this regard, the students in my class (I hope) will "develop a more sophisticated knowledge of their own communication practices” (Brady \& José, 2009, p. 41), and then go on to understand globalization to mean a process that can help them to acquire new ways of learning and doing things.

After analysis they write a report on the state of the manual. This report assignment helps them to identify sections of the user manual which needs to be revised. I follow the report 
assignment with the proposal writing process where they persuade the Commission to release funds for a revision of the manual. They proceed with manual revision when I report to them that the Commission has accepted that they should revise the manual. While working on these projects I assign readings that will enable them to reflect on cultural encounters and the necessity to value rhetorical and cultural patterns of different contexts.

By working with students to revise the user manual that accompanied the biometric technology, I adhere to Carolyn Miller's claim that we should teach a kind of "enculturation" that will enable students to understand how to belong to a community. Belonging to a community is a quintessence of technical communication. In a forward to an edited collection of articles in Reshaping technical communication: new directions and challenges for the $21^{\text {st }}$ century, Janice Redish states that "community is going to be a major theme of this new century" (Mirel \& Spilka, 2002). As Miller suggests, if we want students to take social action, we should involve the virtue of practical wisdom or phronesis (the ability to reason about the ends and not the means). "Phronesis enables a person to deliberate about the good rather than the expedient and, as such, to act in the political sphere rather than in the sphere of work" (Sullivan, 2004). Social action, based on phronesis enables students to become good citizens. The students must leave technical communication classes ready and willing to take socially responsible actions.

\section{Limitation of Work}

As with every research, my work has some limitations and I discuss two of such limits here. First and major point of identification is the nature of data collected. Because my 
focus is on the role of technical documents, I did not make room for qualitative data gathering practices such as interviewing and observation. Thus, my research cannot speak to usability concerns in a confident way. My only point of call as regards the usable nature of the manual will be the Deputy Chairman of the Electoral Commission's report that Data Clerks could not follow simple instructions and the design issues I identified when I analyzed the user manual. I believe I would have made a lot of gains if I interviewed Data clerks and other polling officials who used the manual. They will be the appropriate sources to talk about their experiences with the user manual. For instance, when Agboka (2013a) interviewed users of the manuals that accompanied the aphrodisiacs introduced to Accra, Ghana, he was able to quantify the usability problems posed by documentation and also the source of the problem. For instance, he found out that " $43.5 \%$ of users reported either having encountered problems using some type of documentation or having known someone with problems" or that " $60.8 \%$ of all participants thought the problems could be a result of a lack of - or- - poor documentation" (pp. 39-40). Similarly, when Thatcher (2011) interviewed, for instance, the chief Mexican engineer at the Chihuahua Maquila site in Mexico, he revealed that "original U.S. 'instruction manuals were vague' and that the Mexican engineers could not figure out what to do with them" (pp. 308-9). And when Fukuoka et al (1999) performed experiments on both American and Japanese readers to identify their preference of illustration in user manual, they identified among other things that, contrary to previous research, no clear distinction exists between American and Japanese readers in regard to their preferences for formats in illustrations used in manuals (p. 171). By incorporating observation, interviews and experimental methods, Agboka, Thatcher and Fukuoka et al 208 
had variety in data analyzed. They were able to assess and include users in the design of the research. This is a strength my research lacks. Thus, even though there were evidence of biometric breakdowns, I cannot attribute such malfunctions to the poor design of the documentation. A gap which my future research will work to resolve.

My work has also not properly addressed issues concerning activism, that is, I have not yet intervened to solve any problem. As scholars in civic engagement identify, it is necessary to act to solve problems. At this point I will say that my work remains at the theoretical level. For instance, I have identified that the manual needs a form of revision, or that we should really interrogate some of the laws enacted during the adoption process. These and many other problems I have identified in this project should open a space for other scholars to further conduct research into the adoption and use of the biometric for subsequent elections. Moreover, some of the issues I have raised in this dissertation will be taken up in my future scholarship. I discuss these below.

\section{Future research}

My future research will reflect my call for scholars to be public intellectuals. My role as a public intellectual will span two boundaries. First, I work to bridge the gap between my private political beliefs and civic society. In this direction, I have indicated that the user manual needs to be revised. Thus my future project will seek to find available means to help the Commission revise the manual to incorporate the needs of the users. In this direction, I intend to help the Electoral Commission revise and redesign some electoral documents such as the user manual and pink sheets. I seek to interview Data Clerks, Electoral Commission Officials, officials from SuperLock Technologies and some 
polling station agents to record their views on the effectiveness of the user manual and the biometric device. Data collected will enable an understanding of how to proceed with the design of the technical documents. This will also help to incorporate the needs of users of the manual and other documents. Another document that will be revised is pink sheets. At the peak of the electoral petition, for instance, "pink sheets," that is, the "primary records of an election" (Judgement, p. 25) became an issue of concern. It was revealed that such documents contained "errors of omission..." (ibid). To an amazing degree, Justice Atuguba proclaimed that the Chairman of the Electoral Commission's contradictory evidence in regard to the printing errors and the instructions on how to use the technical document is to be considered "a technical error of recollection that not much weight should be attached to it." He also affirmed that "I am not aware of any judicial University that has awarded or conferred a graduate or doctorate degree on the pink sheet" (Judgment, p. 26). As simplistic as Justice Atuguba may reduce the pink sheets, I find it as a concern, mostly because I am a technical communicator and I believe that technical documents are powerful genres that structure activities. Therefore errors on technical documents must not be taken lightly. I will work with the Commission to revise some of these technical documents that shape the electoral process in Ghana. Pink Sheets, I hold, need not contain technical or grammatical errors. And even though no university awards degrees in pink sheets, a technical communicator can apply his/her "specialized knowledge" in the design of documents to help revise and make such documents usable. It is not enough to accept that the pink sheet is only a primary document and that errors on the document should not be considered in adjudication processes. 
My work with the Electoral Commission will lead to the second boundary that needs to be bridged: research and academy. Thus I intend to publish articles from the consulting work I do with the Commission. I hope to publish papers that will educate the scholarly society on such topics as: usability and user experience studies in international context; challenges of doing civic engagement research in international contexts; and document design in international contexts. These papers will be targeted towards such journals as Technical Communication Quarterly, Journal of Business and Technical Communication and Journal of Technical Writing and Communication. Ultimately, I intend to mentor and work with graduate students on these projects I have outlined. This way, students will develop interests in international technical communication research. They will also acquire the needed skill and methodological tool required to conduct research in international contexts. 


\section{References}

1992 Constitution of the Republic of Ghana. (1992).

. African Union Observation Report: Ghana. (2012): African Union Commission.

Agboka, G. (2012). Liberating Intercultural Technical Communication from" Large Culture" Ideologies: Constructing Culture Discursively. Journal of Technical Writing and Communication, 42(2), 159-181.

Agboka, G. (2013a). Participatory localization: A social justice approach to navigating unenfranchised/disenfranchised cultural sites. Technical Communication Quarterly, 22(1), 28-49.

Agboka, G. (2013b). Thinking about social justice: interrogating the international in international technical communication discourse. Connexions: international professional communication journal, 1(1), 29-38.

Agboka, G. (2014). Decolonial Methodologies: Social Justice Perspectives in Intercultural Technical Communication Research. Journal of Technical Writing and Communication, 44(3), 297-327.

Althusser, L. (1971). Ideology and Ideological State Apparatuses (notes Towards an Investigation).

Amant, S. K. (2006). Globalizing rhetoric: Using rhetorical concepts to identify and analyze cultural expectations related to genres. Hermes-Journal of Language and Communication Studies, 37, 47-66.

Arendt, H. (2013). The human condition: University of Chicago Press.

Aristotle. (2014). On "Techne" and "Episteme". In R. a. V. D. Scharf (Ed.), Philosophy of Technology: The Technological Condition: An Anthology (Second ed., pp. 19-22). West Sussex: Wiley Blackwell and Sons Inc. 
Banks, A. J. (2005). Race, rhetoric, and technology: Searching for higher ground: Routledge.

Barnum, C. M., \& Li, H. (2006). Chinese and American technical communication: A crosscultural comparison of differences. Technical communication, 53(2), 143-166.

Bawarshi, A. S., \& Reiff, M. J. (2010). Genre: An introduction to history, theory, research, and pedagogy: Parlor Press West Lafayette, IN.

Bazerman, C. (1998). The production of technology and the production of human meaning. Journal of Business and Technical Communication, 12, 381-387.

Beamer, L. (2003). Directness in Chinese business correspondence of the nineteenth century. Journal of Business and Technical Communication, 17(2), 201-237.

Berlin, J. A. (1987). Rhetoric and reality: Writing instruction in American colleges, 1900-1985: SIU Press.

Bertens, H. (2013). Literary theory the basics: Routledge.

. The Biometric Verification Device User Manual. (2012). In T. E. C. o. Ghana (Ed.). Accra.

Bitzer, L. F. (1992). The rhetorical situation. Philosophy \& rhetoric, 1-14.

Blyler, N. (1998). Taking a political turn: the critical perspective and research in Professional communication. Technical Communication Quarterly, 7(1), 33-52.

Boiarsky, C. (1995). The relationship between cultural and rhetorical conventions: Engaging in international communication. Technical Communication Quarterly, 4(3), 245-259.

Bowdon, M. (2004). Technical communication and the role of the public intellectual: A community HIV-prevention case study. Technical Communication Quarterly, 13(3), 325340.

Bowen, L. M., Arko, K., Beatty, J., Delaney, C., Dorpenyo, I., Moeller, L., . . Velat, J. (2014). Community Engagement in a Graduate-Level Community Literacy Course. Community Literacy Journal, 9(1). 
Brady, A. (2004). Rhetorical research: Toward a user-centered approach. Rhetoric Review, 23(1), $57-74$.

Brady, A., \& José, L. (2009). Writing for an International Audience in a US Technical Communication Classroom: Developing Competences to Communicate Knowledge Across Cultures. Nordic Journal of English Studies, 8(1), 41-60.

. Communique: At the National Conference on Biometric Voter Registration and E-Voting in Ghana. (2010): Danquah Institute.

Connor, U. (1998). Comparing research and not-for-profit grant proposals. Written discourse in philanthropic fundraising: Issues of language and rhetoric, 45-64.

Cowan, R. S. (1983). More work for mother: The ironies of household technology from the open hearth to the microwave (Vol. 5131): Basic Books.

Cushman, E., \& Grabill, J. T. (2009). Writing theories/changing communities: Introduction. Reflections: Writing, Service-Learning, and Community Literacy, 8(3), 1-20.

Daabu, M. A. (2015). 76,000 Foreigners Found on Ghana's Voter's Register. Retrieved 9/6, 2015, from http://www.myjoyonline.com/politics/2015/August-18th/76000-foreignersfound-on-ghanas-voters-register.php

Dean, M. (2010). Governmentality: Power and rule in modern society: Sage publications. deWinter, J. (2014). Integrating Chinese Emphasis into a Professional Communication Program. Programmatic Perspectives, 6(2), 41-61.

Ding, H., \& Savage, G. (2013). Guest Editors' Introduction: New Directions in Intercultural Professional Communication. Technical Communication Quarterly, 22(1), 1-9.

Dobrin, D. (2004). What's Technical about Technical Writing. In S. Johnson-Eilola, Stuart A (Ed.), Central works in technical communication (pp. 107-123). New York: Oxford University Press. 
Doheny-Farina, S. (1992). Rhetoric, innovation, technology: Case studies of technical communication in technology transfers: MIT Press.

Dong, Q. (2007). Cross-cultural considerations in instructional documentation: contrasting Chinese and US home heater manuals. Paper presented at the Proceedings of the 25th annual ACM international conference on Design of communication.

Dubinsky, J. M. (2004a). Guest Editor's Introduction. Technical Communication Quarterly, 13(3), 245-249.

Dubinsky, J. M. (2004b). Teaching technical communication: Critical issues for the classroom: Macmillan.

Durack, K. T. (1997). Gender, technology, and the history of technical communication. Technical Communication Quarterly, 6(3), 249-260.

Durao, R. (2013). International Professional Communication: An Overview. Connexions. International Professional Communication Journal, 1(1), 1-24.

Electoral Commission of Ghana: A Guide to Candidates and the Agents. (2012).

Fahnestock, J. (1986). Accommodating Science The Rhetorical Life of Scientific Facts. Written Communication, 3(3), 275-296.

Feenberg, A. (1991). Critical theory of technology.

. Final Report on Ghana's 2012 Presidential and Parliamentary Elections. (2013). Accra: Coalition of Domestic Election Observers.

Flower, L. (2008). Community literacy and the rhetoric of public engagement: SIU Press.

Foucault, M. (1977). Discipline and punish (A. Sheridan, Trans.). New York: Pantheon.

Foucault, M. (2009). Security, Territory, Population: Lectures at the Collège de France 1977-1978 (M. Senellart Ed. Vol. 4). New York: Macmillan. 
Foucault, M., Senellart, M., Ewald, F., Fontana, A., \& Burchell, G. (2010). The birth of biopolitics: lectures at the Collège de France, 1978-1979: Palgrave Macmillan New York.

Fukuoka, W., Kojima, Y., \& Spyridakis, J. H. (1999). Illustrations in user manuals: Preference and effectiveness with Japanese and American readers. Technical communication, 46(2), 167-176.

Goodall, H. L. J. (2000). Writing the New Ethnography. New York: Rowman and Littlefield Publishers, Inc.

Grabill, J. T. (2001). Community literacy programs and the politics of change: SUNY Press.

Grabill, J. T., \& Simmons, W. M. (1998). Toward a critical rhetoric of risk communication: Producing citizens and the role of technical communicators. Technical Communication Quarterly, 7(4), 415-441.

Gregory, P., \& Simon, M. A. (2008). Biometrics for dummies: John Wiley \& Sons.

Grossberg, L. (1986). On Postmodernism and Articulation an Interview with Stuart Hall. Communication Inquiry, 10(2), 45-60.

Group, J. (Producer). (2014, 10/11). Nana Akufo-Addo's Concession Speech on the Supreme Court Ruling on the 2012 Presidential Petition.

Gurak, L. J., \& Lannon, J. M. (2012). Strategies for technical communication in the workplace: Pearson Higher Ed.

Gyimah-Boadi, E. (2004). Ensuring Violence-Free December 2004 Elections in Ghana: Early Warning Facilities. Paper presented at the Briefing Paper: Ghana Center for Democratic Development.

Gyimah-Boadi, E. (2013). Strengthening Democratic Governance in Ghana: Proposals for Intervention and Reform: Accra: A publication of Star Ghana. 
Haas, A. M. (2012). Race, Rhetoric, and Technology A Case Study of Decolonial Technical Communication Theory, Methodology, and Pedagogy. Journal of Business and Technical Communication, 26(3), 277-310.

Haraway, D. (1988). Situated knowledges: The science question in feminism and the privilege of partial perspective. Feminist studies, 575-599.

Haraway, D. (1991). Simians, cyborgs, and women: The reinvention of women. London and New York: Routledge.

Harding, S. G. (1991). Whose science? Whose knowledge?: Thinking from women's lives: Cornell University Press.

Hart, R. P., \& Daughton, S. M. (2005). Modern rhetorical criticism (Third ed.). United States of America: Pearson Education, Inc.

Heidegger, M. (2014). The Question Concerning Technology. In R. a. V. D. Scharf (Ed.), Philosophy of Technology: The Technological Condition: An Anthology (Second ed., pp. 305-317). West Sussex: Willey Blackwell and Sons, Inc.

Hoft, N. L. (1995). International technical communication: How to export information about high technology: John Wiley \& Sons, Inc.

Hogan, D. B. Theories that Apply to Technical communication. Connexions. International Professional Communication Journal, 1(1), 155-165.

Honold, P. (1999). Learning how to use a cellular phone: Comparison between German and Chinese users. Technical communication, 46(2), 196-205.

Hunsinger, R. P. (2006). Culture and cultural identity in intercultural technical communication. Technical Communication Quarterly, 15(1), 31-48.

Jockers, H., Kohnert, D., \& Nugent, P. (2010). The successful Ghana election of 2008: a convenient myth? The Journal of Modern African Studies, 48(01), 95-115. 
Johnson, R. (1998a). Complicating technology: Interdisciplinary method, the burden of comprehension, and the ethical space of the technical communicator. Technical Communication Quarterly, 7(1), 75-98.

Johnson, R. (1998b). User Centered Technology: A Rhetorical Theory for Computers and Other Mundane Artifacts. Albany: State University of New York.

Johnson, R. (2010). The ubiquity paradox: further thinking on the concept of user centeredness. Technical Communication Quarterly, 19(4), 335-351.

Jones, N. N. (2014). Methods and meanings: Reflections on reflexivity and flexibility in an intercultural ethnographic study of an activist organization. Rhetoric, Professional Communication, and Globalization, 5(1), 14-43.

Katz, S. B. (1992). The ethic of expediency: Classical rhetoric, technology, and the Holocaust. College English, 255-275.

Keller, E. F. (1996). Feminism and Science. In E. F. a. L. Keller, E. Helen (Ed.), Feminism and Science (pp. 28-39). New York: Oxford University Press.

Kelly, B., \& Bening, R. (2013). The Ghanaian elections of 2012. Review of African Political Economy, 40(137), 475-484.

Kennedy, A. G. (1999). Classical Rhetoric and its Christian and Secular Tradition from Ancient to Modern Times. Chapel Hill and London: The University of North Carolina Press.

Khadka, S. (2014). Geopolitics of Grant Writing: Discursive and Stylistic Features of Nonprofit Grant Proposals in Nepal and the United States. Journal of Technical Writing and Communication, 44(2), 141-170.

Kitalong, K. S. (2000). "You Will” Technology, Magic, and the Cultural Contexts of Technical Communication. Journal of Business and Technical Communication, 14(3), 289-314.

Koerber, A. (2000). Toward a feminist rhetoric of technology. Journal of Business and Technical Communication, 14(1), 58-73. 
Koerber, A. (2006). Rhetorical agency, resistance, and the disciplinary rhetorics of breastfeeding. Technical Communication Quarterly, 15(1), 87-101.

Kynell, T. (1999). Technical communication from 1850-1950: Where have we been? Technical Communication Quarterly, 8(2), 143-151.

Latour, B. (1987). Science in action: How to follow scientists and engineers through society: Harvard university press.

Lawler, S. (2008). Stories and the Social World. In M. Pickering (Ed.), Research Methods for Cultural Studies. 22 George Square, Edinburgh Edinburgh University Press Ltd.

Lindlof, T. R., \& Taylor, B. C. (2011). Qualitative communication research methods (Third ed.). Los Angeles Sage.

Liu, S., \& Silverman, M. (2001). A practical guide to biometric security technology. IT Professional, 3(1), 27-32.

Long, P. O. S., Asif; and Post, Robert C. (2014). Historical Perspectives on Technology, Culture, and Society: An introduction to the Series. Retrieved 1/29, 2015

Longo, B. (1998). An approach for applying cultural study theory to technical writing research. Technical Communication Quarterly, 7(1), 53-73.

Longo, B. (2000). Spurious Coin:A History of Science, Management, and Technical Writing. Albany: State University of New York Press.

Longo, B., \& Fountain, K. (2013). What can history teach us about technical communication? In J.-E. a. S. Selber (Ed.), Solving problems in technical communication (pp. 165-186). Chicago: The University of Chicago Press.

Lovitt, C. R., \& Goswami, D. (1999). Exploring the rhetoric of international professional communication: An agenda for teachers and researchers: Baywood Publishing Company. 
Magnet, S. (2011). When biometrics fail: Gender, race, and the technology of identity: Duke University Press.

Manuh, T. (2011). Towards Greater Representation of Women in National Governance. Governance Newsletter (17). Accra.

Mao, L. (2003). Reflective encounters: Illustrating comparative rhetoric. STYLEFAYETTEVILLE-, 37, 401-425.

Mao, L. (2005). Rhetorical borderlands: Chinese American rhetoric in the making. College Composition and Communication, 426-469.

Markel, M. (2013). Practical Strategies for Technical Communication. Boston: Bedford/ST. Martin.

Matsen, P. P., Rollinson, P. B., \& Sousa, M. (1990). Readings from classical rhetoric: SIU Press. McKeon, R. (2009). The basic works of Aristotle: Random House LLC.

Miller, C. (1978). Technology as a form of consciousness: A study of contemporary ethos. Communication Studies, 29(4), 228-236.

Miller, C. (1984). Genre as social action. Quarterly journal of speech, 70(2), 151-167.

Miller, C. (1994). Opportunity, opportunism, and progress: Kairos in the rhetoric of technology. Argumentation, 8(1), 81-96.

Miller, C. (1998). Learning from History World War II and the Culture of High Technology. Journal of Business and Technical Communication, 12(3), 288-315.

Miller, C. R. (1994). Opportunity, opportunism, and progress: Kairos in the rhetoric of technology. Argumentation, 8(1), 81-96.

Mirel, B., \& Spilka, R. (2002). Reshaping technical communication: New directions and challenges for the 21st century: Routledge.

Mision, Vision and Functions. Retrieved 2/7, 2015 
Mitcham, C. (1994). Thinking through technology: The path between engineering and philosophy: University of Chicago Press.

MyJoyOnline. (2013). Election 2012 Petition Hearing-Day 2. Election 2012 Petition Hearing. Retrieved 4/15, 2015

MyJoyOnline (Producer). (2015, 11/21). NPP Affirmative Action Scrapped; November Congress to Consider Adoption.

Nadesan, M. H. (2010). Governmentality, biopower, and everyday life: Routledge.

Oliu, W. E. (1994). Writing that works : effective communication in business. Scarborough, Ont.: Nelson Canada.

Oquaye, M. (1995). The Ghanaian Elections of 1992--A Dissenting View. African Affairs, 259275.

Oquaye, M. (2012a). Reserving Special Seats for Women in Parliament: Issues and Obstacles. Governance Newsletter. Accra.

Oquaye, M. (2012b). Strenghtening Ghana's Electoral System: A Precondition for Stability and Development. IEA Monograph, (NO. 38). Ghana.

Ornatowski, C. M. (1992). Between efficiency and politics rhetoric and ethics in technical writing. Technical Communication Quarterly, 1(1), 91-103.

Paradis, J. (2004). Text and Action: The Operator's Manual in Context and in Court. In A. S. Johnson-Eilola and Selbe (Ed.), Central works in technical communication (pp. 365-380). New York: Oxford University Press.

. Parliamentary Debates: Official Report (Emergency Meeting). (2012) Parliamentary Debates (Vol. 78, pp. 777-806). Parliament House, Accra: Parliament of Ghana.

Pennycook, A. (2010). Language as a local practice. Milton Park, Abingdon; New York: Routledge.

Pfeiffer, W. S. (2003). Technical writing: a practical approach: Pearson College Division. 
Piller, I. (2007). Linguistics and intercultural communication. Language and linguistics Compass, 1(3), 208-226.

Plato. (2014). On Dialectic and "Techne". In R. a. V. D. Scharf (Ed.), Philosophy of Technology: The Technological Condition: An Anthology (Second ed., pp. 9-18). West Sussex: Wiley Blackwell and Sons Inc.

Powell, M. L., Daisy; Riley-Mukavetz, Andrea; Brooks-Gillies, Marilee; Novotny, Maria; FischFerguson, Jennifer. (2014). Our Story Begins Here: Constellating Cultural Rhetorics. Retrieved 11/6/2014, 2014

Pugliese, J. (2010). Biometrics: bodies, technologies, biopolitics (Vol. 12): Routledge.

Reed, T. V. (2014). Digitized Lives: Culture, Power, and Social Change in the Internet Era: Routledge.

. Revision of the Voters Register 2014: User Manual for Data Entry Clerks. (2014). In T. E. C. o. Ghana (Ed.).

Roach, K. D., \& Byrne, P. R. (2001). A cross-cultural comparison of instructor communication in American and German classrooms. Communication Education, 50(1), 1-14.

Rude, C. D. (2004). Toward an expanded concept of rhetorical delivery: The uses of reports in public policy debates. Technical Communication Quarterly, 13(3), 271-288.

Saaka, Y. (1997). Legitimizing the illegitimate: The 1992 presidential elections as a prelude to Ghana's fourth republic. Issues and trends in contemporary African politics, 143-172. Salia, A. (2000). 'Voters Register in exess of 1.5 m people--Afare-Gyan, Daily Graphic.

Salvo, M. J. (2001). Ethics of engagement: User-centered design and rhetorical methodology. Technical Communication Quarterly, 10(3), 273-290.

Sapp, D. A., Savage, G., \& Mattson, K. (2013). After the International Bill of Human Rights (IBHR): Introduction to special issue on human rights and professional communication. Rhetoric, Professional Communication, and Globalization, 14(1). 
Scharff, R. C., \& Dusek, V. (2014). Philosophy of technology: The technological condition: An anthology: John Wiley \& Sons.

Scott, B. (2003). Risky Rhetoric: AIDS and the cultural practices of HIV testing. United States: Southern Illinois University Press.

Scott, B., \& Longo, B. (2006). Guest Editors' Introduction: Making the Cultural Turn. Technical Communication Quarterly, 15(1), 3-7.

Scott, B. J., Longo, B., \& Wills, K.V (Ed.). (2006). Critical Power Tools: Technical Communication and Cultural Studies. New York: State University of New York Press.

Scott, J. (2010). Intercultural rhetoric in the technical communication curriculum: A review of the literature. Rhetoric, Professional Communication, and Globalization, 1(1), 77-90.

Seigel, M. (2006). Reproductive technologies: Pregnancy manuals as technical communication: ProQuest.

Seigel, M. (2013). The Rhetoric of Pregnancy: University of Chicago Press.

Selber, S. A. (2010). Rhetorics and technologies: New directions in writing and communication: University of South Carolina Press.

Selfe, C. L. (1999). Technology and literacy in the twenty-first century: The importance of paying attention: SIU Press.

Simmons, W. M., \& Grabill, J. T. (2007). Toward a civic rhetoric for technologically and scientifically complex places: Invention, performance, and participation. College Composition and Communication, 419-448.

Slack, J., D., Miller, D. J., \& Doak, J. (1993). The Technical Communicator as Author Meaning, Power, Authority. Journal of Business and Technical Communication, 7(1), 12-36.

Slack, J. D. (2006). Communication as articulation. Communication as...: Perspectives on theory, 223-231

Slack, J. D., \& Wise, J. M. (2005). Culture+ technology: A primer: Peter Lang. 
Smith, B. (2012). Reading and Writing in the Global Workplace: Gender, Literacy, and Outsourcing in Ghana. Lanham: Lexington Books.

Smith, D. (2002). Consolidating democracy? The structural underpinnings of Ghana's 2000 elections. The Journal of Modern African Studies, 40(4), 621-650.

Spinuzzi, C. (2003). Compound mediation in software development: Using genre ecologies to study textual artifacts. Writing selves/writing societies, 97-124.

Spinuzzi, C. (2004). Four ways to investigate assemblages of texts: Genre sets, systems, repertoires, and ecologies. Paper presented at the Proceedings of the 22nd annual international conference on Design of communication: The engineering of quality documentation.

Spinuzzi, C., \& Zachry, M. (2000). Genre ecologies: An open-system approach to understanding and constructing documentation. ACM Journal of Computer Documentation (JCD), 24(3), 169-181.

Staples, K. (1999). Technical communication from 1950-1998: Where are we now? Technical Communication Quarterly, 8(2), 153-164.

Stevens, B. (2000). Russian Teaching Contracts An Examination of Cultural Influence and Genre. Journal of Business and Technical Communication, 14(1), 38-58.

Sullivan, D. L. (2004). Political-ethical implications of defining technical communication as a practice. Central works in technical communication, 211-219.

Sullivan, P., \& Porter, J. E. (2004). On Theory, Practice, and Method: Toward a Heuristic Research Methodology for Professional Writing. In A. S. Johnson-Eilola and Selbe (Ed.), Central Works in Technical Communication (pp. 300-313). New York: Oxford University Press.

Sullivan, P., Porter, J. E. (1997). Opening spaces: Writing technologies and critical research practices: Greenwood Publishing Group. 
Sun, H. (2004). Expanding the scope of localization: A cultural usability perspective on mobile text messaging use in American and Chinese contexts. Rensselaer Polytechnic Institute.

Sun, H. (2006). The triumph of users: Achieving cultural usability goals with user localization. Technical Communication Quarterly, 15(4), 457-481.

Sun, H. (2009a). Designing for a dialogic view of interpretation in cross-cultural IT design Internationalization, Design and Global Development (pp. 108-116): Springer.

Sun, H. (2009b). Toward a rhetoric of locale: Localizing mobile messaging technology into everyday life. Journal of Technical Writing and Communication, 39(3), 245-261.

Sun, H. (2012). Cross-cultural technology design: Creating culture-sensitive technology for local users: Oxford University Press.

. Supreme Court Judgement on the Presidential Election Petition, Akufo-Addo V. Mahama and Others. (A.D 2013): Supreme Court of Judicature.

Swarts, J., \& Kim, L. (2009). Guest editors' introduction: New technological spaces. Technical Communication Quarterly, 18(3), 211-223.

Thatcher, B. (2006). Intercultural rhetoric, technology transfer, and writing in US-Mexico border maquilas. Technical Communication Quarterly, 15(3), 385-405.

Thatcher, B. (2010). Editor introduction: Eight needed developments and eight critical contexts for global inquiry. Rhetoric, Professional Communication, and Globalization, 1(1), 1-34.

Thatcher, B. (2011). Intercultural Rhetoric and Professional Communication: Technological Advances and Organizational Behavior: Technological Advances and Organizational Behavior: IGI Global.

Thatcher, B., \& Amant, K. S. (2011). Teaching Intercultural Rhetoric and Technical Communication: Theories, Curriculum, Pedagogies, and Practices: Baywood Publishing Company. 
Thayer, A., \& Kolko, B. E. (2004). Localization of digital games: The process of blending for the global games market. Technical communication, 51(4), 477-488.

Thralls, C., \& Blyler, N. (2002). Cultural studies: An orientation for research in professional communication (pp. 185-209): Westport, CT: Praeger Publishers.

Thrush, E. A. (1993). Bridging the gaps: Technical communication in an international and multicultural society. Technical Communication Quarterly, 2(3), 271-283.

Tracy, S. J. (2010). Qualitative quality: Eight "big-tent" criteria for excellent qualitative research. Qualitative Inquiry, 16(10), 837-851.

Trompenaars, F. (1994). Riding the waves of culture: Understanding diversity in global business.

Utley, I. (2009). The essential guide to customs and culture: Ghana: London: Kuperard.

Vacca, J. R. (2007). Biometric technologies and verification systems: Butterworth-Heinemann.

Wajcman, J. (1991). Feminism Confronts Technology. Pennsylvania: The Pennslyvania State University Press.

Walton, R. (2013a). Civic Engagment, Information Technology, \& Global Contexts.

Walton, R. (2013b). How trust and credibility affect technology-based development projects. Technical Communication Quarterly, 22(1), 85-102.

Walton, R. (2014). Editor's Introduction to the Special Edition on Methodology. Rhetoric, Professional Communication, and Globalization, 5(1), 1-13.

Wells, S. (2010). Technology, Genre, and Gender. In S. A. Selber (Ed.), Rhetorics and Technologies: New Directions in Writing and Communication

South Carolina: The University of South Carolina Press.

Wickman, C. (2012). Rhetoric, Techne, and the Art of Scientific Inquiry. Rhetoric Review, 31(1), $21-40$. 
Winner, L. (1977). Autonomous technology: Technics-out-of-control as a theme in political thought: Mit Press.

Winner, L. (1980). Do artifacts have politics? Daedalus, 121-136.

Winner, L. (1986). The Whale and the Reactor. A Search for Limits in an Age of High Technology (La Baleine et le réacteur.

Young, I. M. (2011). Justice and the Politics of Difference: Princeton University Press. 


\section{Appendix: Copyright Permission}

The letter below is documentation of permission to republish figures 4.1-4.12 used in my dissertation.

$22^{N D} \mathrm{Feb}, 2016$

THE DIRECTOR

MICHIGAN TECHNOLOGICAL UNIVERSITY

1400 TOWNSEND DRIVE

HOUGHTON.

Dear Sir,

\section{RE-PERMISSION TO USE DOCUMENTS FOR DISSERTATION}

It will be recalled that Mr. Isidore Kafui Dorpengo wrote to the Commission requesting for data to prepare his dissertation which was approved.

We wish to state that he may use the said data in his dissertation.

However, the data collected to be used in his dissertation must be accurate and the same data given to him by the Commission.

Thank you.

Yours faithfully,

SAMUEL TETTEY

DIRECTOR, ELECTIONS

DIRECTOR-ELECTIONS

ELECTORAL COMMISSION

ACCBA 